\title{
SYNTHESIS, CHARACTERIZATION AND APPLICATIONS OF METAL OXIDE NANOSTRUCTURES
}

\section{MUSHTAQUE HUSSAIN}

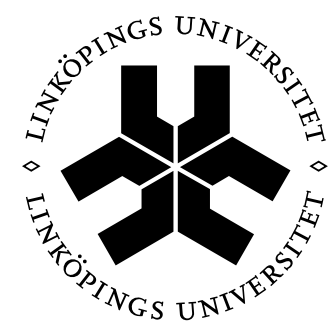

\section{Linköping University}

INSTITUTE OF TECHNOLOGY

\author{
Division of Physics and Electronics \\ Department of Science and Technology (ITN) \\ Campus Norrköping, Linköping University \\ SE-60174 Norrköping, Sweden
}




\section{SYNTHESIS, CHARACTERIZATION AND APPLICATIONS OF METAL OXIDE NANOSTRUCTURES}

MUSHTAQUE HUSSAIN

ISBN: 978-91-7519-265-9

ISSN: 0345-7524

Copyright $@$, 2014, Mushtaque Hussain mushtaq@neduet.edu.pk mushtaque.hussain@liu.se smh8385@yahoo.com

Linköping University

Department of Science and Technology (ITN)

SE-601 74 Norrköping

Sweden

Printed by LiU-Tryck, Linköping 2014. 


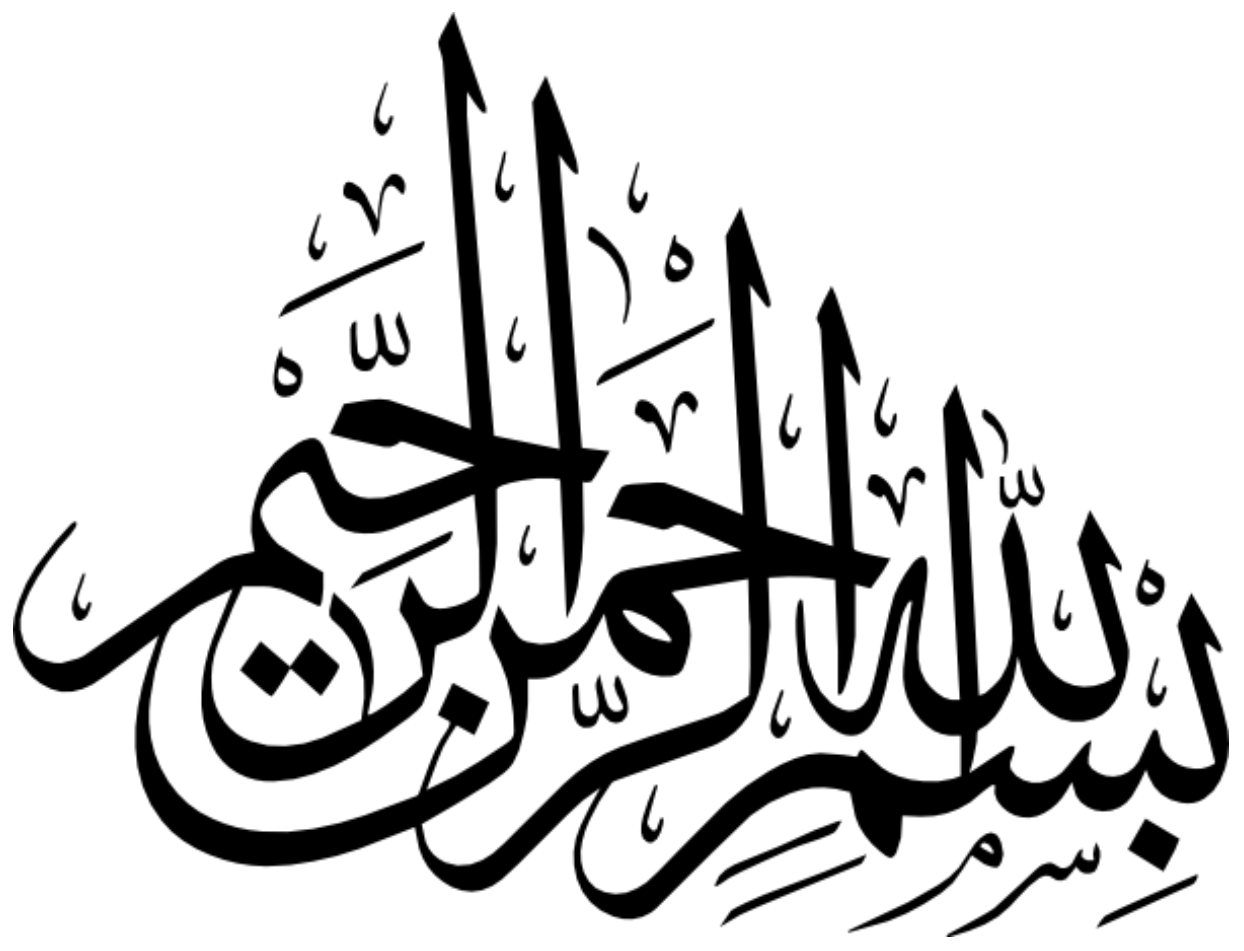

Starting with the name of Allah, the Most Gracious, the Most Merciful 


\section{DEDICATED}

TO MY PARENTS, WHO ARE NOT WITH ME ON THIS DAY, BUT I BELIEVE THEIR PRAYERS ARE WITH ME 


\section{ACKNOWLEDGEMENT}

All praises is only for Allah, the most merciful and beneficent, who through His beloved prophet Muhammad (peace be upon him), taught us the lessons of knowledge for the wellbeing of humanity. He taught that first seek knowledge and then use it for the welfare of human beings. I feel myself one of those persons who got the opportunity to increase knowledge and skills and then try to transfer it to others with full devotion.

Now, I am almost at the end of a long and hard journey in order to get $\mathrm{PhD}$ degree. I feel that it was not possible without the help, support, guidance and encouragement of many people around me. So I like to pay heartiest thanks to all those who contributed one way or the other towards the successful completion of my PhD study.

First and foremost I like to express my heartiest gratitude to my supervisor Prof. Magnus Willander for accepting my request to work under his kind guidance. I feel honored to be your student and will never forget your help, guidance, support, encouragement and your faith in me as a researcher. Due to you I get courage and motivation to face difficult moments in research and life and surpass those to climb the ladder of success. You are an exceptional person with supreme vision.

Beside this, I am extremely thankful to my co-supervisor Dr. Omer Nour for his contribution and critical help in improving the quality of manuscript. Your constructive comments will always remind me that learning and improving process will never ends. I would also like to thank our research administrator Ann-Christin Norén for her every possible help and cooperation in solving administrative problems in time. My special thanks to Lars Gustavsson for his timely efforts in resolving all problems related to equipment in the cleanroom.

I owe my warmest thanks to all my co-authors, who contributed with their knowledge and skills in completing the research articles. Especially Prof. Esteban Broitman and Dr. Galia Pozina are two persons, who played a role of mentor in guiding and helping me. Thank you so much for this act of kindness. It is my pleasure to acknowledge the cooperation of Jonas Wissting for the atomic force microscope measurements. 
My other co-authors including Dr. Mazhar Ali Abbasi, Azam Khan and Dr. Zafar Hussain Ibupoto, all have a lion share in my achievements, May Allah bless you all. I am also thankful from the core of my heart to all past and present members of Physical Electronics and Nanotechnology group. Your good wishes, moral support, cooperation and nice company will remind me these unforgettable days, whenever I will enter in any research lab in future.

I am extremely lucky that I have found few more friends during these four years. Their joyful company not only relaxed me in difficult moments but their support and help in daily life was also admirable. It is not possible to forget the wishes and prayers of my friends in Pakistan, especially Abdul Rehman, Muhammad Anwar and Noor Muhammad, they were with me all the time through their phone calls, SMS and emails. I feel privileged to have friends like you. May Allah give more strength to our threads of friendship? Ameen.

I think there wouldn't be any moment better than this to salute all my teachers, who laid the foundation for my successful academic career, which is ending with the completion of my dream of life that is getting a $\mathrm{PhD}$ degree. I would like to pay especial thanks to Prof. Muhammad Liaquat Ali for the guidance, help, encouragement, support and trust he has in my capabilities. I feel that the only way to pay tribute to all my teachers is to follow their footsteps and try to become a good teacher like them in future.

I am really thankful to the NED University of Engineering \& Technology, Karachi Pakistan for giving me the opportunity to pursue $\mathrm{PhD}$ studies and I also like to acknowledge their financial support as living allowance. Beside this I greatly acknowledge the facilities and working environment provided by the ITN/ Linköping University during the studies.

I found no words to express my deepest gratitude to my late parents for their never ending love, effort and prayers, which paved the way for me and my brothers and sisters to excel in life with proud and zeal. Even though they are no more with us but I have firm belief that their prayers and love is still with us. I just have tears in my eyes 
with bow head in front of Allah that accept our prayers and rest their soul in paradise. Ameen.

I also like to convey many thanks to my entire family including my brothers, Ashfaque Hussain, Zahid Hussain, Akhtar Hussain, Shahid Hussain, all sisters and all in-laws. I have no doubt that without their selfless love and endless support; it was not possible to achieve this goal. The especial prayers of Aapa, my mother in law and mother like friend Mrs. Saeeda Ishtiaq were with us from the day one. May Allah shower millions of blessings on all of them?

As we all know there is always a woman behind the success of a man and for me it's my better half. My loving thanks to my dearest wife Tabassum for her love, taking care, support and prayers. I would never been able to achieve this success without you. You sacrificed your time with patience and stood firm to give me encouragement in each and every difficult moment. Last but not least it's time to appreciate my daughters Nawira, Zonaira and Wareesha, even though I did not spent much time with them they refreshed me with their kisses and smiles and cheer me with their innocent acts. They behaved me as I am in their age group and this feeling wiped off all my worries and tiredness and refreshed me for a new day struggle. Thank you so much to be a part of my life.

\section{Mushtaque Hussain}

\section{Norrköping 2014}




\title{
SYNTHESIS, CHARACTERIZATION AND APPLICATIONS OF METAL OXIDE NANOSTRUCTURES
}

\section{Mushtaque Hussain}

\begin{abstract}
:
The main objective of nanotechnology is to build self-powered nanosystems that are ultra-small in size, exhibit super sensitivity, extraordinary multi functionality, and extremely low power consumption. As we all know that 21st century has brought two most important challenges for us. One is energy shortage and the other is global warming. Now to overcome these challenges, it is highly desirable to develop nanotechnology that harvests energy from the environment to fabricate self-power and low-carbon nanodevices. Therefore a self-power nanosystem that harvests its operating energy from the environment is an attractive proposition. This is also feasible for nanodevices owing to their extremely low power consumption. One advantageous approach towards harvesting energy from the environment is the utilization of semiconducting piezoelectric materials, which facilitate the conversion of mechanical energy into electrical energy. Among many piezoelectric materials $\mathrm{ZnO}$ has the rare attribute of possessing both piezoelectric and semiconducting properties. But most applications of $\mathrm{ZnO}$ utilize either the semiconducting or piezoelectric property, and now it's time to fully employ the coupled semiconducting-piezoelectric properties to form the basis for electromechanically coupled nanodevices. Since wurtzite zinc oxide $(\mathrm{ZnO})$ is structurally noncentral symmetric and has the highest piezoelectric tensor among tetrahedrally bonded semiconductors, therefore it becomes a promising candidate for energy harvesting applications. $\mathrm{ZnO}$ is relatively biosafe and
\end{abstract}


biocompatible as well, so it can be used at large scale without any harm to the living environment.

The synthesis of another transition metal oxide known as $\mathrm{Co}_{3} \mathrm{O}_{4}$ is also important due to its potential usage in the material science, physics and chemistry fields. $\mathrm{Co}_{3} \mathrm{O}_{4}$ has been studied extensively due to low cost, low toxicity, the most naturally abundant, high surface area, good redox, easily tunable surface and structural properties. These significant properties enable $\mathrm{Co}_{3} \mathrm{O}_{4}$ fruitful for developing variety of nanodevices. $\mathrm{Co}_{3} \mathrm{O}_{4}$ nanostructures have been focused considerably in the past decade due to their high electro- chemical performance, which is essential for developing highly sensitive sensor devices.

I started my work with the synthesis of $\mathrm{ZnO}$ nanorods with a focus to improve the amount of harvested energy by utilizing oxygen plasma treatment. Then effect of oxygen plasma treatment on the mechanical properties of $\mathrm{ZnO}$ nanorods has been investigated. After that I grow $\mathrm{ZnO}$ nanorods on different flexible substrates, in order to observe the effect of substrate on the amount of harvested energy. My next target belongs to an innovative approach in which atomic force microscope (AFM) tip decorated with $\mathrm{ZnO}$ nanorods was utilized to improve the output energy. Then I investigated $\mathrm{Co}_{3} \mathrm{O}_{4}$ nanostructures though the effect of anions and utilized one of the nanostructure to develop a fast and reliable $\mathrm{pH}$ sensor. Finally to take the advantage of higher degree of redox chemistry of $\mathrm{NiCo}_{2} \mathrm{O}_{4}$ compared to the single phase of nickel oxide and cobalt oxide, a sensitive glucose sensor is developed by immobilizing glucose oxidase.

However, there were problems with the mechanical robustness, lifetime, output stability and environmental adaptability of such devices, therefore more work is going on to find out new ways and means in order to improve the performance of fabricated nanogenerators and sensors. 


\section{List of articles included in the dissertation}

I. The improved piezoelectric properties of $\mathrm{ZnO}$ nanorods with oxygen plasma treatment on the single layer graphene coated polymer substrate.

Mushtaque Hussain, Mazhar Ali Abbasi, Zafar Hussain Ibupoto, Omer Nur, Magnus Willander.

Physica Status Solidi-A. 2014, 211(2), 455.

II. The effect of oxygen-plasma treatment on the mechanical and piezoelectrical properties of $\mathrm{ZnO}$ nanorods.

Mushtaque Hussain, Azam Khan, Omer Nur, Magnus Willander, Esteban Broitman.

Chemical Physics Letters. 2014, 608, 235.

III. Comparative study of Energy harvesting from $\mathrm{ZnO}$ nanorods using different flexible substrates.

Mushtaque Hussain, Mazhar Ali Abbasi, Azam Khan, Omer Nur, Magnus Willander.

Eneqy Harvesting and Systems. 2014, 1(1-2), 19.

IV. Use of $\mathrm{ZnO}$ nanorods grown AFM tip in the architecture of piezoelectric nanogenerator.

Mushtaque Hussain, Azam Khan, Mazhar Ali Abbasi, Omer Nur, Magnus Willander.

Micro and Nano Letters (Submitted) 
V. Effect of anions on the morphology of $\mathrm{Co}_{3} \mathrm{O}_{4}$ nanostructures grown by hydrothermal method and their $\mathrm{pH}$ sensing application.

Mushtaque Hussain, Zafar Hussain Ibupoto, Mazhar Ali Abbasi, Omer Nur, Magnus Willander.

Journal of Electroanalytical Chemistry. 2014, 717-718, 78.

VI. Synthesis of nano-needles of nickel cobalt oxide in three dimensions on nickel foam, their characterization and glucose sensing application.

Mushtaque Hussain, Zafar Hussain Ibupoto, Mazhar Ali Abbasi, Xianjie Liu, Omer Nur, Magnus Willander.

Sensors. 2014, 14, 5415.

\section{'Contribution to the papers included in this dissertation"}

I was involved in the planning of the paper, performed the synthesis and oxygen plasma treatment. Then carryout structural characterization like XRD, SEM and took part in all the discussions related to the analysis and presentation of the obtained results. Finally wrote the first version of the manuscript and after review process wrote the final version as well. 


\section{List of articles not included in the thesis}

I. Piezoelectric nanogenerator based on zinc oxide nanorods grown on textile cotton fabric.

Azam Khan, Mazhar Ali Abbasi, Mushtaque Hussain, Zafar Hussain Ibupoto, Jonas Wissting, Omer Nur, Magnus Willander.

Applied Physics Letters. 2012, 101, 193506.

II. Potentiometric Zinc ion sensor based on honeycomb-like NiO nanostructures.

Mazhar Ali Abbasi, Zafar Hussain Ibupoto, Mushtaque Hussain, Yaqoob Khan, Azam Khan, Omer Nur, Magnus Willander.

Sensors. 2012, 12(11), 15424.

III. Study of transport properties of copper-zinc oxide nanorods based schottky diode fabricated on textile fabric.

Azam Khan, Mushtaque Hussain, Mazhar Ali Abbasi, Zafar Hussain Ibupoto, Omer Nur, Magnus Willander.

Semiconductor Science and Technology. 2013, 28(12), 125006.

IV. The fabrication of white light-emitting diodes using the n-ZnO/NiO/p-GaN heterojunction with enhanced luminescence.

Mazhar Ali Abbasi, Zafar Hussain Ibupoto, Mushtaque Hussain, Omer Nur, Magnus Willander.

Nanoscale Research Letters. 2013, 8, 320.

V. Analysis of junction properties of gold-zinc oxide nanorods-based Schottky diode by means of frequency dependent electrical characterization on textile.

Azam Khan, Mushtaque Hussain, Mazhar Ali Abbasi, Zafar Hussain Ibupoto, Omer Nur, Magnus Willander.

Journal of Materials Science. 2014, 49(9), 3434. 
VI. Synthesis of $\mathrm{CuO} / \mathrm{ZnO}$ composite nanostructures, their optical characterization and valence band offset determination by X-ray photoelectron spectroscopy. Mushtaque Hussain, Zafar Hussain Ibupoto, Mazhar Ali Abbasi, Azam Khan, Galia Pozina, Omer Nur, Magnus Willander.

Journal of Nanoelectronics and Optoelectronics. 2014, 9(3), 1.

VII. Decoration of $\mathrm{ZnO}$ nanorods with coral reefs like $\mathrm{NiO}$ nanostructures fabricated by hydrothermal growth method and their luminescence study.

Mazhar Ali Abbasi, Zafar Hussain Ibupoto, Mushtaque Hussain, Galia Pozina, Jun Lu, Lars Hultman, Omer Nur, Magnus Willander.

Materials. 2014, 7(1), 430.

VIII. Effect of post growth annealing on the structural and electrical properties of $\mathrm{ZnO} / \mathrm{CuO}$ composite nanostructures.

Mushtaque Hussain, Azam Khan, Omer Nur, Magnus Willander. (Submitted)

IX. Study of piezoelectric properties of vertically synthesized zinc oxide nanorods on textile platform by means of aspect ratio, crystal size and strain.

Azam Khan, Mushtaque Hussain, Omer Nur, Magnus Willander. (Submitted)

X. Analysis of direct and converse piezoelectric responses from zinc oxide nanowires grown on a conductive fabric.

Azam Khan, Mushtaque Hussain, Omer Nur, Magnus Willander, Esteban Broitman. (Submitted)

XI. Mechanical and piezoelectric properties of $\mathrm{ZnO}$ nanaorods grown on conductive textile fabric as an alternative substrate.

Azam Khan, Mushtaque Hussain, Omer Nur, Magnus Willander.

Journal of Physics D: Applied Physics (Accepted) 
XII. Fabrication of zinc oxide nanoneedles based nanogenerator on conductive textile. Azam Khan, Mushtaque Hussain, Omer Nur, Magnus Willander. (Submitted)

XIII. UV detectors and LEDs in different metal oxide nanostructures.

Magnus Willander, Mazhar Ali Abbasi, Kimleang Khun, Mushtaque Hussain, Zafar Hussain Ibupoto, Omer Nur.

Proeedings of SPIE 2014, 8987, 89871Y; DOI:10.1117/12.2038189 


\section{List of Abbreviations}

\begin{tabular}{ll}
\hline Abbreviation & Word or Phrase \\
\hline $\mathrm{ZnO}$ & Zinc Oxide \\
$\mathrm{GaN}$ & Gallium Nitride \\
$\mathrm{CdS}$ & Cadmium Sulfide \\
$\mathrm{ZnS}$ & Zinc Sulfide \\
$\mathrm{Ni}$ & Nickle \\
$\mathrm{Co}_{3} \mathrm{O}_{4}$ & Cobalt Oxide \\
$\mathrm{NiCo} \mathrm{O}_{4}$ & Nickle cobalt oxide \\
$\mathrm{NG}$ & Nanogenerator \\
$\mathrm{NW}$ & Nanowire \\
$\mathrm{NB}$ & Nanobelt \\
$\mathrm{NR}$ & Nanorod \\
$\mathrm{PET}$ & Polyethylene terephthalate \\
$\mathrm{KOH}$ & Potassium hydroxide \\
$\mathrm{ACG}$ & Aqueous Chemical Growth \\
$\mathrm{AFM}$ & Atomic Force Microscope \\
$\mathrm{XRD}$ & X-ray Diffraction \\
$\mathrm{SEM}$ & Scanning ElectronMicroscope \\
$\mathrm{TEM}$ & Transmission ElectronMicroscope \\
$\mathrm{XPS}$ & X-ray Photoelectron Spectroscopy \\
$\mathrm{CL}$ & Cathodoluminescence \\
$\mathrm{EDS}$ & Energy Dispersive X-ray Spectroscopy \\
$\mathrm{RIE}$ & Reactive Ion Etching \\
$\mathrm{SAED}$ & Selective Area Electron Diffraction \\
$\mathrm{UV}$ & Ultra Voilet \\
$\mathrm{FTO}$ & Fluorine doped Tin Oxide \\
$\mathrm{ITO}$ & Indium Tin Oxide \\
$\mathrm{RF}$ & Radio Frequency \\
$\mathrm{Pt}$ & Platinum \\
$3 \mathrm{D}$ & Three Dimensional \\
$\mathrm{pH}$ & Power of Hydrogen \\
$\mathrm{I}-\mathrm{V}$ & Current Voltage \\
$\mathrm{JCPDS}$ & Joint Committee on Powder Diffraction Standards \\
\hline &
\end{tabular}




\section{List of units}

\begin{tabular}{ll}
\hline Symbol & Unit \\
\hline $\mathrm{eV}$ & Electron volt \\
$\mathrm{mbar}$ & Millibar \\
$\AA$ & Angstrom \\
$\mathrm{nm}$ & Nanometer \\
$\mathrm{MHz}$ & Megahertz \\
$\mathrm{W}$ & Watt \\
$\mathrm{sccm}$ & Standard cubic centimeters per minute \\
$\mathrm{Pa}$ & Pascal \\
$\mathrm{mV}$ & Millivolt \\
$\mu \mathrm{m}$ & Micrometer \\
$\mathrm{mM}$ & Millimole \\
${ }^{\circ} \mathrm{C}$ & Degree centigrade \\
\hline
\end{tabular}




\section{List of Tables}

Table 1. Some basic properties of $\mathrm{ZnO}$.

Table 2. Showing the comparison between the reported and presented work.

Table3. Showing the comparison of the characteristics of the presented work and some other previously reported glucose biosensors. 


\section{List of Figures}

Figure 2.1: Wurtzite structure of $\mathrm{ZnO}$ unit cell, in which green balls are $\mathrm{Zn}^{+2}$ ions and blue balls are $\mathrm{O}^{-2}$ ions showing tetrahedral coordination.

Figure 2.2: The unit cell structure of $\mathrm{CO}_{3} \mathrm{O}_{4}$. (Reproduced from wikipedia)

Figure 3.1: Aqueous chemical growth of $\mathrm{ZnO}$ nanorods on different substrates.

(a) Paper (b) Plastic (c) Graphene (d) ITO (e) Si (f) FTO (g) Glass

(h) Aluminum foil.

Figure 3.2: Aqueous chemical growth of different oxide materials.

(a-b) $\mathrm{CuO}$ (c-d) $\mathrm{CO}_{3} \mathrm{O}_{4}$ (e-f) $\mathrm{NiCO}_{2} \mathrm{O}_{4}$

Figure 3.3: $\quad$ Synthesis of $\mathrm{ZnO}$ nanorods on different substrates for reported work.

(a) Graphene (b) Paper (c) Plastic (d) Textile (e) Aluminum foil (f) FTO (g-h) Low and high magnification SEM images of AFM tip.

Figure 3.4: $\quad \mathrm{CO}_{3} \mathrm{O}_{4}$ nanostructures prepared in different salts.

Figure 3.5: $\quad \mathrm{SEM}$ images of $\mathrm{NiCO}_{2} \mathrm{O}_{4}$ nanostructures.

Figure 5.1: $\quad$ (a) SEM image of the as-grown ZnO NRs along with inset showing the diameter of the NRs. (b) SEM image of plasma treated ZnO NRs.

(c) Typical XRD spectra of ZnO NRs. (d) TEM image of the single ZnO NR along with inset of SAED.

Figure 5.2: $\quad$ Piezoelectric power generation from as-grown ZnO NRs (a) 3D plot of the output voltage. (b) Typical AFM tip scanning the surface of $\mathrm{ZnO}$ NRs in micrometers.

Piezoelectric power generation from plasma treated ZnO NRs.

(c) 3D plot of the output voltage. (d) Typical AFM tip scanning the surface of ZnO NRs in micrometers.

Figure 5.3: $\quad$ XPS analysis of ZnO NRs without and with oxygen plasma treatment.

Figure 5.4: $\quad \mathrm{CL}$ spectra of as-grown $\mathrm{ZnO}$ NRs and $\mathrm{ZnO}$ NRs with oxygen plasma treatment. 
Figure 5.5: $\quad$ SEM images of ZnO NRs grown on FTO glass substrate. (a) Without oxygen plasma treatment. (b) With oxygen plasma treatment.

Figure 5.6: $\quad$ XRD spectra of ZnO NRs grown on FTO glass substrate. (a) Without oxygen plasma treatment. (b) With oxygen plasma treatment.

Figure 5.7: Generated piezo-voltage without and with oxygen plasma treatment as a function of maximum applied load. The dotted lines are just for guiding the eyes.

Figure 5.8: Load-displacement curves recorded by using nanoindentation technique. The used probe was a boron-doped diamond Berkovich tip and the measurements were performed in the load-control mode.

(a) Bare FTO glass substrate. (b) NR without oxygen plasma treatment.

(c) NR with oxygen plasma treatment.

Figure 5.9: $\quad$ SEM images of ZnO NRs grown on (a) Common paper (b) Plastic (c) Textile fabric and (d) Aluminum foil.

Figure 5.10: XRD spectra of ZnO NRs grown on (a) Common paper (b) Plastic (c) Textile fabric and (d) Aluminum foil substrates.

Figure 5.11: Schematic diagram showing the mechanism of the electrical pulse generation by ZnO NRs.

Figure 5.12: Three-dimensional plot of the output voltage from $\mathrm{ZnO}$ NRs grown on (a) Common paper (b) Plastic (c) Textile fabric (d) Aluminum foil.

Figure 5.13: $\quad I-V$ characteristics for (a) Common paper (b) Plastic (c) Textile fabric (d) Aluminum foil.

Figure 5.14: Schematic diagram showing the dimensions of the cantilever.

Figure 5.15: The SEM images of ZnO NRs grown on the AFM tip and on the FTO glass substrate. (a) Low resolution image of the AFM tip (b) High resolution image of the AFM tip (c)Low resolution image of the FTO glass substrate (d) High resolution image of the FTO glass substrate.

Figure 5.16: $\quad$ XRD spectra of ZnO NRs grown on FTO glass substrate. 
Figure 5.17: Current-voltage (I-V) characteristics between $\mathrm{ZnO}$ on substrate and (a) Bare (without ZnO NRs) AFM tip (b) AFM tip with ZnO NRs.

Figure 5.18: (a) Three-dimensional plot of the output voltage from ZnO NRs using AFM tip with ZnO NRs (b) Three-dimensional plot of the output voltage from ZnO NRs using AFM tip without ZnO NRs. (c) Tip scan using AFM tip with ZnO NRs. (d) Tip scan using AFM tip without ZnO NRs. (e) Topography image using AFM tip with ZnO NRs (f) Topography image using AFM tip without ZnO NRs.

Figure 5.19: $\mathrm{SEM}$ images of different $\mathrm{CO}_{3} \mathrm{O}_{4}$ nanostructures grown in precursors of (a) Cobalt nitrate (b) Cobalt chloride (c) Cobalt acetate (d) Cobalt sulfate.

Figure 5.20: XRD spectra's of cobalt oxide nanostructures grown in different growth mediums. (a) Cobalt nitrate (b) Cobalt chloride (c) Cobalt acetate (d) Cobalt sulfate.

Figure 5.21: (a-c) HRTEM image of single nanowire (d) TEM image of $\mathrm{CO}_{3} \mathrm{O}_{4}$ nanowires, inset is the SAED pattern of $\mathrm{CO}_{3} \mathrm{O}_{4}$ for multi nanowires.

Figure 5.22: (a) The calibration curve of $\mathrm{pH}$ sensor based on $\mathrm{Co}_{3} \mathrm{O}_{4}$ nanostructures grown in precursor solution of cobalt chloride for the $\mathrm{pH}$ range of $3-$ 13. (b) The repeatability of proposed $\mathrm{pH}$ sensor.

Figure 5.23: (a) The reproducibility of $\mathrm{pH}$ sensor measured in $\mathrm{pH} 6$.

(b) The response time of $\mathrm{pH}$ sensor measured in $\mathrm{pH} 7$.

Figure 5.24: (a) SEM image of bare Ni foam substrate.

(b-d) Typical SEM images at different magnifications of $\mathrm{NiCO}_{2} \mathrm{O}_{4}$ nanostructures grown via low temperature hydrothermal method.

Figure 5.25: The XRD spectrum of $\mathrm{NiCO}_{2} \mathrm{O}_{4}$ nanostructures and inset is showing the XRD spectra of bare Ni foam substrate.

Figure 5.26: XPS spectrum of $\mathrm{NiCO}_{2} \mathrm{O}_{4}$ nanostructures (a) wide scan spectrum (b) $\mathrm{O} 1 \mathrm{~s}$ spectrum (c) Co $2 p$ spectrum (d) Ni $2 p$ spectrum. 
Figure 5.27: (a) The calibration curve of glucose biosensor based on $\mathrm{NiCO}_{2} \mathrm{O}_{4}$ nanostructures for linear concentration range of $0.005 \mathrm{mM}$ to $15 \mathrm{mM}$. (b) The response time of glucose biosensor in $1 \mathrm{mM}$ glucose concentration.

Figure 5.28: (a) The reproducibility of glucose biosensor in $0.1 \mathrm{mM}$ glucose concentration. (b) The repeatability curve of the proposed glucose biosensor for 3 consecutive experiments. 


\section{CONTENTS}

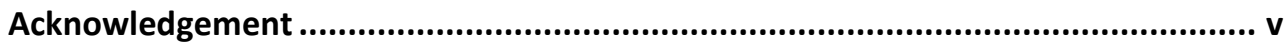

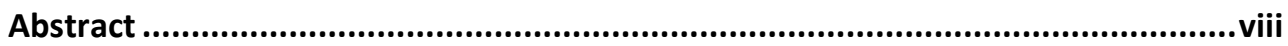

List of articles included in the dissertation............................................................. $\mathrm{x}$

List of articles not included in the thesis................................................................ii

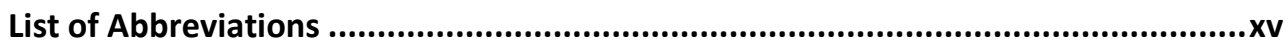

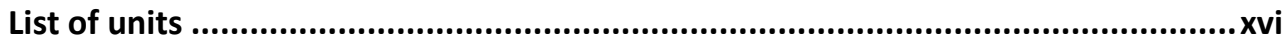

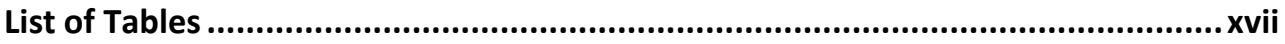

List of Figures ................................................................................................... xviii

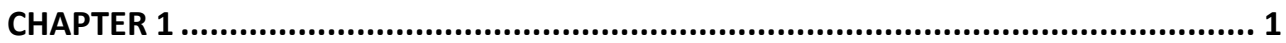

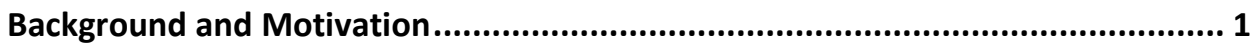

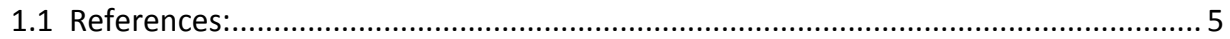

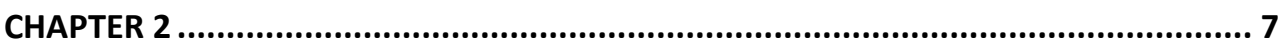

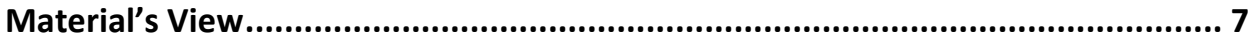

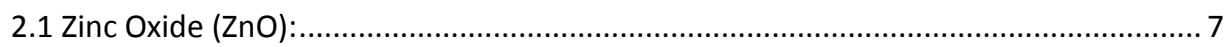

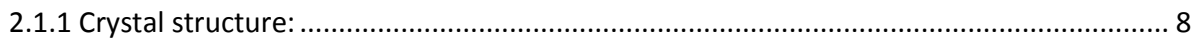

2.1.2 Piezoelectric properties:.................................................................................... 10

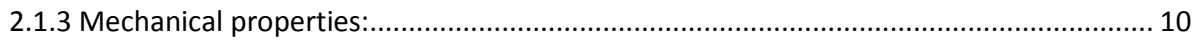

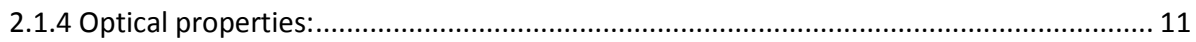

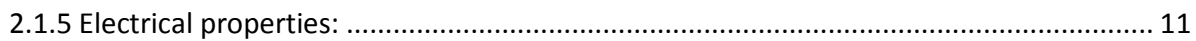

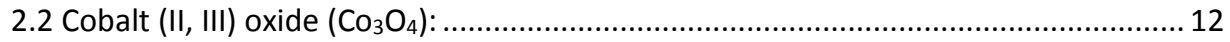

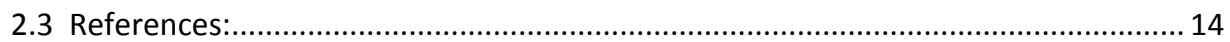

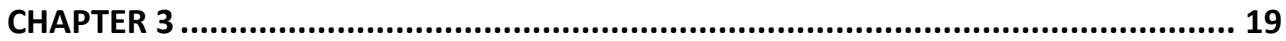

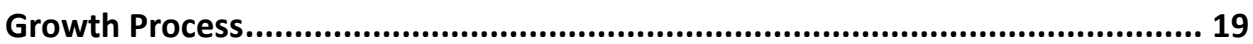

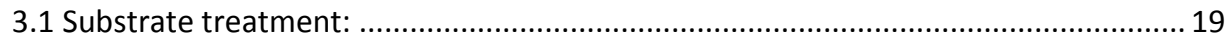

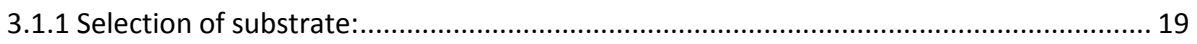

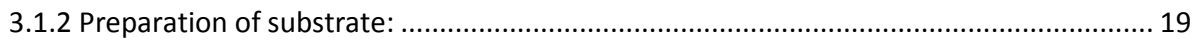

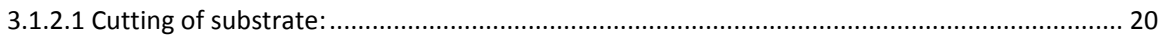

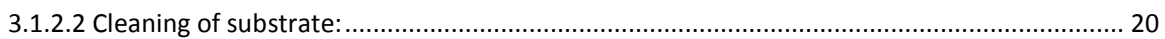

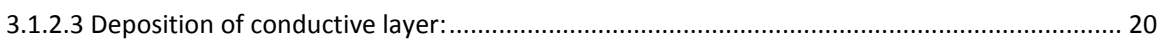

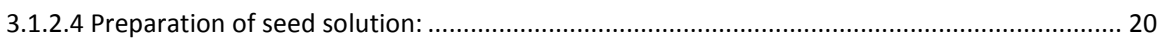

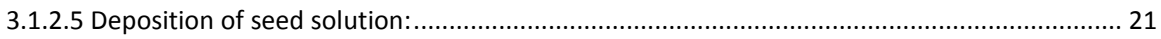

3.1.2.6 Annealing of seed layer containing substrate: ............................................................... 22

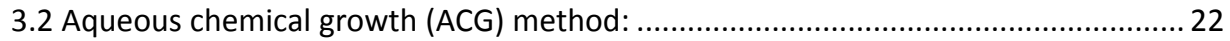

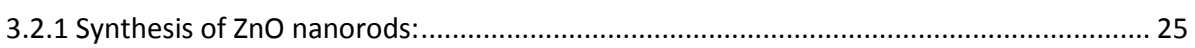

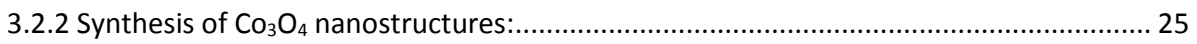

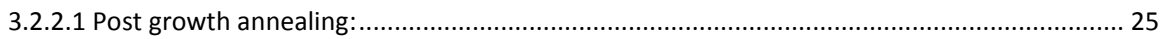

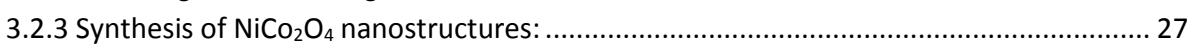

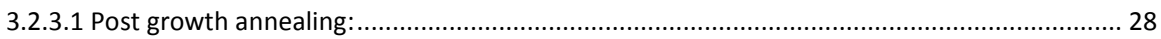

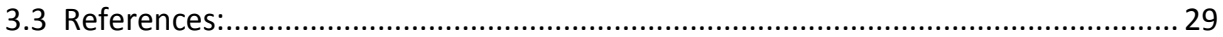


Characterization and Processing Techniques ............................................ 31

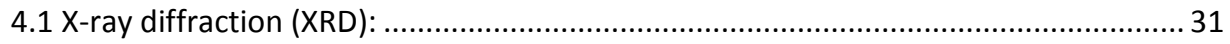

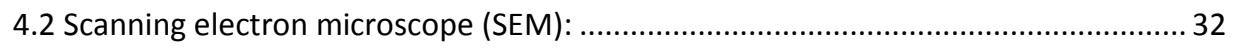

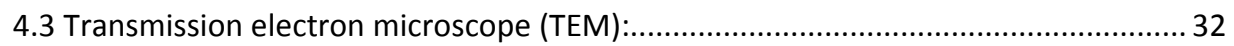

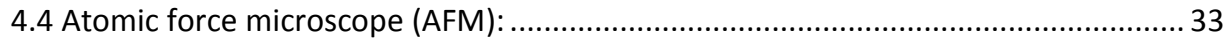

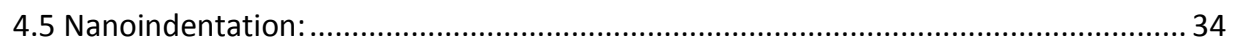

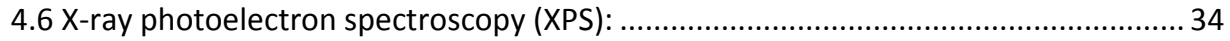

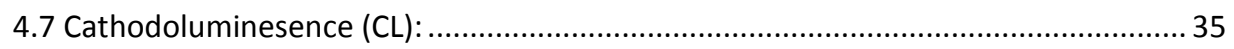

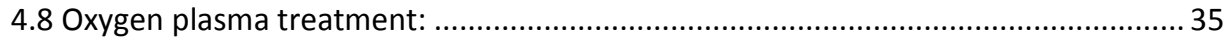

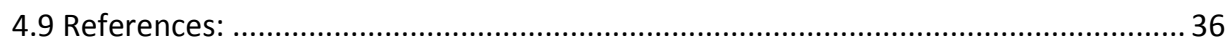

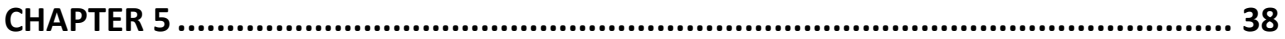

Discussion on Results ................................................................................. 38

5.1 The improved piezoelectric properties of $\mathrm{ZnO}$ nanorods with oxygen plasma treatment on the single layer graphene coated polymer substrate................................ 38

5.2 The effect of oxygen-plasma treatment on the mechanical and piezoelectrical

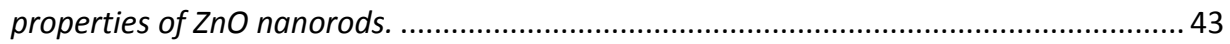

5.3 Comparative study of energy harvesting from $\mathrm{ZnO}$ nanorods using different flexible

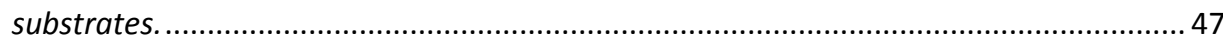

5.4 Use of ZnO nanorods grown AFM tip in the architecture of piezoelectric nanogenerator.

5.5 Effect of anions on the morphology of $\mathrm{CO}_{3} \mathrm{O}_{4}$ nanostructures grown by hydrothermal method and their $\mathrm{pH}$ sensing application.

5.6 Synthesis of three dimensional nickel cobalt oxide nanoneedles on nickel foam, their characterization and glucose sensing application.

5.7 References:

CHAPTER 6

Conclusion \& future plans ................................................................ 69

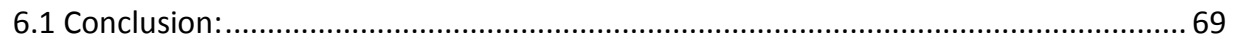

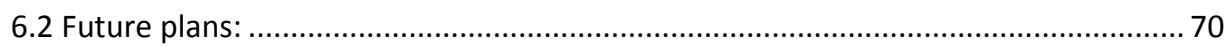




\section{CHAPTER 1}

\section{Background and Motivation}

The 21st century economy development strongly depends on the supply of energy and thus causes an environmental impact on the global climate due to the combustion of fossil fuels. These fossil fuels with high percentages of carbon include coal (27\%), petroleum (36\%) and natural gas (23.4\%) amounting to $86.4 \%$ share for fossil fuels. The burning of these fossil fuels produces around 21.3 billion tonnes of carbon dioxide $\left(\mathrm{CO}_{2}\right)$ per year [1]. $\mathrm{CO}_{2}$ is one of the greenhouse gases that enhances radiative forcing and contributes to global warming. Since these natural resources on earth are limited and could not be regenerated over a short period of time, therefore human beings in general and scientists/researchers in particular must be able to face these severe energy and environmental problems originating from the traditional energy consumption. So in order to improve the sustainability of our society, it is necessary:

1- To move from fossil fuels to renewable energy sources.

2- Harvest unexploited energy from the environment to power small electronic devices and systems.

3- Fabricate low-carbon energy devices.

For the development of clean alternative energies, a wide range of approaches have been explored by scientists both at large and small scale. On the larger scale, besides the well-known energy resources that power the world today, such as petroleum, hydroelectric, natural gas, and nuclear, active research and development are taking place in order to explore alternative energy resources like solar, geothermal, biomass, wind, and hydrogen. But on smaller scale, it is highly desirable to explore novel technologies to develop a self-powered nanosystem that harvests energy from the environment so that it operates wirelessly, remotely, and independently with an uninterrupted energy supply. Therefore the goal of nanotechnology is to build selfpowered nanosystems that are ultra-small in size, and exhibit super sensitivity, extraordinary multi functionality, and extremely low power consumption. Building 
self-powered nanosystems is a future direction of nanotechnology and there are three possible ways for achieving these self-powered nanosystems.

One is to use a battery as power source, but the main challenges in this regard are the size, weight, toxicity of the used material and lifetime of the battery. The other approach is to harvest energy from the environment by converting mechanical, chemical, or thermal energy into electricity [2]. The resultant energy harvested from the environment should be sufficient to power the system. A self-powering nanosystem that harvests its operating energy from the environment is an attractive proposition. This can not only enhance the adaptability of the devices but also greatly reduce the size and weight of the system. This is in principle feasible for nanodevices owing to their extremely low power consumption. The third approach, which depends on developing nanomaterial enabled technologies for energy harvesting has attracted a lot of interest in recent years $[3,4]$. One advantage that makes this approach fruitful for harvesting energy is the utilization of low cost semiconducting piezoelectric materials [5], which facilitate the conversion of mechanical energy into electrical energy. Generation of electric energy from conversion of mechanical energy through this approach is of great interest owing to its abundance and unique fit for some applications. This approach is a critical step towards developing self-powered nanosystems by utilizing piezoelectric materials.

Nanostructured materials such as $\mathrm{ZnO}, \mathrm{GaN}$, CdS, and possibly ZnS can play an important role in dealing with the challenges regarding new sustainable and renewable energy resources. Especially, oxide nanostructures with infinite variety of structural motifs and manifold morphological features exhibit indispensable surface properties for energy harvesting, conversion, and storage devices. By using the piezoelectricity of these semi conductive materials, nanoscale mechanical-electrical energy conversion devices known as the nanogenerators (NGs) have been demonstrated in recent years [6-10], in which the electric current in an external circuit is driven by the piezoelectric potential created by the bent nanowires (NWs)/nanobelts (NBs)/nanorods (NRs) [10]. Remember that NWs/NBs/NRs are natural cantilevers that can be easily bent to create a large deformation. The basic principle is to use piezoelectric and semiconducting coupled materials, such as $\mathrm{ZnO}$, to convert mechanical energy into electricity [10, 11]. 
On the basis of the coupled behavior between piezoelectric and semiconducting properties, piezotronic effect [12] has been revealed, which utilizes the piezoelectric potential to modulate the carrier transport process in the $\mathrm{NWs} / \mathrm{NBs} / \mathrm{NRs}$. The mechanical flexibility of piezoelectric compound NWs/NBs/NRs provides a more versatile platform to utilize the physics of piezoelectricity in semiconductors, as one sees in NGs and in nanopiezotronics. Piezoelectric NGs using NWs/NRs are a method for converting mechanical energy into electricity $[13,14]$. The concept of the NG was first introduced by examining the piezoelectric properties of $\mathrm{ZnO}$ NWs with an atomic force microscope (AFM) [10]. The mechanism of the NG relies on the coupling of piezoelectric and semiconducting dual properties of piezoelectric materials as well as the elegant rectifying function of the Schottky barrier formed between the metal tip and the NW/NR [15]. The development of a NG to convert the available form of mechanical energy into electric energy would not only facilitate the development of nanodevices in fields like medical science, defense technology, sensing and even personal electronics; but can also be useful for developing a battery-less system for future applications.

On the other side the fast growing development in the field of science \& technology has creating new ways and means in order to improve the life quality of human beings. Nanotechnology is one of the fields that creating new opportunities to make human life more safe by fabricating nanoscale devices, especially for medical use. Because the novel properties of nanostructures like high surface area to volume ratio, bettered solubility, low toxicity, surface tailoring power and multiple use making them strong candidate for biomedicine. In our daily life, the controlled level of glucose concentration in the blood is one of the crucial parameters for the prevalence of many major life threatening diseases. It has been well established that diabetes is a major disease throughout the world and it is estimated that approximately 347 million people live with this disease worldwide [16]. If left untreated, diabetes increases the risk of developing complications such as retinopathy, nephropathy, and neuropathy [17]. The conventional method of monitoring blood glucose level involves pricking the finger and drawing blood onto a test strip. However, this is a very inconvenient way to monitor blood glucose. An alternative method would be to use an implantable glucose 
sensor that would continuously monitor blood glucose levels and transmit the data to a proximal receiver eliminating the frequent painful process of prinking the fingers. These facts motivates the researchers/scientists to fabricate robust, simple, cheap and non-invasive glucose biosensors with high sensitivity, good selectivity, fast and stable response, and high thermal stability. Glucose investigation is also very important in a number of ways, like food industry for quality control purposes, in fermentation, and as a clinical indicator for diabetes [18, 19]. For almost four decades, researchers engaged in the development of glucose-sensing devices which monitored the glucose levels in biological fluids rapidly, accurately and continuously, especially to help diabetes mellitus patients to monitor their daily sugar levels [20]. Because selfmonitoring of blood glucose is an important part of diabetes care [21, 22] and its effectiveness will be increased with the availability of various portable, economic, and sensitive glucose sensors. Beside glucose detection biosensors can play a vital role in fields like environmental quality, medicine, food and beverages, and biocrime mainly by identifying material and the degree of concentration present? Metal oxide nanostructures can play an important role in this regard. Because these nanostructures with improved kinetics of electron transfer, chemical stability, low toxicity, biocompatibility, and high adsorption capability pave the way to make desirable surroundings for the immobilization of biomolecule and bettered bio-sensing features [23-26]. Therefore it is of great importance to select that metal oxide nanostructure, which favor's most the immobilization of the biomolecules. That is why transition metal oxides, hydroxides, and their compounds are being widely explored in recent years [27-32]. Beside this they are very economical, less toxic and have great flexibility in structures/morphology. Among the reported transition metal oxides, the cobalt oxide $\left(\mathrm{Co}_{3} \mathrm{O}_{4}\right)$ has shown a lot of promise as an electrode material for sensors. The electrode materials play a vital role in the performance of sensors and therefore great efforts have been made to develop alternative electrode materials with improved electrochemical properties. The employment of cobalt based oxide materials can provide new opportunities for sensing applications with higher energy density and better stability. 


\subsection{References:}

[1]. http://en.wikipedia.org/wiki/.

[2]. J. A. Paradiso, T. Starner, Pervasive Computing. 2005, 05, 18.

[3]. B. Tian, X. Zheng, T. J. Kempa, Y. Fang, N. Yu, Y. Yu, J. L. Huang, C. M. Lieber, Nature. 2007, 449, 885.

[4]. L. Shi, D. Li, C. Yu, W. Jang, D. Kim, Z. Yao, P. Kim, A. J. Majumdar, Heat Transfer. 2003, 125, 881.

[5]. Y. Zhang, Y. Liu, Z. L. Wang, Advanced Materials. 2011, 23, 3004.

[6]. P. X. Gao, J. H. Song, J. Liu, Z. L. Wang, Advanced Materials. 2007, 19 (1), 67.

[7]. Y. Gao, Z. L. Wang, Nano Letters. 2007, 7 (8), 2499.

[8]. J. Liu, F. Peng, J. H. Song, X. D. Wang, C. S. Lao, R. Tummala, Z. L. Wang, Nano Letters. 2007, 8 (1), 328.

[9]. X. D. Wang, J. H. Song, J. Jiu, Z. L. Wang, Science. 2007, 316,102.

[10]. Z. L. Wang, J. H. Song, Science. 2006, 312, 242.

[11]. J. H. Song, J. Zhou, Z. L. Wang, Nano Letters. 2006, 6, 1656.

[12]. X. D. Wang, J. Zhou, J. H. Song, J. Liu, N. S. Xu, Z. L. Wang, Nano Letters. 2006, 6 (12), 2768.

[13]. Z. L. Wang, Advanced Functional Materials. 2008, 18, 1.

[14]. Z. L. Wang, Scientific American. 2008, 298, 82.

[15]. Z. L. Wang, Advanced Functional Materials. 2008, 18, 3553.

[16]. G. Danaei, M. M. Finucane, Y. Lu, G. M. Singh, M. J. Cowan, C. J. Paciorek, J. K. Lin, F. Farzadfar, Y. H. Khang, G. A. Stevens, M. Rao, M. K. Ali, L. M. Riley, C. A. Robinson, M. Ezzati. The Lancet. 2011, 378, 31.

[17]. D. M. Nathan, The new England Journal of medicine. 1993, 328, 1676.

[18]. American Diabetes Association, Diabetes Care. 1994, 17, 81.

[19]. American Diabetes Association, Diabetes Care. 1999, 22, 77.

[20]. H. Patel, X. Li, H. I. Karan, Biosensors and Bioelectronics. 2003, 18, 1073.

[21]. S. R. Lee, Y. T. Lee, K. Sawada, H. Takao, M. Ishida, Biosensors and Bioelectronics. 2008, 24, 410.

[22]. S. R. Lee, M. M. Rahman, M. Ishida, K. Sawada, Biosensors and Bioelectronics. 2009, 24 (7), 1877. 
[23]. P. R. Solanki, A. Kaushik, V. V. Angrawal, B. D. Malhotra, NPG Asia Materials. 2011, 3, 17.

[24]. J. Wang, The Analyst. 2005, 130, 421.

[25]. F. Valentini, G. Palleschi, Analytical Letters. 2008, 41, 479.

[26]. N. Chopra, V. G. Gavalas, L. G. Bachas, B. J. Hinds, L. G. Bachas, Analytical Letters. 2007, 40, 2067.

[27]. C. Yuan, J. Li, L. Hou, L. Yang, L. Shen, X. Zhang, Journal of Materials Chemistry. 2012, 22, 16084.

[28]. L. Yan, X. M. Zhang, T. Ren, H. P. Zhang, X. L. Wang, J. S. Suo, Chemical Communications. 2002, 860.

[29]. J. Wollenstein, M. Burgmair, G. Plescher, T. Sulima, J. Hildenbrand, H. Bottner, I. Eisele, Sensors and Actuators B. 2003, 93, 442.

[30]. N. Pinna, M. Niederberger, Angewandte Chemie-International Edition. 2008, 47, 5292.

[31]. Q. Wang, B. Liu, X. Wang, S. Ran, L. Wang, D. Chen, G. Shen, Journal of Materials Chemistry. 2012, 22, 21647.

[32]. B. Guo, C. S. Li, Z-Y. Yuan, Journal of Physical Chemistry C. 2010, 114, 12805. 


\section{CHAPTER 2}

\section{Material's View}

Nanomaterials based on metal oxide semiconductors have been on research fore front due to their enormous use in diverse areas including electronics, piezoelectricity, optoelectronics, bio sensors, catalysis, etc. Among all metal oxides, zinc oxide ( $\mathrm{ZnO})$, cobalt oxide $\left(\mathrm{CO}_{3} \mathrm{O}_{4}\right)$ and nickel cobalt oxide $\left(\mathrm{NiCo}_{2} \mathrm{O}_{4}\right)$ have been considered in the present work.

\subsection{Zinc Oxide (ZnO):}

$\mathrm{ZnO}$ as mineral zincite is present in the earth's crust [1] and has been extensively used as an additive in different products such as rubber, ceramics, pigments, cement, sealants, plastic and paint [2]. $\mathrm{ZnO}$ is also an attractive material for biomedical applications, because it is a bio-safe material [3,4]. With the passage of time $\mathrm{ZnO}$ proved to be a versatile material because of its direct/wide band gap (3.37 eV) and high exciton binding energy $(60 \mathrm{meV})[1,5,6]$. The features related to wide band gap such as minimum electronic noise, ability to maintain high breakdown voltages, ability to run at high power and ability to adapt huge amount of intrinsic defects are critical for many electronic/optoelectronic devices. On the other hand the larger exciton binding energy (60 meV) than thermal energy (25 meV) at ambient temperature is responsible for stable electron-hole pair recombination, which paves the way for good luminescence behavior of $\mathrm{ZnO}$ [7]. Beside these there are some other properties that make $\mathrm{ZnO}$ more preferable material than other II-VI semiconductors. For example near UV emission and transparent conductivity, piezoelectricity and pyroelectricity, biocompatibility, relatively bio safe/environment friendly, negligible toxicity, increased sensitivity, simple synthesis and low cost [8-16]. More importantly ZnO is unique in a way that it holds both semiconducting and piezoelectric properties, which pave the way for number of applications in energy harvesting devices [17-24]. Therefore $\mathrm{ZnO}$ has an important role in producing carbon dioxide $\left(\mathrm{CO}_{2}\right)$ emission free 
energy. Some of the basic characteristics of $\mathrm{ZnO}$ have also been highlighted in Table1.

\begin{tabular}{ll}
\hline Property & Value \\
\hline Molecular Mass & $81.37 \mathrm{~g} / \mathrm{mol}$ \\
Crystal Structure & Wurtzite \\
Density & $5.606 \mathrm{~g} / \mathrm{cm}^{3}$ \\
Melting Point & $1975^{\circ} \mathrm{C}$ \\
Boiling Point & $2360^{\circ} \mathrm{C}$ \\
Solubility in water & $0.16 \mathrm{~g} / 100 \mathrm{~mL}$ \\
Thermal Conductivity & $0.6 ; 1-1.2$ \\
Energy gap & $3.37 \mathrm{eV}$ \\
Exciton binding energy & $60 \mathrm{mV}$ \\
Intrinsic carrier concentration & $<10^{6} \mathrm{~cm}$ \\
Electron effective mass & $0.24 \mathrm{~m} 0$ \\
Hole effective mass & $0.59 \mathrm{~m}_{0}$ \\
Electron Hall mobility & $200 \mathrm{~cm}{ }^{2} / \mathrm{V} . \mathrm{s}$ \\
Hole Hall mobility & $5-50 \mathrm{~cm} / \mathrm{V} . \mathrm{s}$ \\
Static dielectric constant & 8.656 \\
Bulk effective piezoelectric constant & $9.9 \mathrm{pm} / \mathrm{V}$ \\
Bulk hardness; H(GPa) & $5.0 \pm 0.1$ \\
\hline
\end{tabular}

Table 1 Some basic properties of $\mathrm{ZnO}$.

Following is a brief discussion on crystal structure and those properties of $\mathrm{ZnO}$ which are directly related to the presented work such as piezoelectric, mechanical, optical, and electrical characteristics of $\mathrm{ZnO}$.

\subsubsection{Crystal structure:}

ZnO has three kinds of crystal structures namely wurtzite (B4), zinc blende (B3) and rocksalt (B1) [25]. Among these, the thermodynamically stable phase at room temperature is wurtzite and all the discussion covered in this thesis is based on wurtzite crystal structure. The wurtzite structure of $\mathrm{ZnO}$ comprise of a hexagonal unit cell as shown in figure 2.1. 


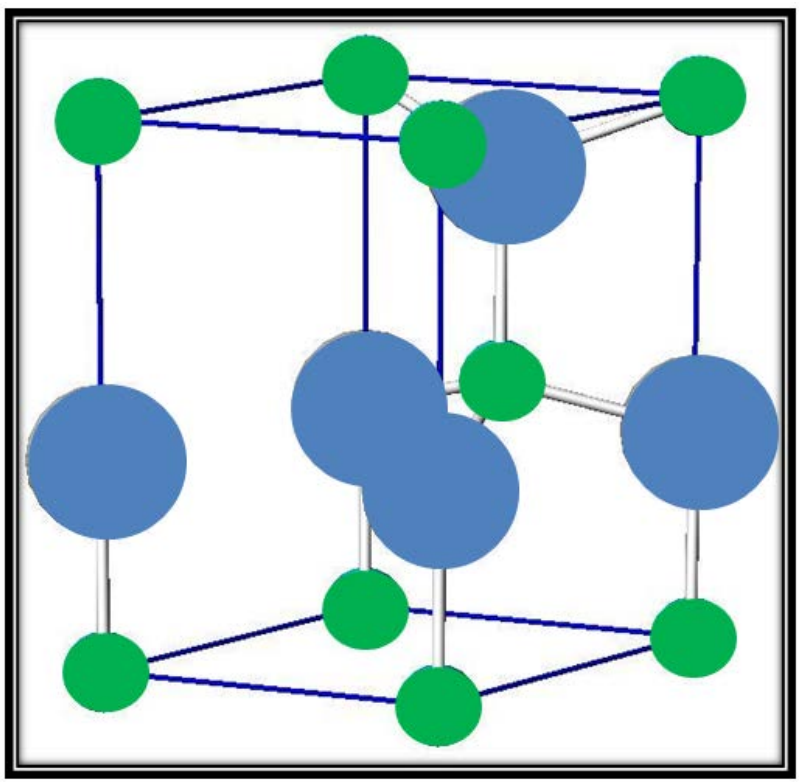

Figure 2.1 Wurtzite structure of $\mathrm{ZnO}$ unit cell, in which green balls are $\mathrm{Zn}{ }^{+2}$ ions and blue balls are $\mathrm{O}^{-2}$ ions showing tetrahedral coordination.

It has two lattice parameters namely $a$ and $c$ and its space group identified as $C^{4}{ }_{6 \mathrm{v}}$ or $P 63 m c$ at ambient conditions [26, 27]. As shown in figure 2.1 wurtzite $\mathrm{ZnO}$ has four face terminations, two are polar and other two are non-polar. The polar faces include Zn terminated ( $\left(\begin{array}{llll}0 & 0 & 0 & 1\end{array}\right)$ and $O$ terminated $\left(\begin{array}{llll}0 & 0 & 0 & \overline{1}\end{array}\right)$ (c-axis oriented), while the non-

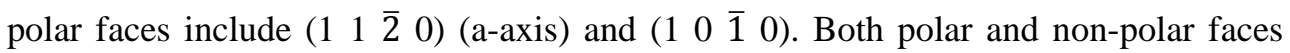
have equal number of $\mathrm{Zn}$ and $\mathrm{O}$ atoms, but the chemical and physical properties of polar faces are different from non-polar faces [28]. Both the polar surfaces are stable, while among non-polar surfaces ( $\left(\begin{array}{llll}1 & 0 & \overline{1} & 0\end{array}\right)$ surface is stable and $\left(\begin{array}{llll}1 & 1 & \overline{2} & 0\end{array}\right)$ face is relatively less stable and has relatively much higher surface roughness. These features of polar and non-polar faces have key role in growing different $\mathrm{ZnO}$ nanostructures. It is important to point out that three fastest growth directions of $\mathrm{ZnO}$ are along $\left(\begin{array}{llll}0 & 0 & 0 & 1\end{array}\right)$,

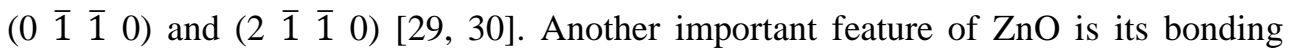
nature. The bond between zinc and oxygen has firm ionic character, whereas the tetrahedral coordination of the $\mathrm{ZnO}$ crystal structure also points out the $\mathrm{sp}^{3}$ covalent bonding. That is why $\mathrm{ZnO}$ sorted out as covalent as well as ionic compound [31]. It is well known that among all the semiconductors, which have tetrahedral bond; $\mathrm{ZnO}$ 
holds the highest piezoelectric tensor [32]. Due to these features $\mathrm{ZnO}$ become more important than others in applications where electromechanical coupling plays a role [33].

\subsubsection{Piezoelectric properties:}

$\mathrm{ZnO}$ is a promising piezoelectric material, because it shows an effective accumulation of charges when mechanical stress is applied on it. Since $\mathrm{ZnO}$ has both semiconducting and piezoelectric properties, therefore it has enormous potential in energy harvesting applications [13-24]. The polarity present in the ZnO crystal is because of its tetrahedral structure in which oppositely charged ions produce positively charged zinc and negatively charged oxygen polar surfaces, that creates conventional dipole moment and spontaneous polarization along the c-axis. Therefore one can say that piezoelectricity initiates from the polarization of the tetrahedrally coordinated unit. In principle the piezoelectric effect changes an applied mechanical stress into an electrical voltage or vice versa and it is not similar to ferroelectricity. There are two possible ways to determine piezoelectric properties. One is called direct piezoelectric effect and the other is called converse or indirect piezoelectric effect. In the direct piezoelectric effect force is applied on the material in order to create strain in it, which generates charges on the material's surface due to electrical polarization that results output voltage signal. Vice versa in converse piezoelectric effect an external voltage is applied in order to generate strain in the material. Polarity in $\mathrm{ZnO}$ is also critical because it has substantial influenced on different properties like growth direction, etching, piezoelectricity and defect generation. Moreover due to the absence of center of symmetry in the wurtzite crystal structure of $\mathrm{ZnO}$, it exhibits pyroelectric behavior as well besides being piezoelectric.

\subsubsection{Mechanical properties:}

Since $\mathrm{ZnO}$ has been extensively used in developing piezoelectric nanodevices, therefore it is very important to have good understanding of mechanical stability and reliability of $\mathrm{ZnO}$ nanostructures. Because if a piezoelectric device is fabricated and it is not working properly, then it is hard to understand that whether it is due to the 
failure of the grown nanostructures or the failure of something else. So in such a case the mechanical characterization of nanostructures plays an important role. These include parameters like hardness, stiffness, toughness, yield strength, piezoelectric constant; Young's and bulk moduli, and adhesion to the substrate [34-36]. It is important to point out that if the diameter and length of the nanostructure varies then it also affects the mechanical properties [34-36]. Therefore in order to have efficient and reliable piezoelectric devices, the characterization of its mechanical properties is the backbone. That is why mechanical properties of different materials have been extensively studied [34-43].

\subsubsection{Optical properties:}

$\mathrm{ZnO}$ holds some exceptional properties which make $\mathrm{ZnO}$ an excellent luminescent material [7]. These properties include direct and wide band gap, large excitons binding energy and deep level defect emission [1, 8, 44, 45]. As direct band gap is good for short wavelength photonics, high excitons binding energy permits effective excitonic emission at ambient temperature [46] and deep level defect emission is responsible for covering the whole visible region beside ultra violet emission $[1,8,46,47]$. The optical properties rely heavily on intrinsic and extrinsic defects present in the crystal structure and it is possible to tune the optical/electrical properties just by manipulating the nature and quantity of defects present there $[48,49]$. These defects can occur at the time of growth or annealing. The intrinsic defects (like vacancy) are those in which host atom is absent, while extrinsic defects are those in which foreign atoms (like impurities) are involved. $\mathrm{ZnO}$ have two most common defects known as oxygen vacancy and zinc vacancy.

\subsubsection{Electrical properties:}

It is very much essential to realize the electrical properties of $\mathrm{ZnO}$ nanostructures for different applications especially in electronics. But it is difficult to measure the electrical properties of $\mathrm{ZnO}$ that is why lot of variation in the reported results has been found [50-57]. It is believed that current transport properties have been strongly affected by the concentration of intrinsic defects. It is considered that oxygen 
vacancies and zinc interstitials are responsible for the n-type electrical behavior of un-doped $\mathrm{ZnO}$ [58]. At ambient temperatures the electron and hole mobility has been figured as $200 \mathrm{~cm}^{2} / \mathrm{V}$.s and 5-50 $\mathrm{cm}^{2} / \mathrm{V}$.s [59,60] respectively and the effective mass of electron and holes has been figured as $0.24 \mathrm{~m}_{0}$ and $0.59 \mathrm{~m}_{0}$ respectively. Since the gap between the effective masses of electrons and holes is relatively larger therefore the electrons have relatively high mobility than holes [61, 62].

\subsection{Cobalt (II, III) oxide $\left(\mathrm{Co}_{3} \mathrm{O}_{4}\right)$ :}

In different fields of science and technology cobalt based oxide materials have captured a lot of interest among research community because of their potential applications [63-65]. Cobalt has two stable oxide states known as $\mathrm{CoO}$ and $\mathrm{Co}_{3} \mathrm{O}_{4}$. At room temperature both compounds are found to be kinetically stable [66]. In the present work the discussion will be focused on $\mathrm{Co}_{3} \mathrm{O}_{4}$ and $\mathrm{NiCo}_{2} \mathrm{O}_{4}$. Cobalt (II, III) oxide is an inorganic compound and as a mixed valence compound, its formula is written as $\mathrm{CoIICoIII}{ }_{2} \mathrm{O}_{4}$ or $\mathrm{CoO}_{2} \mathrm{Co}_{2} \mathrm{O}_{3}$ or $\mathrm{Co}_{3} \mathrm{O}_{4}$. It adopts the normal spinel structure, with $\mathrm{Co}^{2+}$ ions occupy the tetrahedral $8 \mathrm{a}$ sites and $\mathrm{Co}^{3+}$ ions in the octahedral $16 \mathrm{~d}$ sites based on the cubic close-packed arrays of oxide anions as shown in figure 2.2.

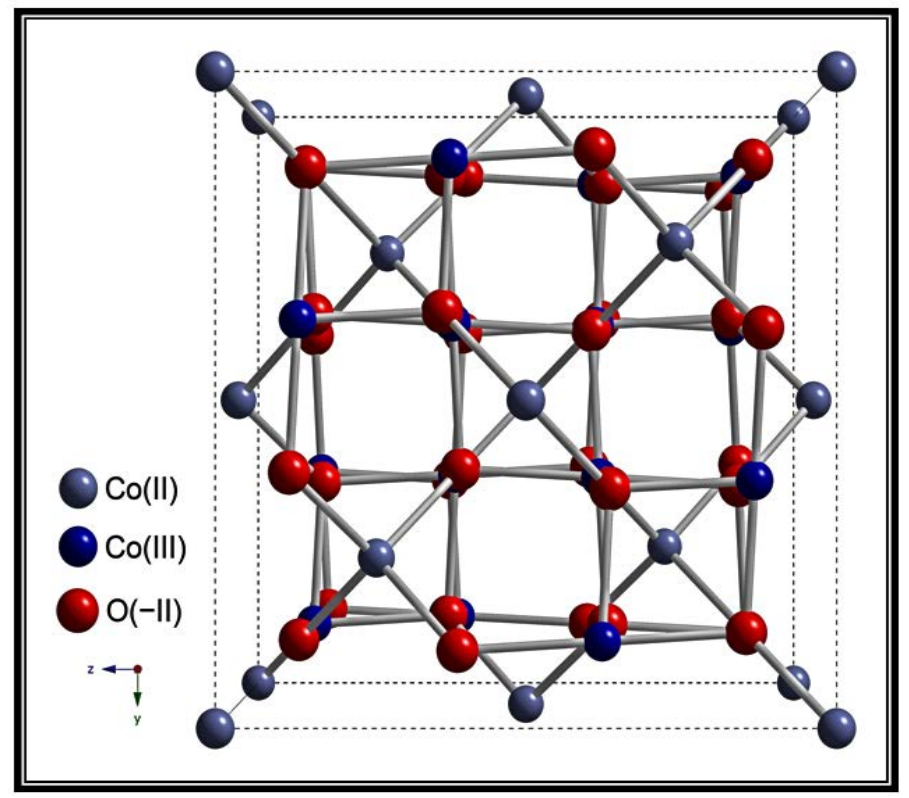

Figure 2.2 The unit cell structure of $\mathrm{Co}_{3} \mathrm{O}_{4}$.(Reproduced from wikipedia) 
$\mathrm{Co}_{3} \mathrm{O}_{4}$ is an important magnetic p-type semiconductor having direct optical band gaps as 1.48 and $2.19 \mathrm{eV}$ [67], but $1.6 \mathrm{eV}$ is also reported in the literature [68, 69]. It is believed that transition metal oxides are good candidates as electrode materials, because they have variation in oxide states which is suitable for effective redox charge transfer [70-72]. That is why as the most active transition metals, $\mathrm{Co}_{3} \mathrm{O}_{4}$ has been used extensively as heterogeneous catalysts, solid-state sensors and in pigment, magnet as well [73-75]. In last decade researchers have spent a lot of time on $\mathrm{Co}_{3} \mathrm{O}_{4}$ nanostructures due to their high electro- chemical performance; because the features like high surface area, short path length for ion transport and easily tunable surface have made $\mathrm{Co}_{3} \mathrm{O}_{4}$ a promising material for electrochemical devices [76-78]. Therefore in order to get maximum advantage of these properties an economical, stable, fast and sensitive $\mathrm{H}_{2} \mathrm{O}_{2}$ sensor has been prepared in the presented work. 


\subsection{References:}

[1]. C. Klingshirn, ChemPhysChem. 2007, 8(6), 782.

[2]. D. R. Lide, CRC Handbook of Chemistry and Physics. Internet version 2005. http://www.hbcpnetbase.com, CRC Press, Boca Raton, FL, 2005.

[3]. S. Al-Hill, M. Willander. Nanotechnology, 2009, 20, 175103.

[4]. Z. L. Wang, Materials Today, 2004, 7, 26.

[5]. Ü. Özgür, Y. I. Alivov, C. Liu, A. Teke, M. A. Reshchikov, S. Dogan, V. Avrutin, S. J. Cho, H. Morkoc, Journal of Applied Physics. 2005, 98, 041103.

[6]. D. C. Reynolds, D. C. Look, B. Jogai, C. W. Litton, G. Cantwell, W. C. Harsch, Physical Review B. 1999, 60, 2340.

[7]. J. Zhang, Z. Zhang, T. Wang, Chemistry of Materials, 2012-14, 16, 768.

[8]. N. H. Alvi, K. Ul Hasan, O. Nur, M. Willander, Nanoscale Research Letters, 2011, 6, 130.

[9]. A. B. Djurišić, Y. H. Leung, K. H. Tam, L. Ding, W. K. Ge, H. Y. Chen, S. Gwo, Applied Physics Letters. 2006, 88, 103107.

[10]. M. Willander, O. Nur, Q. X. Zhao, L. L. Yang, M. Lorenz, B. Q. Cao, J. Z. Pérez, C. Czekalla, G. Zimmermann, M. Grundmann, A. Bakin, A. Behrends, M. Al-Suleiman, A. El-Shaer, A. C. Mofor, B. Postels, A. Waag, N. Boukos, A. Travlos, H. S. Kwack, J. Guinard, D. L. S. Dang, Nanotechnology, 2009, 20, 332001.

[11]. P. D. Batista, M. Mulato, Applied Physics Letters.2005, 87, 143508.

[12]. B. S. Kang, F. Ren, Y. W. Heo, L. C. Tien, D. P. Norton, S. J. Pearton, Applied Physics Letters. 2005, 86, 112105.

[13]. Z. L. Wang, Advanced Functional Materials. 2008, 18, 3553.

[14]. Z. L. Wang, J. H. Song, Science, 2006, 312, 242.

[15]. P. G. Gao, J. H. Song, J. Liu, Z. L. Wang, Advanced Materials. 2007, 19, 67.

[16]. Z. L. Wang, Advanced Materials. 2007, 19, 889.

[17]. J. H. Song, X. D. Wang, J. Liu, H. B. Liu, Y. L. Li, Z. L. Wang, Nano Letters. 2008, 8, 203.

[18]. M. P. Lu, J. H. Song, M. Y. Lu, M. T. Chen, Y. F. Gao, L. J. Chen, Z. L. Wang, Nano Letters. 2009, 9, 1223. 
[19]. J. Song, J. Zhou, Z. L. Wang, Nano Letters. 2006, 6, 1656.

[20]. S. Xu, Y. Qin, C. Xu, Y. Wei, R. Yang, Z. L. Wang, Nature Nanotechnology. 2010, 5, 366.

[21]. Y. Qin, X. Wang, Z. L. Wang, Nature. 2008, 451, 809.

[22]. C. L. Hsu, K. C. Chen, Journal of Physical Chemistry C. 2012, 116, 9351.

[23]. S. Xu, Y. Wei, J. Liu, R. Yang, Z. L. Wang, Nano Letters. 2008, 8(11), 4027.

[24]. A. Khan, M. A. Abbasi, M. Hussain, Z. H. Ibupoto, J. Wissting, O. Nur, M. Willander, Applied Physics Letters. 2012, 101, 193506.

[25]. J. S. S. Michelle, Progress in Materials Science. 2012, 57, 437.

[26]. C. F. Klingshirn, B. K. Meyer, A. Waag, A. Hoffmann, J. Geurts, Zinc oxide from fundamental properties towards novel applications. Springer, 2010.

[27]. S. Xu, Z. L. Wang, Nano Research. 2011, 4, 10138.

[28]. C. Jagadish, S. J. Pearton. Zinc oxide bulk, thin films and nanostructures: processing, properties and applications. Elsevier; 2006.

[29]. Z. L. Wang, Journal of Physics: Condensed Matter. 2004, 16, R829.

[30]. Ü. Özgür, Y.Alivov, C. Liu, A. Teke, M. Reshchikov, S. Dog-brevean, V. Avrutin, S. J.Cho, H. Morkoc, Journal of Applied Physics. 2005, 98, 041301.

[31]. V. A. Coleman, C. Jagadish, J. Chennupati, P. Stephen, Basic Properties and Applications of ZnO, Chapter 1 of Zinc oxide Bulk, Thin Films and Nanostructures. Elsevier. 2006.

[32]. A. D. Corso, M. Posternak, R. Resta, A. Baldereschi, Physical Review B. 1994, 50, 10715.

[33]. I. K. Bdikin, J. Gracio, R. Ayouchi, R. Schwarz, A. L. Kholkin, Nanotechnology, 2010, 21, 235703.

[34]. M. Riaz, J. Song, O. Nur, Z. L. Wang, M. Willander, Advanced Functional Materials. 2011, 21(4), 628.

[35]. M. Riaz, A. Fulati, Q. X. Zhao, O. Nur, M. Willander, P. Klason, Nanotechnology. 2008, 19, 415708.

[36]. M. Riaz, A. Fulati, L. L. Yang, O. Nur, M. Willander, P. Klason, Journal of Applied Physics. 2008, 104, 104306. 
[37]. M. Riaz, A. Fulati, G. Amin, N. H. Alvi, O. Nur, M. Willander, Journal of Applied Physics. 2009, 106, 034309.

[38]. S. Chowdhury, M. T. Laugier, Nanotechnology. 2004, 15, 1017.

[39]. E. W. Wong, P. E. Sheehan, C. M. Lieber, Science. 1997, 277, 1971.

[40]. J. Gong, H. Miao, Z. Peng, Journal of Materials Science Letters. 2003, 22, 267.

[41]. Z. L. Wang, P. Poncharal, W. A. de Heer, Journal of the Physics and Chemistry of Solids. 2000, 61, 1025.

[42]. Z. L. Wang, R. P. Gao, Z. W. Pan, Z. R. Dai, Advanced Engineering Materials. 2001,3, 657.

[43]. W. Mai, Z. L. Wang, Applied Physics Letters. 2006, 89, 073112.

[44]. S. Kishwar, K. ul Hasan, G. Tzamalis, O. Nur, M. Willander, H. S. Kwack, D. L. S. Dang, Physica Status Solidi. A. 2010, 207, 67.

[45]. A. V. Dijken, J. Makkinje, A. Meijerink, Journal of Luminescence, 2001, 92, 323.

[46]. A.B. Djurišić, A.M.C. Ng, X.Y. Chen, Progress in Quantum Electronics, 2010, 34, 191.

[47]. A.B. Djurišić, Y.H. Leung, K.H. Tam, L. Ding, W.K. Ge, H.Y. Chen, S. Gwo, Applied Physics Letters. 2006, 88, 103107.

[48]. Ü. Özgür, Y. I. Alivov, C. Liu, A. Take, M. A. Reshchikov, S. Dogan, V. Avrutin, S. J. Cho, H. Morkoc, Journal of Applied Physics. 2005, 98, 041301.

[49]. D. Florescu, L. G. Mourok, F. H. Pollack, D. C. Look, G. Cantwell, X. Li, Journal of Applied Physics. 2002, 91, 8902.

[50]. K. Subannajui, D. S. Kim, M. Zacharias, Journal of Applied Physics. 2008, 104, 014308.

[51]. F. Jones, F. Leonard, A. A. Talin, N. S. Bell, Journal of Applied Physics. 2007, 102, 014305.

[52]. C. Xu, J. Chun, D. E. Kim, J. -J. Kim, B. Chon, T. Joo, Applied Physics Letters. 2007, 90, 083113.

[53]. M. Sakurai, Y. G. Wang, T. Uemura, M. Aono, Nanotechnology, 2009, 20, 155203. 
[54]. C. H. Liu, W. C. Yiu, F. C. K. Au, J. X. Ding, C. S. Lee, S. T. Lee, Applied Physics Letters. 2003, 83, 3168.

[55]. W. Q. Yang, H. B. Huo, L. Dai, R. M. Ma, S. F. Liu, G. Z. Ran, B. Shen, C. L. Lin, G. G. Qin, Nanotechnology. 2006, 17, 4868.

[56]. L. Liao, J. C. Li, D. F. Wang, C. Liu, C. S. Liu, Q. Fu, L. X. Fan, Nanotechnology. 2005,16, 985.

[57]. S. Han, D. Zhang, C. Zhou, Applied Physics Letters. 2006, 88, 133109.

[58]. D. Seghier, H. P. Gislason, Journal of Materials Science-Materials in Electronics. 2008, 19, 687.

[59]. S. J. Pearton, D. P. Norton, K. Ip, Y. W. Heo, T. Steiner, Superlattices and Microstructures. 2003, 34, 3.

[60]. S. Adachi, Properties of group-IV, III-V, and II-VI semiconductors, John Wiley \& Sons. 2005.

[61]. S. J. Pearton, D. P. Norton, K. Ip, Y. W. Heo, T. Steiner, Progress in Materials Science. 2005, 50, 293.

[62]. D. C. Look, B. Claflin, Y. I. Alivov, S. J. Park, Physica Status Solidi A. 2004, 201, 2203.

[63]. V. M. Jime'nez, A. Ferna’ndez, J. P. Espino’s, A. R. Gonza' lez-Elipe, Journal of Electron Spectroscopy and Related Phenomena. 1995, 71, 65.

[64]. H. Hamada, M. Haneda, N. Kakuta, H. Miura, K. Inomi, T. Nanba, W. Qi Hua, A. Veno, H. Ohfune, Y. Udagawa, Chemistry Letters. 1997, 887.

[65]. M. Tanaka, M. Mukaia, Y. Fujimuri, M. Kondoh, Y. Tasaka, H. Baba, S. Usami, Thin Solid Films. 1996, 453, 281.

[66]. N. N. Greenwood, A. Earnshaw, Chemistry of the Elements, ButterworthHeinemann, Amsterdam, 1997.

[67]. A. O. Gulino, P. Dapporto, P. Rossi, I. Fragalà, Chemistry of Materials. 2003, $15,3748$.

[68]. K. J. Kim, Y. R. Park, Solid State Communications. 2003, 127, 25.

[69]. V. R. Shinde, S. B. Mahadik, T. P. Gujar, C. D. Lokhande, Applied Surface Science. 2006, 252, 7487.

[70]. A. K. Shukla, S. Sampath, K. Vijayamohanan, Current Science. 2000, 79, 1656. 
[71]. P. J. Hall, M. Mirzaeian, S. I. Fletcher, F. B. Sillars, A. J. R. Rennie, G. O. Shitta-Bey, G. Wilson, A. Cruden, R. Carter, Energy \& Environmental Science. 2010, 3, 1238.

[72]. P. Simon, Y. Gogotsi, Nature Materials. 2008, 7, 845.

[73]. S. Weichel, P.J. Moller, Surface Science. 1998, 399, 219.

[74]. M. Ando, T. Kobayashi, S. Iijima, M. Haruta, Journal of Materials Chemistry. 1997, 7 (9), 1779.

[75]. F. Svegl, B. Orel, M.G. Hutchins, K. Kalcher, Journal of Electrochemical Society. 1996, 143, 1532.

[76]. J. Wollenstein, M. Burgmair, G. Plescher, T. Sulima, J. Hildenbrand, H. Bottner, I. Eisele, Sensors Actuators B. 2003, 93, 442.

[77]. E. M. Logothesis, R. Park, A . H. Meitzler, K. K. Laud, Applied Physics Letters. 1975, 26, 209.

[78]. L. Yan, X. M. Zhang, T. Ren, H. P. Zhang, X. L. Wang, J. S. Suo, Chemical Communications. 2002, 860. 


\section{CHAPTER 3}

\section{Growth Process}

In this chapter all the experimental details regarding the synthesis of $\mathrm{ZnO}$ nanorods, $\mathrm{Co}_{3} \mathrm{O}_{4}$ nanostructures using different salts and $\mathrm{NiCo}_{2} \mathrm{O}_{4}$ nanostructures have been given. It is important to point out that the given experimental protocol is in the same order that has been used in the presented work and ensures the reproducibility of the nanostructures. The experimental details can be divided in three parts. First part belongs to substrate treatment, the second part describes that why aqueous chemical growth method has been used and finally how synthesis has been conducted.

\subsection{Substrate treatment:}

The substrate is the core of the synthesis process. The treatment of the substrate prior to growth process has substantial influence on the morphology and quality of the grown nanostructures. Some important steps related to substrate treatment are highlighted here.

\subsubsection{Selection of substrate:}

Selection of the substrate is very crucial because it is directly related to the objective of the work. In the presented work different substrates have been utilized keeping the main objective in mind. These include single layer graphene on PET, common paper, flexible plastic, cotton textile, aluminum foil; fluorine doped tin oxide coated glass, simple glass, p-type Silicon and nickel foam.

\subsubsection{Preparation of substrate:}

Prior to the growth the most important step is preparation of substrate. This includes the cutting of substrate, cleaning of substrate, deposition of conductive material, deposition of seed layer and pre growth annealing (if required). 


\subsubsection{Cutting of substrate:}

Cutting of substrate is very critical as we have two objectives in mind at the time of cutting of substrate. One is to preserve the original architecture of the substrate and the other is to choose an appropriate size that not only suitable for the growth equipment but equally suitable for different characterizations and making device (if needed).

\subsubsection{Cleaning of substrate:}

The main purpose of the cleaning is to remove/eliminate the unseen dust or organic contaminant or any other unknown particles (if present there). Cleaning of substrate prior to growth has great importance for obtaining high quality, dense, uniform, defects free and well aligned nanostructures as the dust particles and other unwanted chemicals/particles present on the surface of the substrate can damage the quality, stability, alignment and predictability of the grown nanostructures. Cleaning also plays an important role for reproducing the nanostructures. The cleaning has been performed via ultrasonic bath by using acetone and isopropanol respectively for 5 minutes each, then washed with deionized water and dried by flow of nitrogen gas.

\subsubsection{Deposition of conductive layer:}

In some cases there is a need of conductive layer on the substrate in order to use as a bottom electrode during the measurements. For example if we are preparing samples for the fabrication of nanogenerators then we should have a conductive substrate. So a metal evaporator (Satis-having a pressure of $2.5 \times 10^{-6}$ mbar) has been utilized in order to make surface of the substrate conductive by setting a layer of any conductive material such as Silver, Platinum, Gold, and Aluminum. Before and after the deposition of conductive layer it is mandatory to clean the substrates by repeating the same process as explained above.

\subsubsection{Preparation of seed solution:}

\section{(i) For ZnO nanorods:}

The seed solutions can be prepared by using different solvents and precursors. We utilized two different kinds of seed solutions for the growth of $\mathrm{ZnO}$ nanorods. First 
seed solution was prepared by dissolving $5 \mathrm{mM}$ of zinc acetate dihydrate $\left(\mathrm{Zn}\left(\mathrm{CH}_{3} \mathrm{COO}\right)_{2} \cdot 2 \mathrm{H}_{2} \mathrm{O}\right)$ in pure ethanol solution as reported by Green et al. [1]. This seed solution was used for hard substrates like Glass, Silicon, FTO and ITO; because these substrates need pre growth annealing in order to decompose zinc acetate dihydrate into $\mathrm{ZnO}$ nanoparticles. Another seed solution was prepared by following the method of Pacholski et al. [2]. In this case, we dissolved $5 \mathrm{mM}$ of zinc acetate dihydrate and $\mathrm{KOH}$ in pure methanol solution. This kind of seed solution is suitable for soft/flexible substrates like common paper, plastic, textile fibre and aluminum foil, because zinc acetate dihydrate converts to $\mathrm{ZnO}$ nanoparticles at room temperature.

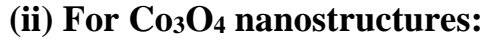

A seed crystal solution was prepared by dissolving $274 \mathrm{mg}$ of cobalt acetate anhydrous in $125 \mathrm{ml}$ methanol and left for stirring at a temperature of $60^{\circ} \mathrm{C}$ for two hours. After two hours cobalt acetate anhydrous was dissolved completely and a uniform blue color solution was appeared.

\section{(iii) For $\mathrm{NiCo}_{2} \mathrm{O}_{4}$ nanostructures:}

A seed crystal solution was prepared by dissolving $274 \mathrm{mg}$ of cobalt chloride hexahydrate in $125 \mathrm{ml}$ methanol and left for stirring at a temperature of $60^{\circ} \mathrm{C}$ for two hours. After two hours cobalt chloride hexahydrate was dissolved completely and a uniform blue color solution was appeared.

\subsubsection{Deposition of seed solution:}

Two drops of the prepared seed solution were applied on the substrate by using a spin coater (Laurell WS-650-8B) running at around 4000 r.p.m. The process was repeated three times for 30 seconds each time. The thickness/surface coverage of the seed layer can be insured by adjusting the spinning speed. The main purpose of using seed layer is to supply nucleation sites by diluting the thermodynamic barrier between heterogeneous materials [3]. Another advantage that has been observed is that when seed layer was used, the grown nanostructures were found to be well aligned, highly dense and uniform. 


\subsubsection{Annealing of seed layer containing substrate:}

Thermal annealing [4] is a process in which the substrate is heated for specific duration and temperature. After applying the seed solution on the substrates (only hard substrates), thermal annealing was performed at $100^{\circ} \mathrm{C}$ for few minutes in order to decompose $\mathrm{Zn}\left(\mathrm{CH}_{3} \mathrm{COO}\right)_{2} 2 \mathrm{H}_{2} \mathrm{O}$ into $\mathrm{ZnO}$ nanoparticles and to get proper adhesion of the $\mathrm{ZnO}$ seed particles on the surface of the substrate.

\subsection{Aqueous chemical growth (ACG) method:}

Over the years different kinds of synthesis techniques/methods have been developed. These can be categorized as gas phase approaches and solution phase approaches. In gas phase approaches high vacuum and/or elevated temperature, long reaction time, costly equipment and use of toxic components (in some cases) are normally required. Whereas the solution phase approaches can be carried out at low temperature and pressure. The solution based approaches have many other advantages like low cost, high productivity, low energy consumption, possible in-situ doping [5], flexibility in equipment and compatibility for both organic and inorganic materials. Due to these features low temperature solution based approaches have found their place in different branches of science and technology and this has led the foundation for some other techniques strongly based on solution phase approach. These approaches can further be divided in three categories namely hydrothermal, chemical bath deposition or aqueous chemical growth and electrochemical deposition method [6]. Among these, aqueous chemical growth is one of the techniques that have been extensively employed for synthesis. The term aqueous chemical stands for the heterogeneous reactions occurred in the presence of aqueous solvents/minerals. Now for many years aqueous chemical growth method has been heavily used for the synthesis of metal oxide nanostructures [7-11]. Considering different aspects of synthesis process, we conclude that aqueous chemical growth method is the most simple, cheap and effective method to synthesize different metal oxide nanostructures [12-15]. Some of the advantages associated with aqueous chemical growth method are low temperature, low manufacturing cost, simple equipment, superior throughput, in-situ doping and environment friendly [16]. 


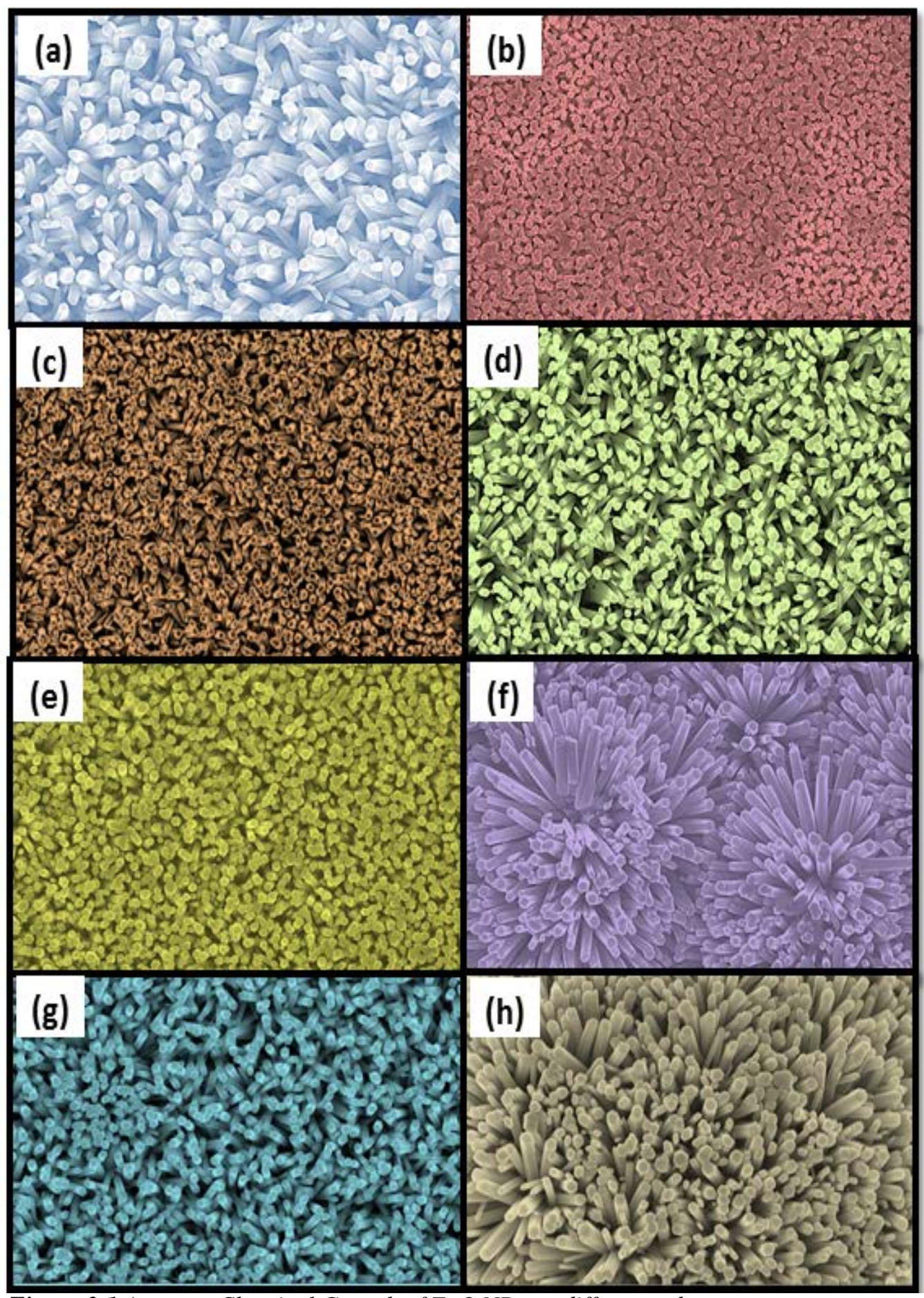

Figure 3.1 Aqueous Chemical Growth of $\mathrm{ZnO}$ NRs on different substrates.

(a)Paper (b) Plastic (c) Graphene (d) ITO (e) Si (f) FTO (g) Glass (h) Al foil. 


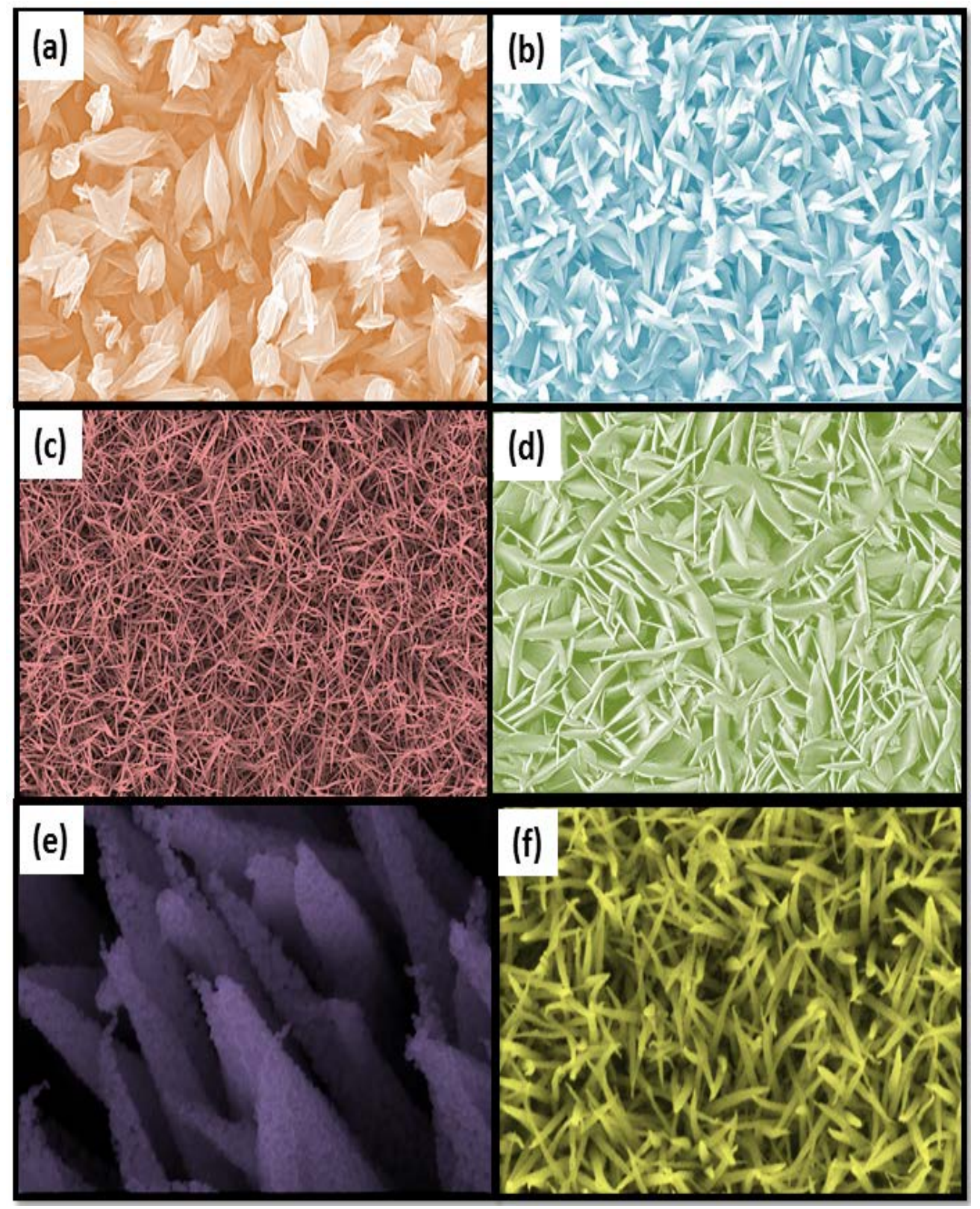

Figure 3.2 Aqueous Chemical Growth of different oxide materials.

$(a-b) \mathrm{CuO}(c-d) \mathrm{Co}_{3} \mathrm{O}_{4}(e-f) \mathrm{NiCo}_{2} \mathrm{O}_{4}$

Most importantly by using aqueous chemical growth method variety of metal oxide nanostructures can easily be grown on different substrates like metal surface, semiconductors, glass, plastic, common paper, aluminum foil, graphene, cotton textile, 
etc. [3, 14, 17-23]. In the presented work, we investigated three types of nanostructures, i.e. $\mathrm{ZnO}$ nanorods, $\mathrm{Co}_{3} \mathrm{O}_{4}$ nanostructures using different salts and $\mathrm{NiCo}_{2} \mathrm{O}_{4}$ nanostructures by using the aqueous chemical growth method.

\subsubsection{Synthesis of $\mathrm{ZnO}$ nanorods:}

After conducting a series of experiments following conditions were optimized in order to get well aligned, dense and uniform growth of $\mathrm{ZnO}$ nanorods. An equi-molar (0.075) solution of hexamethylenetetramine $\left(\mathrm{C}_{6} \mathrm{H}_{12} \mathrm{~N}_{4}\right)$ and zinc nitrate hexahydrate $\left(\mathrm{Zn}\left(\mathrm{NO}_{3}\right)_{2} .6 \mathrm{H}_{2} \mathrm{O}\right)$ were dissolved in $100 \mathrm{ml}$ deionized water and left for stirring until the solution becomes transparent. Then substrates decorated with $\mathrm{ZnO}$ seed particles were placed in a beaker facing downward by the help of a Teflon sample holder. After that the beaker was kept in a preheated electric oven at $95^{\circ} \mathrm{C}$ for $5-6$ hours. After the completion of the growth duration the substrates were washed carefully with the deionized water to remove residual solid particles from the surface. Finally, the samples were dried in air at room temperature.

\subsubsection{Synthesis of $\mathrm{Co}_{3} \mathrm{O}_{4}$ nanostructures:}

The growth solutions for different cobalt salts have been prepared by taking equi-molar $(0.1 \mathrm{M})$ concentration of urea with precursors including cobalt nitrate, cobalt acetate, cobalt chloride and cobalt sulfate, each in $50 \mathrm{ml}$ of deionized water and then all solutions were left on stirring for $30 \mathrm{~min}$. The Silicon substrates decorated with $\mathrm{Co}_{3} \mathrm{O}_{4}$ particles were placed in these growth solutions by the help of a Teflon sample holder facing downward. Then samples were kept in preheated electric oven at $95^{\circ} \mathrm{C}$ for 5-6 hours. After the growth duration samples with the $\mathrm{Co}_{3} \mathrm{O}_{4}$ nanostructures were taken out from the growth solution and washed in the deionized water in order to remove residual solid particles from the surface. Then, the samples were dried in air at room temperature.

\subsubsection{Post growth annealing:}

Since the grown samples have $\mathrm{Co}(\mathrm{OH})_{2}$ phase, therefore were annealed at $450^{\circ} \mathrm{C}$ for 4 h on a hot plate to convert cobalt hydroxide into $\mathrm{Co}_{3} \mathrm{O}_{4}$ nanostructures. 


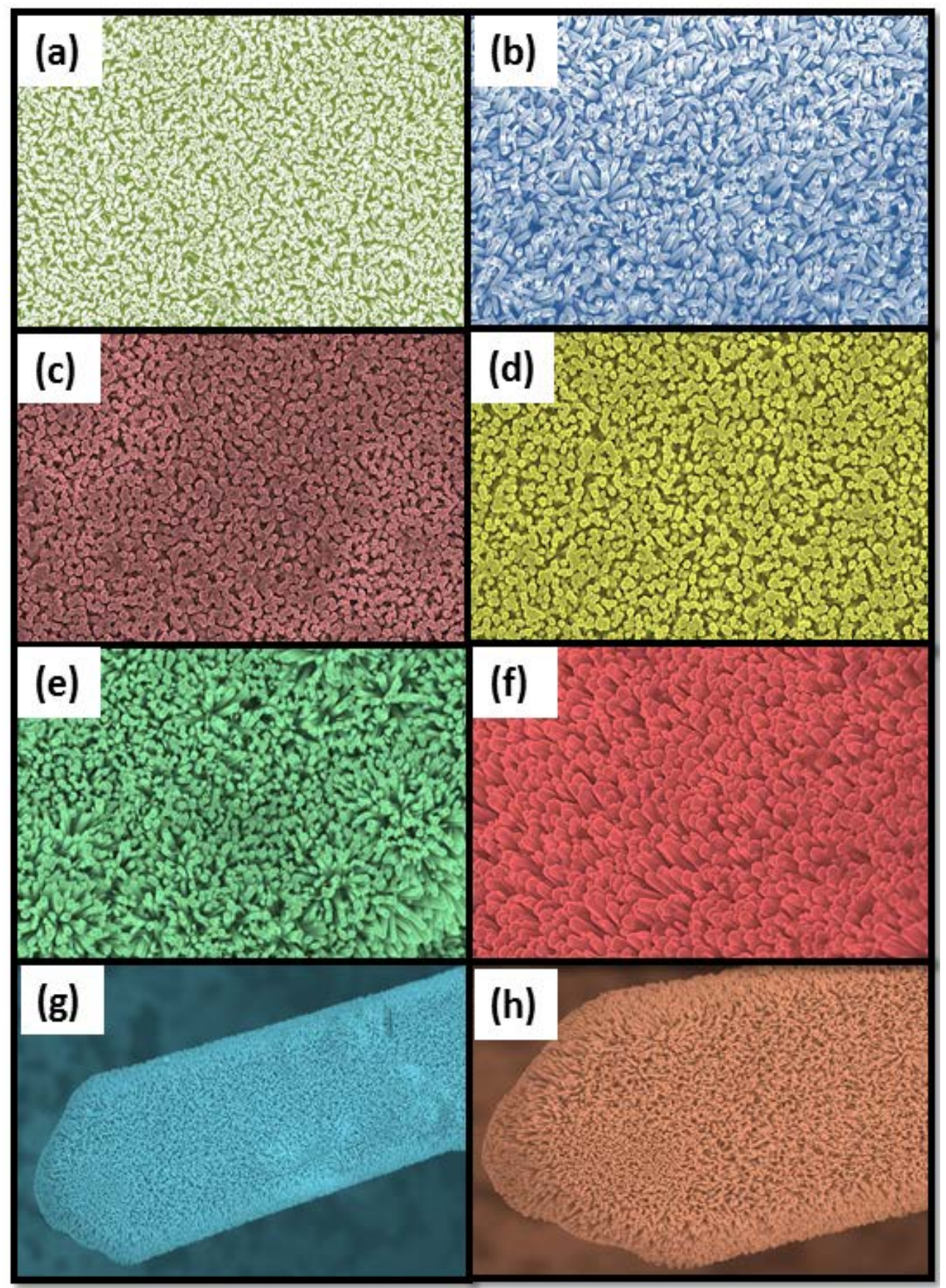

Figure 3.3 Synthesis of ZnO NRs for presented work.on (a) Graphene (b) Paper (c) Plastic (d) Textile (e) Al foil (f) FTO (g-h) low and high magnification SEM images of AFM tip. 


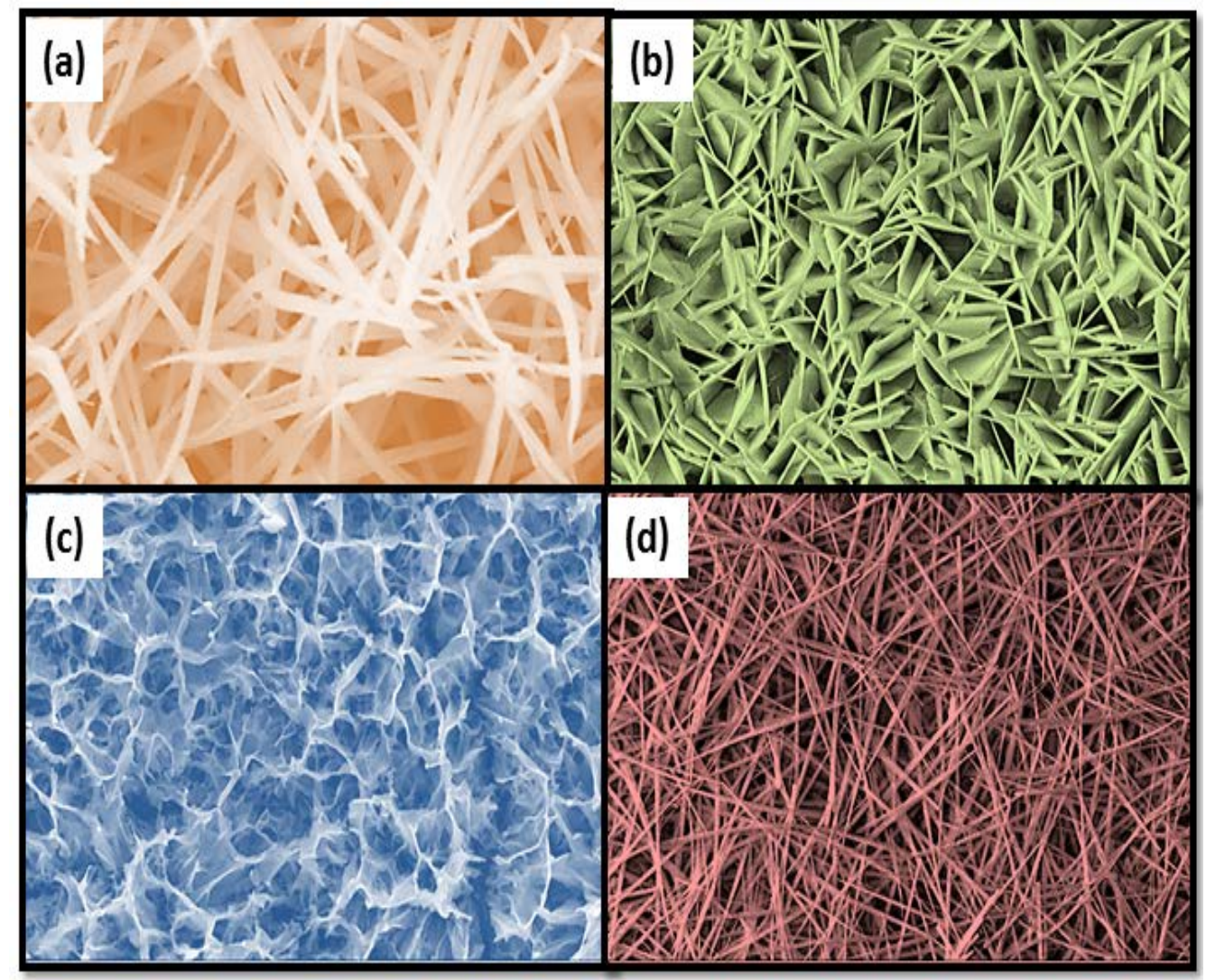

Figure $3.4 \mathrm{Co}_{3} \mathrm{O}_{4}$ nanostructures prepared in different salts.

\subsubsection{Synthesis of $\mathrm{NiCo}_{2} \mathrm{O}_{4}$ nanostructures:}

Aqueous chemical growth method has been employed for the growth of $\mathrm{NiCo}_{2} \mathrm{O}_{4}$ nanostructures on nickel foam as substrate. The precursor solution was prepared by dissolving $2.37 \mathrm{~g}$ of cobalt chloride hexahydrate, $1.185 \mathrm{~g}$ of nickel chloride hexahydrate and $2.7 \mathrm{~g}$ of urea in $75 \mathrm{~mL}$ of deionized water and then the solution was left on stirring for $30 \mathrm{~min}$. After that, the nickel foam pieces decorated with seed particles of cobalt chloride hexahydrate were placed in the beaker containing precursor solution by the help of a Teflon sample holder facing downward and the beaker was kept in a preheated oven at $95^{\circ} \mathrm{C}$ for $5-6 \mathrm{~h}$. After the growth period nickel foam pieces with the $\mathrm{NiCo}_{2} \mathrm{O}_{4}$ nanostructures were taken out from the growth solution and washed in the deionized water in order to remove residual solid particles from the surface. Finally, the samples were dried in air at room temperature. 


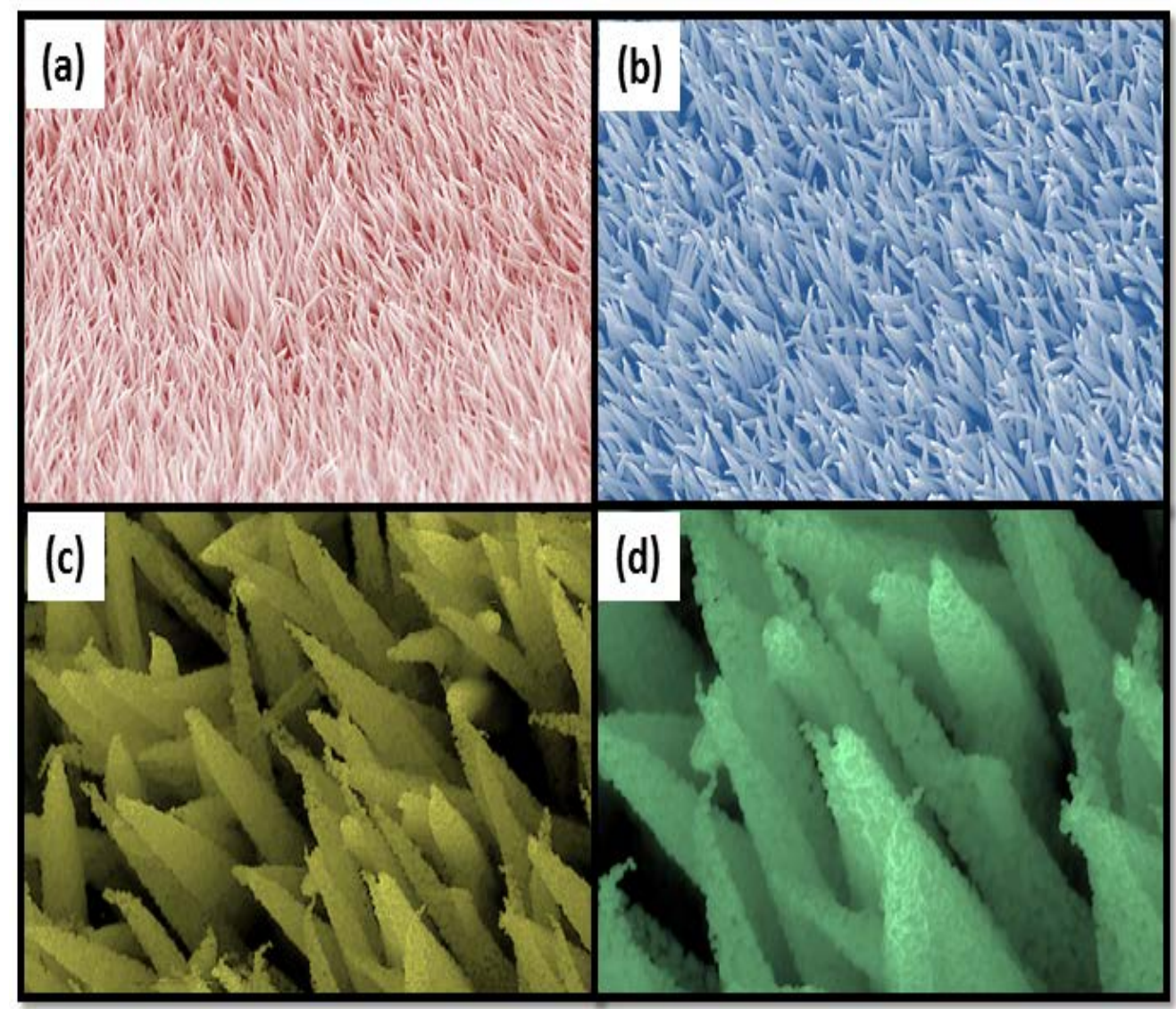

Figure 3.5 SEM images of $\mathrm{NiCo}_{2} \mathrm{O}_{4}$ nanostructures.

\subsubsection{Post growth annealing:}

In order to vanish the hydroxide phase from the as grown nanostructures of $\mathrm{NiCo}_{2} \mathrm{O}_{4}$ thermal annealing was performed by the help of a hot plate. A process in which the substrate with grown nanostructures is heated for a particular time and temperature is known as thermal annealing [4]. In the case of as grown $\mathrm{NiCo}_{2} \mathrm{O}_{4}$ nanostructures, we annealed the nickel foam substrate at $450^{\circ} \mathrm{C}$ for $3 \mathrm{~h}$ in order to get the complete conversion of the hydroxide phase into the oxide phase of nickel cobalt. The temperature and time used for post growth annealing has been optimized through a number of experiments. 


\subsection{References:}

[1]. L. E. Greene, M. Law, D. H. Tan, M. Montano, J. Goldberger, G. Somorjai, P. Yang. Nano Letters. 2005, 5(7), 1231.

[2]. C. Pacholski, A. Kornowski, H. Weller, Angewandte Chemie, International Edition. 2004, 116, 4878.

[3]. A. Zainelabdin, S. Zaman, G. Amin, O. Nur, M. Willander, Crystal Growth \& Design. 2010, 10, 3250.

[4]. T. M. Brseth. Annealing of Ion-Implanted and As-Grown Zinc Oxide. PhD thesis, University of Oslo, 2007.

[5]. E. V. Monakhov, A. Yu. Kuznetsov, B. G. Svensson, Journal of Physics D. Applied Physics. 2009, 42(15), 153001.

[6]. L. L. Yang, Linköping studies in science \& technology, 2008, Licentiate thesis no: 1384.

[7]. N. H. Alvi, K. Ul Hasan, O. Nur, M. Willander, Nanoscale Research Letters, 2011, 6, 130.

[8]. A. Khan, M. A. Abbasi, M. Hussain, Z. H. Ibupoto, J. Wissting, O. Nur, M. Willander, Applied Physics Letters. 2012, 101, 193506.

[9]. M. Riaz, A. Fulati, L. L. Yang, O. Nur, M. Willander, P. Klason, Journal of Applied Physics. 2008, 104,104306.

[10]. M. Riaz, A. Fulati, G. Amin, N. H. Alvi, O. Nur, M. Willander, Journal of Applied Physics. 2009, 106, 034309.

[11]. M. H. Asif, S. M. U. Ali, O. Nur, M. Willander, C. Brännmark, P. Strålfors, U. H. Englund, F. Elinder, B. Danielsson, Biosensors and Bioelectronics, 2010, 25, 2205.

[12]. M. Hussain, Z. H. Ibupoto, M. A. Abbasi, X. Liu, O. Nur, M. Willander, Sensors, 2014, 14, 5415.

[13]. M. Hussain, Z. H. Ibupoto, M. A. Abbasi, O. Nur, M. Willander, Journal of Electroanalytical Chemistry. 2014, 717-718, 78.

[14]. M. Hussain, M. A. Abbasi, Z. H. Ibupoto, O. Nur, M. Willander , Physica Status Solidi A. 2014, 211(2), 455. 
[15]. Z. H. Ibupoto, K. Khun, J. Lu, M. Willander, Applied Physics Letters. 2013, 102, 103701.

[16]. G. Amin, M. Sandberg, A. Zainelabdin, S. Zaman, O. Nur, M. Willander, Journal of Material Science. 2012, 47, 4726.

[17]. L. Vayssieres, K. Kies, S. E. Lindquist, A. Hagfeldt, Journal of Physical Chemistry B. 2001, 105, 3350.

[18]. L. Vayssieres, Advanced Materials. 2003, 15, 464.

[19]. I. Hussain, N. Bano, S. Hussain, O. Nur and M. Willander, Journal of Material Science. 2011, 46, 7437.

[20]. B. Postels, M. Kreye, H. H. Wehmann, A. Bakin, N. Boukos, A. Travlos, A. Waag, Journal of Superlattice \& Microstructures. 2007, 42, 425.

[21]. N. Bano, S. Zaman, A. Zainelabdin, S. Hussain, I. Hussain, O. Nur, M. Willander, Journal of Applied Physics. 2010, 108, 043103.

[22]. A. Manekkathodi, M.-Y. Lu, C. W. Wang, L.-J. Chen, Advanced Materials. 2010, 22, 4059.

[23]. M. Hussain, M. A. Abbasi, A. Khan, O. Nur, M. Willander, Energy Harvesting and Systems. 2014, doi 10.1515/ehs-2013-0025. 


\section{CHAPTER 4}

\section{Characterization and Processing Techniques}

The characterization of as grown nanostructures for in-depth knowledge regarding their morphology and various properties has been largely based on number of methods and techniques that were developed for this purpose. These include X-rays diffraction (XRD), scanning electron microscope (SEM), transmission electron microscope (TEM), atomic force microscopy (AFM), X-ray photoelectron spectroscopy (XPS), cathodoluminescence (CL) and nanoindentation. These highlighted techniques are just those that were used in the presented work. Following is a brief discussion on each of them regarding their use and obtained information.

\subsection{X-ray diffraction (XRD):}

Typically X-ray is an electromagnetic radiation having a wave length of $1 \AA$ in between ultraviolet and gamma-rays. In material science X-rays diffraction is known as a characterization technique capable of investigating the crystalline structures of the grown nanostructures. This non-destructive analytical technique is quite useful for studying chemical composition, crystal structures and their phases, size, symmetry of the unit cell, lattice constants of nanoparticles and physical properties of grown materials. It is important to point out that more than $90 \%$ solid materials are crystalline in nature [1] and each crystalline has a unique X-ray diffraction pattern that can be used just like 'fingerprint"' in order to identify the material. The interaction of X-ray beam with crystal resulted in a diffraction pattern [2] that identifies the material and corresponding phase. The information obtained from the diffraction pattern includes size of the crystallite, symmetry of the unit cell, stress, strain and growth orientation, etc. The working phenomenon behind the generation of diffraction pattern can be described in this way. When an X-ray beam having wave length $\lambda$ strikes the solid crystal with an angle $\theta$, the resulted scattered radiation can be determined by virtue of Bragg's law (i.e. $n \lambda=2 d \operatorname{Sin} \theta$ ). Where $\mathrm{n}$ is called the diffraction order and d denotes 
the distance in between the diffracting planes. Remember that the set of d-planes is unique for each and every material. It is important to point out that by manipulating different parameters like the geometry of incident rays and the orientation of the detector and crystal, one can obtain all the possible diffraction directions of the lattice [2, 3]. In the presented work a Phillips PW 1729 powder diffractometer equipped with $\mathrm{Cu} \mathrm{K} \alpha$ radiation $(\lambda=1.5418 \AA$ ) having a generator voltage of $40 \mathrm{kV}$ and current of 40 $\mathrm{mA}$ has been used.

\subsection{Scanning electron microscope (SEM):}

Scanning electron microscope (SEM) is one of the most important tools in order to study the overall appearance of the grown nanostructures. It helps us in analyzing different parameters like quality, shape, density, diameter, thickness, length and orientation of the as grown nanostructures. SEM belongs to the family of microscopes, but it uses a beam of electrons in lieu of light in order to make an image. The beam of electrons passes through the electromagnetic lenses and strikes the surface of the sample. The bombardment of electrons does not cause any damage to the samples. The detector collects the secondary/backscattered electrons ejected from the sample and converts them into a signal. Finally this signal is directed towards displaying screen [4]. SEM has the ability to capture the images in the range of visible to few nanometers, while the magnification range is around 20X-30000X along with a spatial resolution of 50-100nm [5-7]. The electron acceleration voltages are normally in the range of 5-20 kV. Further details can be found in ref [8]. In the presented work SEM (model LEO 1550 Gemini microscope) running at $15 \mathrm{kV}$ was used to investigate the morphology of the as grown nanostructures.

\subsection{Transmission electron microscope (TEM):}

Transmission electron microscope (TEM), like SEM, belongs to the family of electron microscopes. In order to get structural information at atomic level TEM is one of the most commonly used techniques. The working principle of TEM is just like optical microscope but with a relatively high energy electron source of around $200 \mathrm{KeV}$. The TEM is also very valuable tool for the material's analysis, as one can get variety of 
information including chemical composition [9], crystal/surface structure information and images up to few angstrom resolutions just by switching the operational mode. In comparison with SEM, TEM is multi-purpose and has much improved magnification and resolution. But unlike SEM, TEM has some disadvantages as well, which must be kept under consideration. Few of them are highlighted here.

1- It is a destructive technique.

2- It is also time consuming (in order to prepare sample).

3- Only provides local information.

4- Relatively difficult to operate.

In the presented work the measurements were conducted by using TEM (model FEI Tecnai G2 TF20 UT) accompanied with field emission gun running at $200 \mathrm{kV}$ with a point resolution of $1.9 \AA$, and also equipped with energy dispersive spectrum (EDS).

\subsection{Atomic force microscope (AFM):}

Atomic force microscope (AFM) is a characterization tool that has been extensively used for imaging, measuring, and manipulating samples at the nanoscale. Some of the notable features of AFM are highlighted here.

1- It is a non-destructive technique.

2- Useful for measuring the surface profile of the material with high resolution three dimensional images.

3- Useful for measuring the force at the nano-newton level [10, 11].

4- No particular sample preparation is needed.

5- Measurements can be performed at room temperature.

6- All kinds of substrates like hard and soft, conductive and isolative can be investigated.

The working of AFM is dependent on silicon made cantilever with a sharp platinum coated tip at one of its ends. When this tip is brought in the vicinity of the surface of the sample, the cantilever is deflected due to the Van der Waals force and the laser is responsible for capturing the magnitude of deflection. It is important to point out that 
the scanning height of the tip is not constant in order to avoid the collision of tip with the surface of the sample. Therefore there exists a feedback mechanism in order to adjust the distance between the tip and the surface of the sample, so the force between the tip and the surface of the sample remain constant. There are two working styles of AFM known as contact mode and tapping mode. In contact mode the tip touches the surface of the sample, while in tapping mode the tip tapes across the surface of the sample. In the presented work the piezoelectric measurements were recorded in contact mode by using a Digital Instruments Multimode AFM (Netherlands) and a custom-made trans-impedance amplifier along with stiff platinum coated probes (NTMDT NSG11/Pt, Russian Federation).

\subsection{Nanoindentation:}

Nanoindentation technique is a modified AFM technique. In this technique the cantilever used in AFM has been replaced with a nanoindentation device known as hysitron triboscope. This nanoindentation device is pushed on the material in order to get information about the hardness and elastic modulus of the material. That is why this technique has been used quite often for the characterization of the mechanical properties of the material [12-15]. In the presented work nanoindentation was performed by using a Triboindenter TI-950 (Hysitron) with a conductive boron-doped diamond Berkovich tip of $\sim 3 \Omega \mathrm{cm}$ resistivity.

\subsection{X-ray photoelectron spectroscopy (XPS):}

X-ray photoelectron spectroscopy (XPS) is a technique used for the investigation of surface composition in order to identify the surface recombination centers. This technique is based on the photo-ionization effect $[16,17]$. As per working principle of the XPS, when the surface of the sample is illuminated by X-ray beam, atom's core electron on the surface of the sample ingests whole X-ray photon energy. As a result if the X-ray photon energy is high enough then the core electron will eject from the atom with specific kinetic energy called as photoelectron. The relation between kinetic energy and photon energy can be expressed as

$$
E_{K}=h v-E_{b}
$$


where $E_{K}$ is the kinetic energy, $E_{b}$ is the binding energy and $h v$ is the X-ray photon energy. In the presented work the XPS measurements were carried out by using a Scienta ${ }^{\circledR}$ ESCA200 in ultra-high vacuum (UHV) having a base pressure of $10^{-10}$ mbar. The measurement chamber was equipped with a monochromatic $\mathrm{Al}(\mathrm{K} \alpha) \mathrm{X}$-ray source for photons (i.e. $h v=1486.6 \mathrm{eV}$ ). The measurements were conducted room temperature with a zero degree photoelectron take-off angle. The obtained binding energies (with an error of $\pm 0.1 \mathrm{eV}$ ) were with reference to the Fermi level.

\subsection{Cathodoluminesence (CL):}

Cathodoluminescence (CL) is a nondestructive technique used to find out the origin of the luminescence from a particular part of the grown nanostructures. CL technique records luminescence on the bombardment of high energy electron through a cathode gun in order to create electron-hole pairs that cause light emission. The resulting luminescence gives textures and compositional variations, which are not possible through light microscopy. CL is also very useful in getting deep insight of impurity induced defects and extended defects. In the presented work the CL measurements were performed by using a MonoCL4 system integrated with a LEO 1550 Gemini SEM and equipped with a fast CCD detection system or a Peltier cooled PMT for spectral acquisition.

\subsection{Oxygen plasma treatment:}

The grown $\mathrm{ZnO}$ NRs were treated with oxygen plasma through reactive ion etching (RIE) system (SAMCO, RIE-10RU). The RIE system was equipped with the parallel plate type plasma reactor chamber. The oxygen plasma was induced for only three minutes by setting the other parameters as RF power of $250 \mathrm{~W}$, RF frequencies of 13.56 MHz, a gas flow of $400 \mathrm{sccm}$ and a pressure of $600 \mathrm{~Pa}$. The main objective of treating $\mathrm{ZnO}$ NRs with the oxygen plasma was to reduce the defects levels in the as grown $\mathrm{ZnO} \mathrm{NRs}$ and to observe its effect on the piezoelectric properties of $\mathrm{ZnO}$ [18]. 


\subsection{References:}

[1]. G. Will, Powder Diffraction, Springer Berlin Heidelberg, 2006.

[2]. Basics of X Ray Diffraction (Chapter 7), Scintag Inc., 1999.

[3]. Christine M. Clark, Barbara L. Dutrow ,Single Crystal X-ray Diffraction, Retrieved from

http://serc.carleton.edu/research_education/geochemsheets/techniques/SXD.html

[4]. W. Zhou, R. Apkarian, Z.L. Wang, D. Joy, Fundamentals of Scanning Electron Microscopy (SEM )Scanning Microscopy for Nanotechnology, Springer New York, 2007.

[5]. Instrument Database: JEOL - JSM-6480LV, (2007), Retrieved April 22, 2010 from http://www.speciation.net/Appl/Techniques/technique.html?id=47

[6]. Scanning Electron Microscopy (SEM), Susan Swapp, University of Wyoming, Retrieved April 222010 from http://serc.carleton.edu/research_education/geochemsheets/techniques/SEM.html

[7]. Regional Sophisticated Instrumentation Centre PU, Chd, Retrieved on May 4, 2010 from http://rsic.puchd.ac.in/em.html

[8]. R. F. Egerton, Physical principle of electron microscopy: an introduction to TEM, SEM and AFM, Springer, 2005.

[9]. Y. Ding, Z. L. Wang, Journal of Physical Chemistry B, 2004, 108, 12280.

[10]. http://en.wikipedia.org/wiki/Atomic_microscopy.

[11]. http://www.chembio.uoguelph.ca/educmat/chm729/afm/introdn.htm.

[12]. M. Riaz, A. Fulati, L. L. Yang, O. Nur, M. Willander, P. Klason, Journal of Applied Physics. 2008, 104, 104306.

[13]. M. Riaz, A. Fulati, G. Amin, N. H. Alvi, O. Nur, M. Willander, Journal of Applied Physics. 2009, 106, 034309.

[14]. M. Riaz, O. Nur, M. Willander, P. Klason, Applied Physics Letters. 2008, 92, 103118.

[15]. M. Riaz, A. Fulati, Q. X. Zhao, O. Nur, M. Willander, P. Klason, Nanotechnology. 2008, 19, 415708.

[16]. D. J. O'connor, B. A. Sexton, R. St. C. Smart (eds), Crystal Research and Technology. 1992, 27, 1078. 
[17]. http://www.chem.qmul.ac.uk/surfaces/scc/scat5 3.htm

[18]. Y. F. Hu, L. Lin, Y. Zhang, Z. L. Wang., Advanced Materials. 2011, 20, 1. 


\section{CHAPTER 5}

\section{Discussion on Results}

The obtained results of the presented work are discussed in this chapter, which is divided in two parts for the better clarification and understanding. The first part is comprised on paper I-IV in which the obtained results are related to piezoelectric properties:

with oxygen plasma treatment,

$>$ and effect on mechanical properties with oxygen plasma treatment

$>$ on different flexible substrates and

$>$ with $\mathrm{ZnO}$ nanorods grown AFM tip.

The second part is comprised on paper V and VI and the obtained results in these papers are related to

Anion effect on the morphology of $\mathrm{Co}_{3} \mathrm{O}_{4}$ and its sensing application.

Synthesis of $\mathrm{NiCo}_{2} \mathrm{O}_{4}$ nanostructures on nickel foam and fabrication of an efficient glucose sensor.

\subsection{The improved piezoelectric properties of $\mathrm{ZnO}$ nanorods with oxygen plasma} treatment on the single layer graphene coated polymer substrate.

In this work, we have developed an efficient flexible nanogenerator (NG) by coupling the $\mathrm{ZnO}$ nanorods (NRs) with the single layer graphene coated polymer substrate. The single layer graphene coated polymer substrate offered an excellent platform for the fabrication of flexible and transparent devices with enhanced performance. ZnO NRs were grown on the single layer graphene substrate by aqueous chemical growth method (ACG) and resulting flexible NG possessed attractive features including excellent mechanical elasticity, optical transparency, and simple fabrication methodology. 


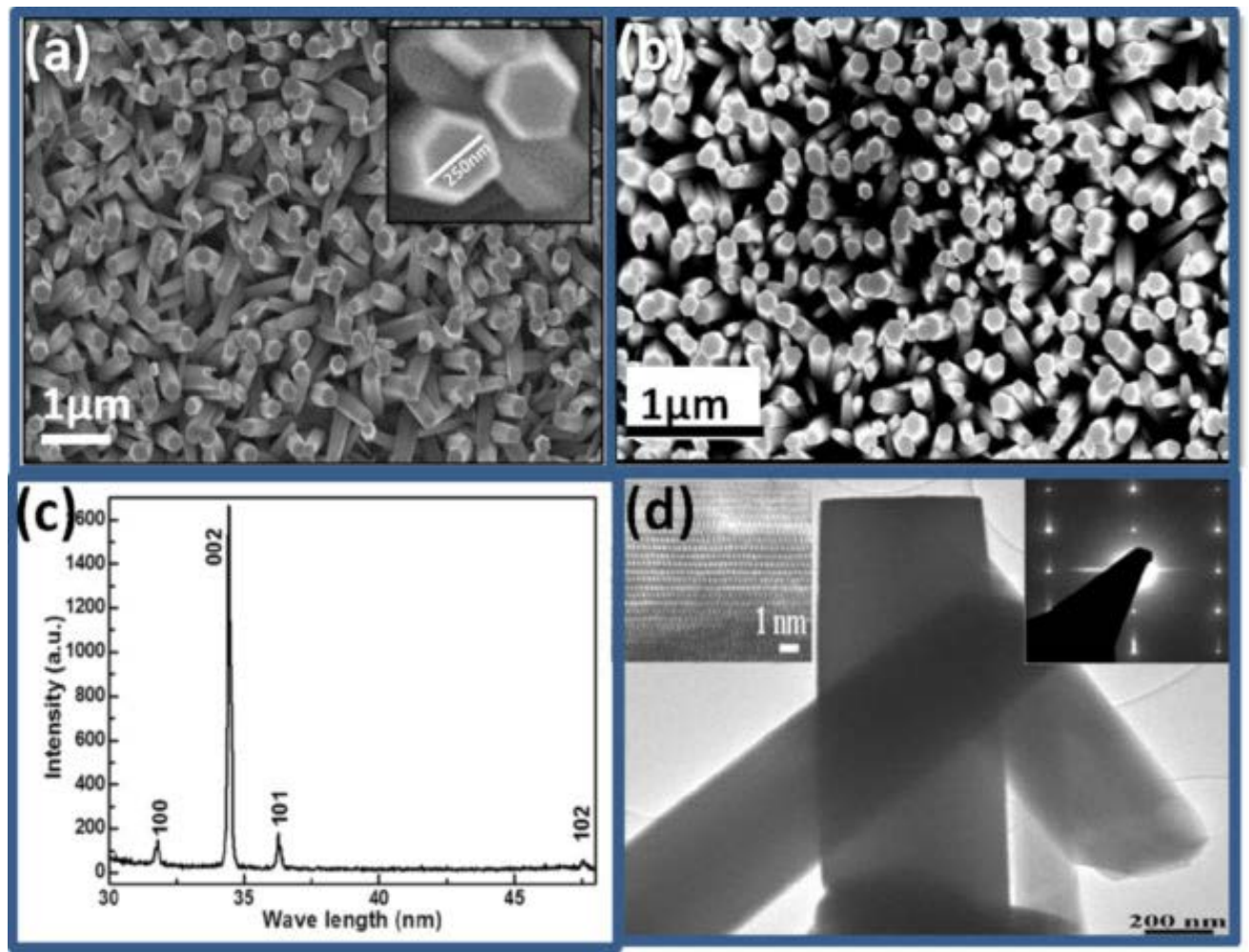

Figure 5.1 (a) SEM image of the as-grown ZnO NRs along with inset showing the diameter of the NRs. (b) SEM image of plasma treated ZnO NRs. (c) Typical XRD spectra of ZnO NRs. (d) TEM image of the single ZnO NRs along with inset of SAED.

Figure 5.1 (a) is showing the SEM image of ZnO NRs grown on the single layer graphene on PET substrate. It is clear that ZnO NRs are well aligned, uniform, highly dense and perpendicular to the substrate. The average diameter of NRs is around 250$300 \mathrm{~nm}$ as shown in inset of Fig. 5.1 (a). SEM image in Fig. 5.1 (b) is confirming that the oxygen plasma treatment did not damage the ZnO NRs. Figure 5.1 (c) is the typical XRD pattern of the ZnO NRs. The relatively high intense (002) peak in the XRD pattern is confirming the c-axis oriented growth of $\mathrm{ZnO}$ NRs. All peaks appeared in the XRD spectra are consistent with the standard JCPDS card No. 36-1451 and revealing the hexagonal wurtzite phase of $\mathrm{ZnO}$ NRs. Figure 5.1 (d) is revealing the TEM and SAED images of ZnO NRs. The preferred orientation of the ZnO NRs is along (0001) direction and ZnO NRs exhibited a single crystalline array. The TEM study is verifying the results obtained from SEM and XRD study. 

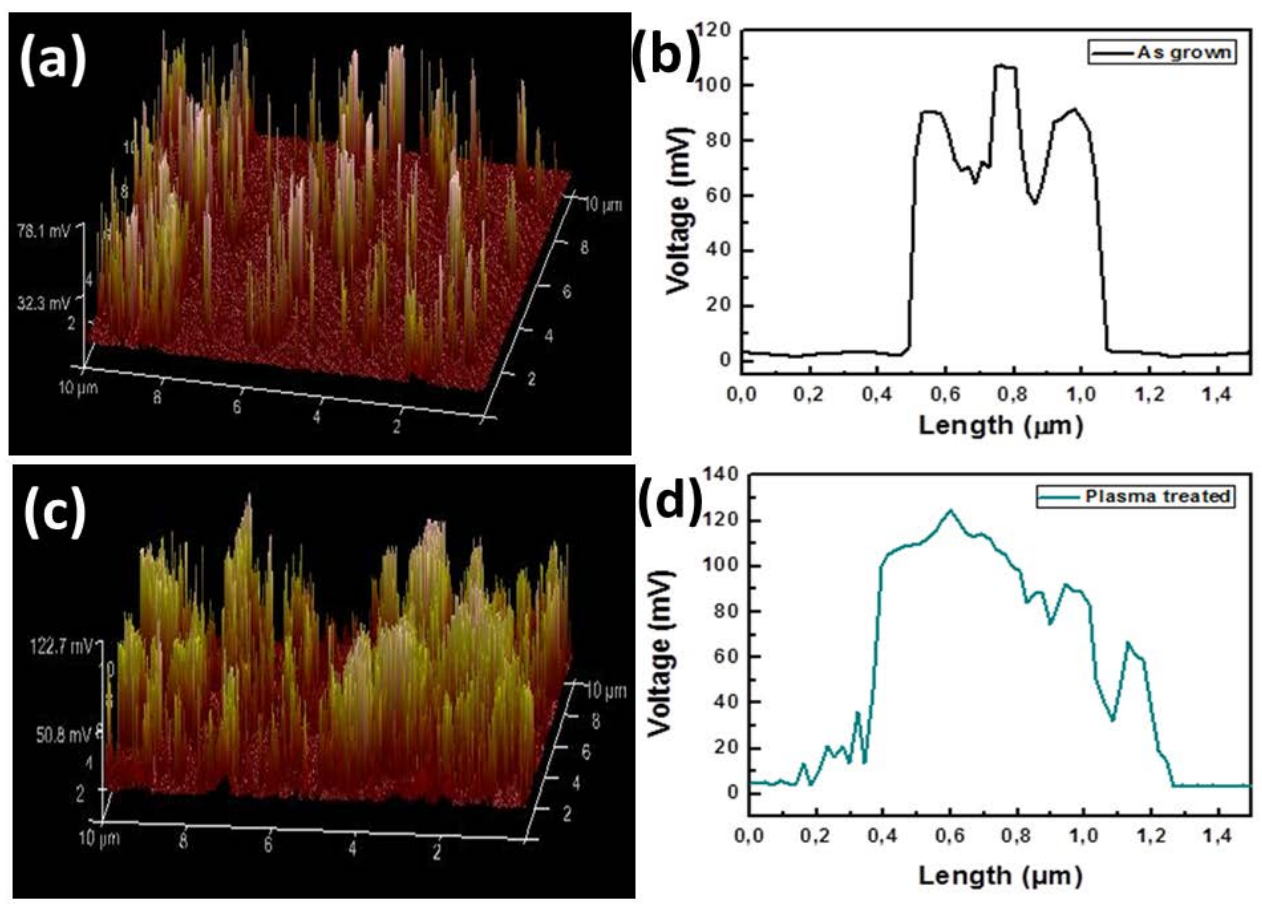

Figure 5.2 Piezoelectric power generation from as-grown ZnO NRs (a) 3D plot of the output voltage. (b) Typical AFM tip scanning the surface of $\mathrm{ZnO}$ NRs in micrometers. Piezoelectric power generation from plasma treated $\mathrm{ZnO}$ NRs. (c) 3D plot of the output voltage. (d) Typical AFM tip scanning the surface of ZnO NRs in micrometers.

Figure 5.2 (a) is showing the 3-dimensional current image of the as grown ZnO NRs. When the AFM tip in contact mode scanned the ZnO NRs, the NRs were bent consecutively and an average output potential of $80-100 \mathrm{mV}$ was recorded as soon as the bending of NRs achieved its maximum. When the AFM tip released the ZnO NRs then no output potential was found, this suggests that the piezoelectric potential was only realized at the end of the scanning of NRs surface as shown in Fig. 5.2 (b). In order to reduce the defect levels in the grown ZnO NRs and to observe the effect of oxygen plasma treatment on the piezoelectric properties of ZnO NRs [1], ZnO NRs were treated with the $\mathrm{O}_{2}$ plasma through reactive ion etching (RIE) system. The oxygen plasma was induced for three minutes using an applied RF power of $250 \mathrm{~W}$, RF frequency of $13.56 \mathrm{MHz}$, a gas flow of $400 \mathrm{sccm}$ and a pressure of $600 \mathrm{~Pa}$. Figure 5.2 (c) is showing the piezoelectric potential as $122.7 \mathrm{mV}$ after the oxygen plasma 
treatment of as grown $\mathrm{ZnO}$ NRs and it clear that the piezoelectric current increased significantly after the oxygen plasma treatment. This increase can be attributed to the decrease in the defects level in the $\mathrm{ZnO}$ NRs due to the oxygen plasma treatment. Because induced oxygen ions and radicals diffused into the $\mathrm{ZnO}$ NRs and occupied the oxygen vacancies, which decreased the free carrier concentration in the $\mathrm{ZnO}$, resulted in an improved piezoelectric potential. Moreover, the induction of oxygen plasma also contributed in the possible filling of vacancies that results an improvement in the elastic property of $\mathrm{ZnO}$ NRs. Figure 5.2 (d) is showing the tip scan profile of the oxygen plasma treated $\mathrm{ZnO}$ NRs.

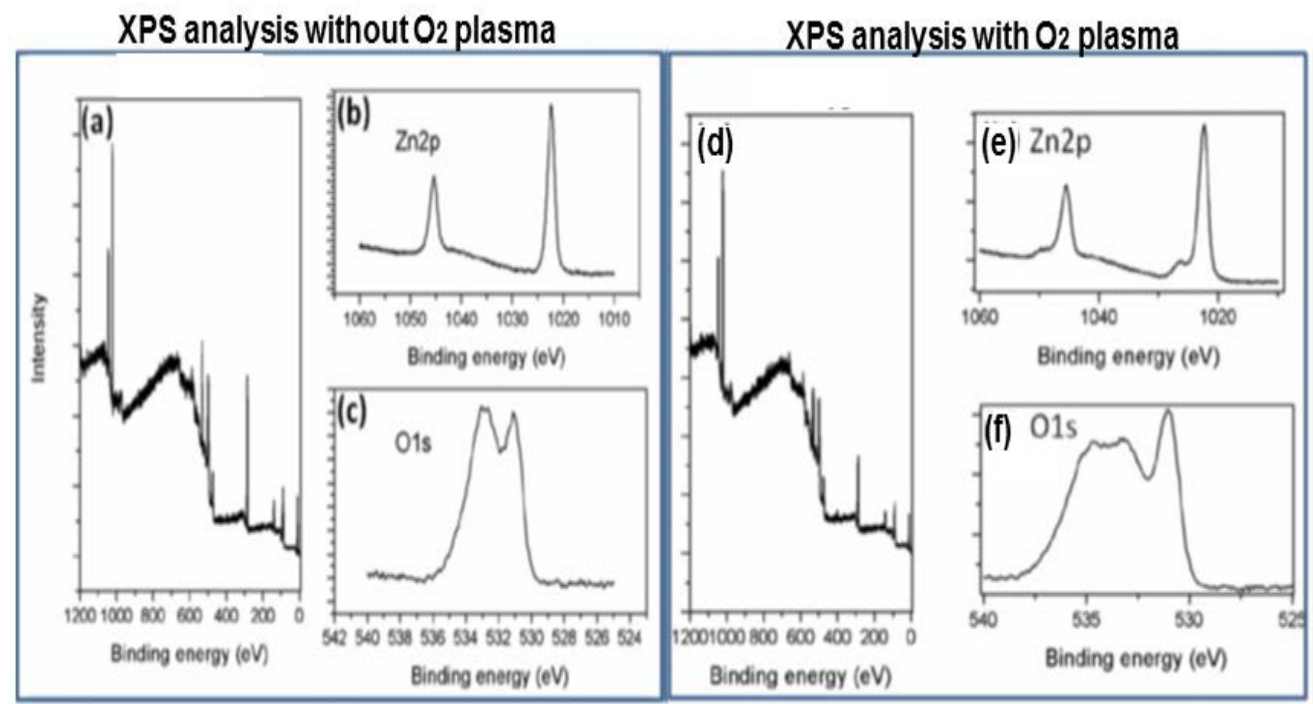

Figure 5.3 XPS analysis of ZnO NRs without and with oxygen plasma treatment.

In order to confirm the enhancement of piezoelectric potential of $\mathrm{ZnO}$ NRs due to the effect of oxygen plasma treatment, the X-ray photoelectron spectroscopy (XPS) was carried out. Figure 5.3 (a) is the XPS scan of as grown ZnO NRs showing that it only contains zinc, oxygen and very little carbon (because carbon is used as reference). Figure 5.3 (b) is the core level XPS spectra of $\mathrm{Zn}\left(2 \mathrm{p}^{3 / 2}\right)$, the peak at $1921.4 \mathrm{eV}$ can be assigned to the formation of hexagonal $\mathrm{ZnO}$ NRs [2]. Figure 5.3 (c) describes the asymmetry in the $\mathrm{O} 1 \mathrm{~s}$, showing the presence of single oxygen specie on the surface and the peak around $530.2 \pm 0.1 \mathrm{eV}$ is because of the $\mathrm{Zn}-\mathrm{O}$ bonding $[3,4]$. Figure 5.3 (d) is showing the XPS analysis of oxygen plasma treated sample, almost identical as 
Fig 5.3 (a). We observed similar result for $\mathrm{Zn} 2 \mathrm{p}^{3 / 2}$ as was in Fig 5.3 (b), but a different result was observed for $\mathrm{O}$ 1s. As shown in Fig. 5.3 (f) the peak around $532 \mathrm{eV}$ is vanished due to the filling of oxygen vacancies and a tiny shoulder around $532.0 \pm 0.1$ $\mathrm{eV}$ is appeared because of the loosely bound oxygen on the surface [5]. This filling of vacancies by oxygen enhanced the polarization of charges during the applied force and therefore better deflection was observed, which caused improved piezoelectric response for oxygen plasma treated sample. Moreover, during the oxygen plasma treatment the relative intensity of the $\mathrm{O}-\mathrm{Zn}$ peak to the $\mathrm{O}-\mathrm{OH}$ was enhanced resulted the successive removal of hydroxide layer.

Figure 5.4 is the room temperature CL spectra of $\mathrm{ZnO}$ NRs without and with plasma treatment at the accelerating voltage of $10 \mathrm{kV}$. It showed that the defect level in the plasma treated sample is decreased, which suggests the filling of interstitial vacancies either by $\mathrm{O}_{2}$ molecules or by $\mathrm{O}$ radicals during the plasma treatment $[6,7]$. This study has not only backs the XPS study, but also confirmed that the decrease in the defect levels increases the piezoelectric potential.

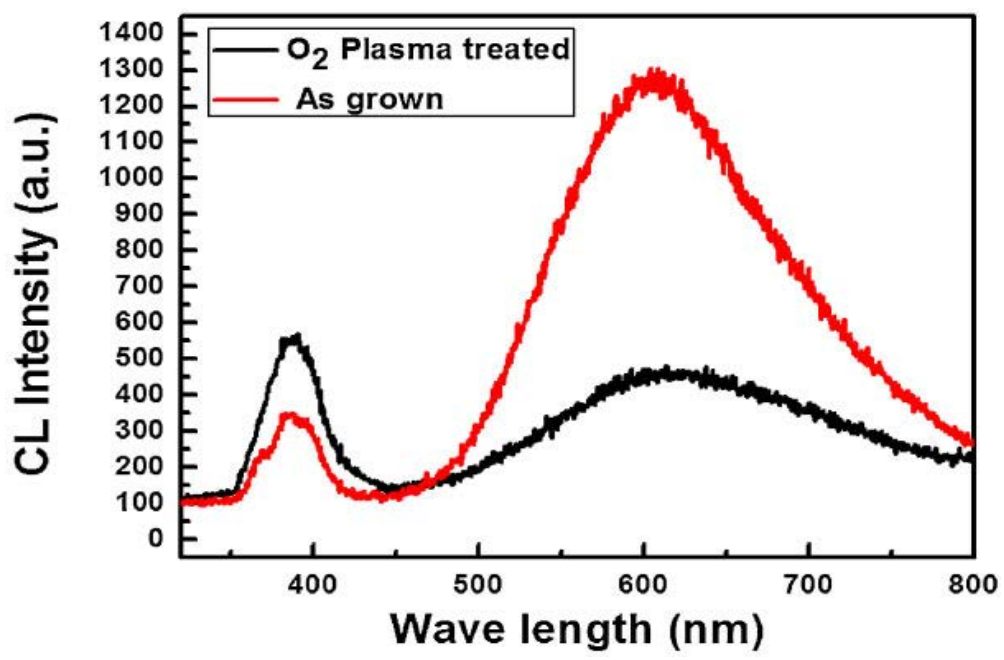

Figure 5.4 CL spectra of as-grown $\mathrm{ZnO}$ NRs and $\mathrm{ZnO}$ NRs with oxygen plasma treatment. 


\subsection{The effect of oxygen-plasma treatment on the mechanical and piezoelectrical} properties of $\mathrm{ZnO}$ nanorods.

The two most common defects in $\mathrm{ZnO}$ are known as oxygen and zinc vacancies. Since oxygen vacancy has less formation energy than the zinc interstitial, therefore dominates in those growth conditions that are zinc rich. This study demonstrates that by utilizing the oxygen-plasma treatment, it is possible to enhance the harvested amount of piezoelectricity in order to fabricate reliable, efficient and low cost nanodevices with improved performance. In the present study the effect of oxygen plasma treatment on piezoelectric response and on mechanical stability of $\mathrm{ZnO}$ nanorods (NRs) has been investigated by using nanoindentation technique in a force controlled mode in order to obtain more precise information about the effect of the plasma treatment.
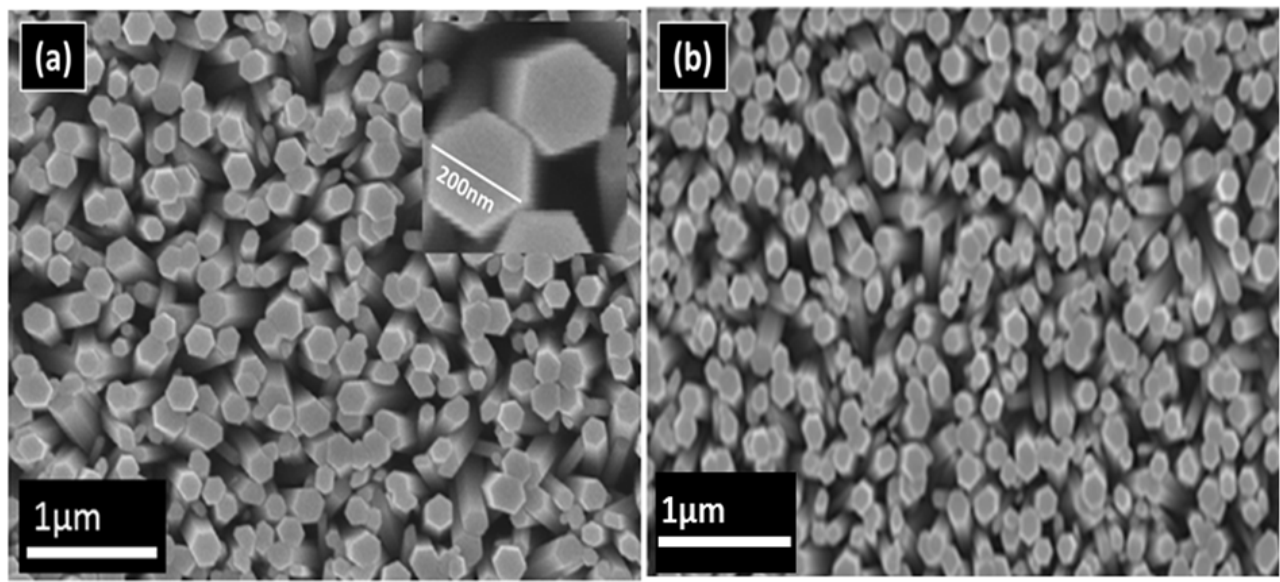

Figure 5.5 SEM images of ZnO NRs grown on FTO glass substrate. (a) Without oxygen plasma treatment. (b) With oxygen plasma treatment.

Figure 5.5 is showing the SEM images of as-grown and $\mathrm{O}_{2}$ plasma treated $\mathrm{ZnO} \mathrm{NRs}$ on FTO glass substrate. It can be seen in Fig. 5.5 (a) that as grown ZnO NRs are dense, well aligned, uniformly distributed over the surface and perpendicularly oriented in caxis direction. The inset of Fig. 5.5 (a) is showing that NRs have length of $\sim 1 \mu \mathrm{m}$ and diameter of $\sim 200 \mathrm{~nm}$. Oxygen plasma treated ZnO NRs have been shown in Fig. 5.5 (b) and it is clear that oxygen plasma treatment did not disturb the density, alignment and uniformity of the NRs. 
The crystallinity of as-grown and oxygen plasma treated ZnO NRs was investigated by XRD technique. Figure 5.6 (a) and (b) showed that the only difference is in the intensity of (002) peak, which is probably due to the oxygen plasma treatment. The (002) peak at $34.4^{\circ}$ is demonstrating the c-axis orientation of the NRs, while other present peaks are just the reflections for ZnO. All the diffraction peaks could be assigned to crystalline $\mathrm{ZnO}$ as per JCPDS card no. (36-1451). This study confirmed the presence of pure phase of $\mathrm{ZnO}$ and no other impurities were found at all.
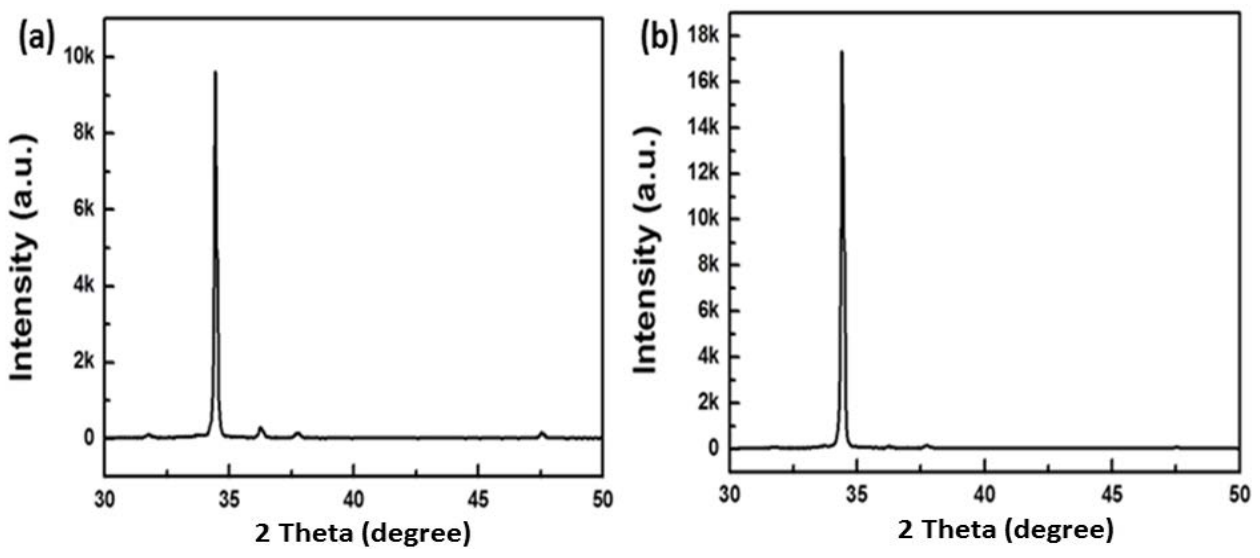

Figure 5.6 XRD spectra of ZnO NRs grown on FTO glass substrate. (a) Without oxygen plasma treatment. (b) With oxygen plasma treatment.

Piezoelectric measurements were conducted by using nanoindentation technique. Figure 5.7 is showing the generated piezo-voltage against different applied forces. We observed that between 15 and $450 \mu \mathrm{N}$ load, oxygen plasma treated sample has generated higher voltage than as-grown one. Especially between 30 and $200 \mu \mathrm{N}$ load the oxygen plasma treated sample showed more generated voltage. The increase in the piezoelectric potential can be attributed to the reduced defects level of the ZnO NRs after oxygen plasma treatment. The oxygen plasma generated oxygen ions and radicals, which diffused into the $\mathrm{ZnO}$ NRs and occupied the oxygen vacancies. The oxygen plasma treatment also decreased the free carrier concentration in the $\mathrm{ZnO} \mathrm{NRs}$, which increased the piezoelectric potential. In addition to this, the oxygen plasma filled the vacancies resulting in an improvement in the piezoelectric properties of $\mathrm{ZnO}$ NRs by providing excess polarization of charges during the applied force. 


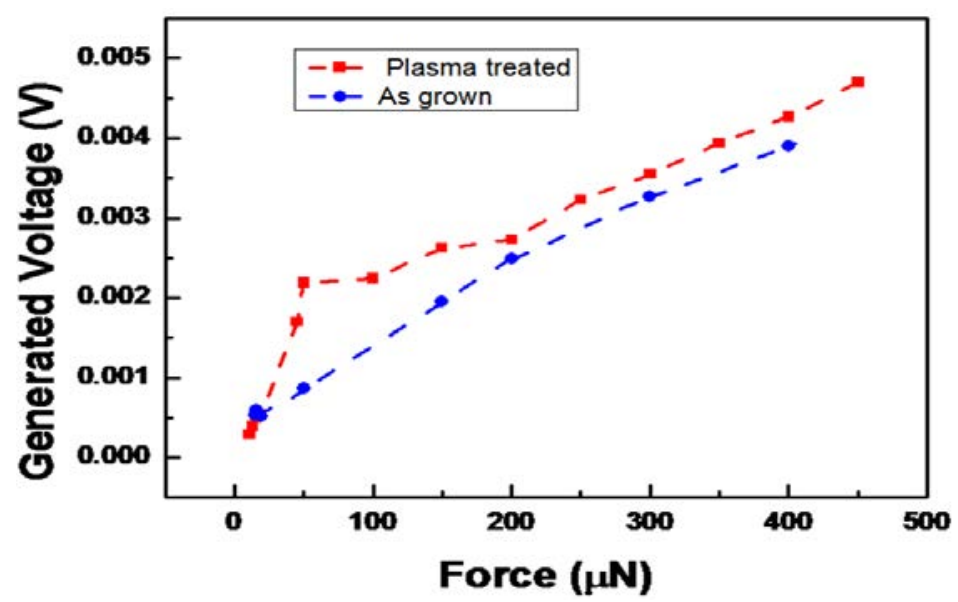

Figure 5.7 Generated piezo-voltage without and with oxygen plasma treatment as a function of maximum applied load. The dotted lines are just for guiding the eyes.
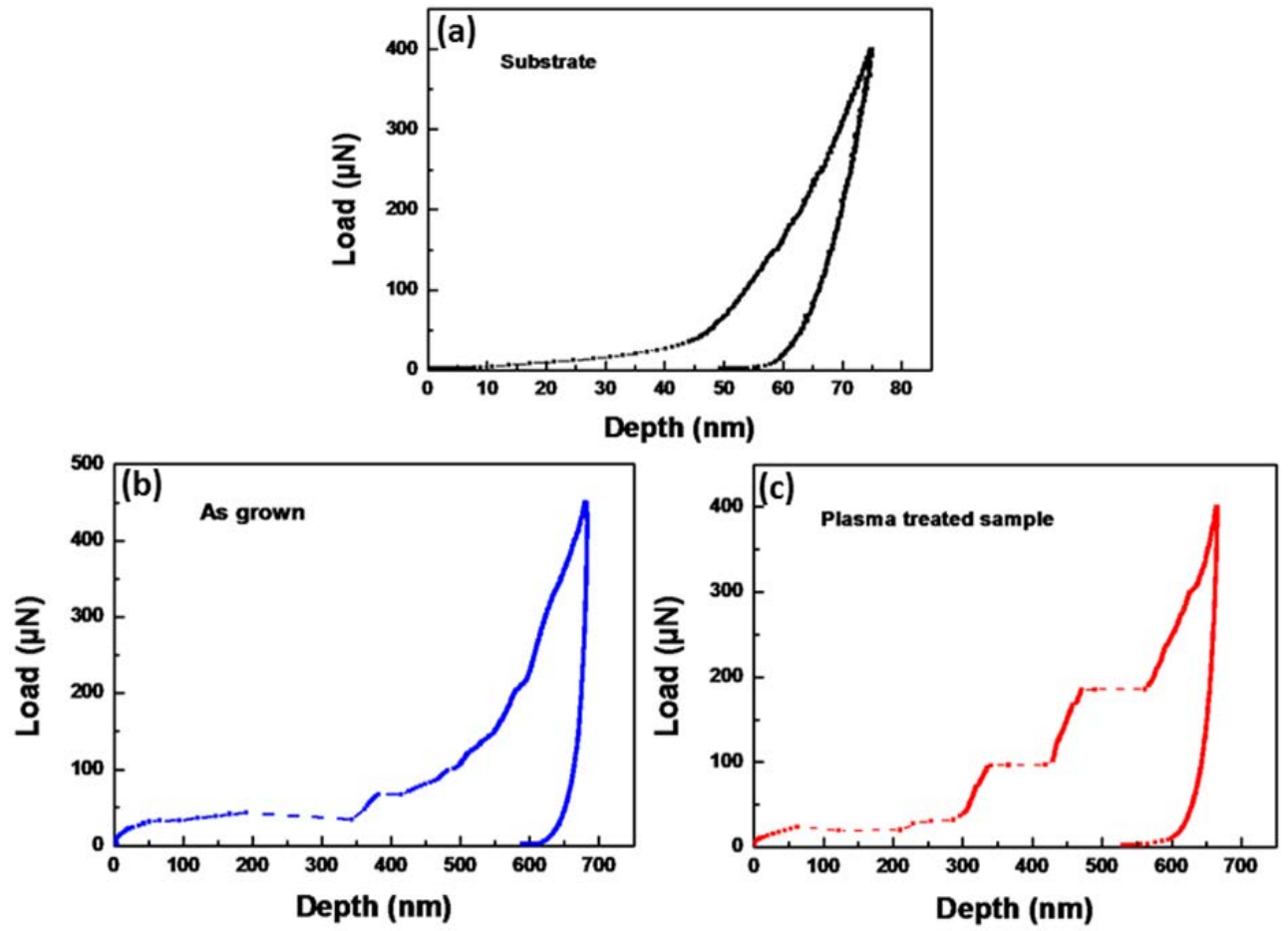

Figure 5.8 Load-displacement curves recorded by using nanoindentation technique. The used probe was a boron-doped diamond Berkovich tip and the measurements were performed in the load-control mode. (a) Bare FTO glass substrate. (b) NR without oxygen plasma treatment. (c) NR with oxygen plasma treatment. 
Moreover, the reduction of defects also leads to the better elastic property/improved bending of $\mathrm{ZnO}$ NRs.

Figure 5.8 is demonstrating the curves of load-displacement recorded by using the nanoindentation technique in a force controlled mode at room temperature. Figure 5.8 (a) is showing the load displacement curve for bare FTO glass substrate, when a maximum load of $400 \mu \mathrm{N}$ was applied, a tip penetration of $\sim 75 \mathrm{~nm}$ was observed. Figure 5.8 (b) is for the as grown $\mathrm{ZnO}$ NRs and in this case the tip penetration was about $\sim 650 \mathrm{~nm}$. Figure 5.8 (c) revealed that after a penetration of $300 \mathrm{~nm}$ tip needs to apply more force in order to bent/buckle the oxygen plasma treated NR. The comparative study of Fig. 5.8 (b) and (c) showed that $\mathrm{O}_{2}$ plasma treated NRs are much stiffer than as grown ones [21-23]. 


\subsection{Comparative study of energy harvesting from $\mathrm{ZnO}$ nanorods using different}

\section{flexible substrates.}

In past two decades piezoelectric properties of $\mathrm{ZnO}$ have been studied extensively, but mostly on the hard substrates such as GaN, glass, sapphire, ITO or Si [8-12]. It is important to point out that by using hard substrates it is not easy to enhance the piezoelectric energy [13]. Therefore, as an alternative one can use conventional/nonconventional flexible substrates like textile fabric, common paper and flexible plastic [14-16] for the improvement in the amount of harvested energy. However, it is mandatory that these substrates have conductive adhesive layer before growth. Moreover, paper and textile also needed an insulating layer in order to reduce the surface roughness. In this study, textile fabric, common paper, flexible plastic and aluminum foil have been used as substrates keeping identical conditions for growth and measurement of piezoelectricity to see the effect of substrate on the amount of output voltage. Moreover the use of aluminum foil not only eliminates the necessity of insulating/conductive layer, but it is also flexible and low cost and can be formed into large-area substrates.

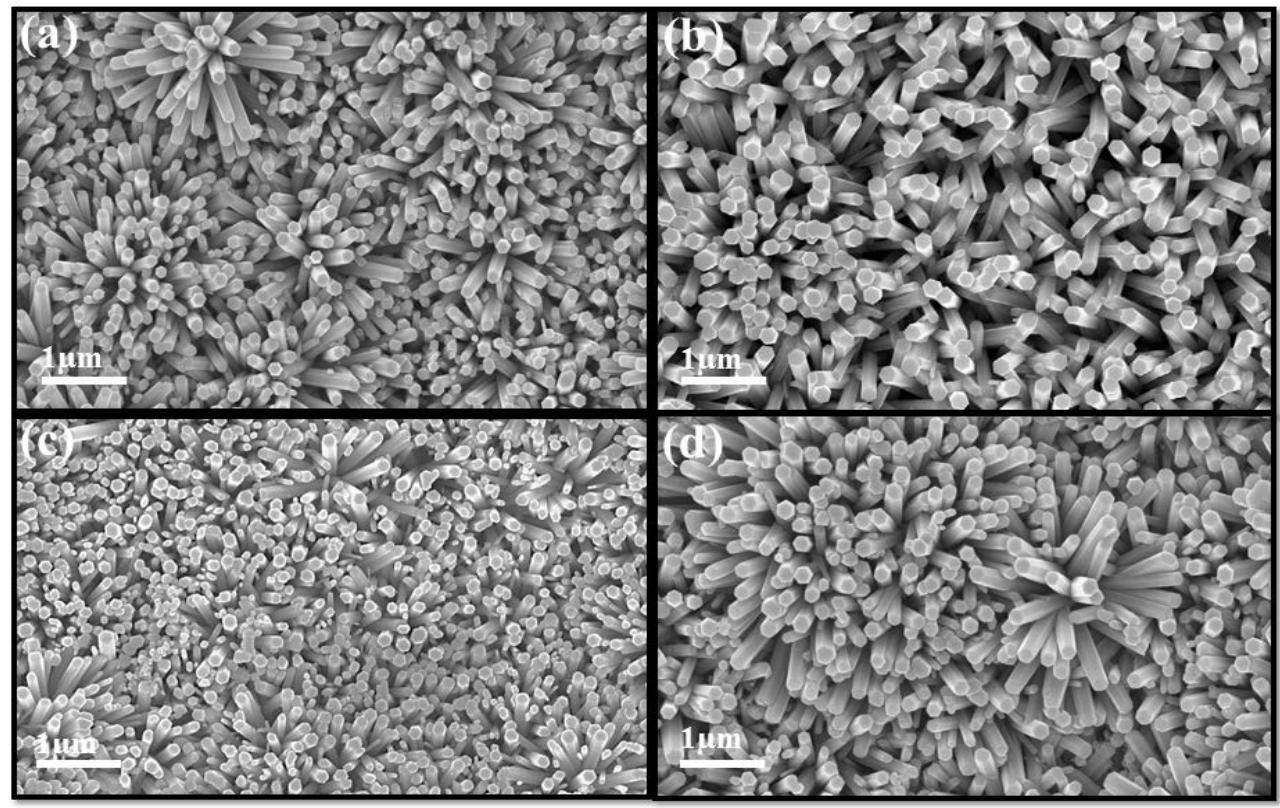

Figure 5.9 SEM images of ZnO NRs grown on (a) Common paper (b) plastic (c) textile fabric (d) aluminum foil. 
Figure 5.9 (a-d) is showing the SEM images of ZnO NRs grown on common paper, flexible plastic, textile fabric and aluminum foil, respectively. It is clear in all figures that NRs have not only hexagonal faces, but also well aligned, uniform, highly dense and perpendicular to the substrates as well. As shown in Fig. 5.9 (a-d) the average lengths of NRs are around $\sim 1-1.2 \mu \mathrm{m}, \sim 2 \mu \mathrm{m}, \sim 1.5 \mu \mathrm{m}, \sim 2-2.4 \mu \mathrm{m}$, while the average diameters of NRs are around 100-120nm, 160-170 nm, 100-110 nm, 170-180 nm, for common paper, flexible plastic, textile fabric and aluminum foil respectively. It has been reported that not the substrate but the crystal quality, length, diameter and density of NRs are the main parameters for the performance of the nanogenerators [17]. In this study, aspect ratio and density of NRs have been the main parameters that affected the recorded output signals, which is also in accordance with published report [8].
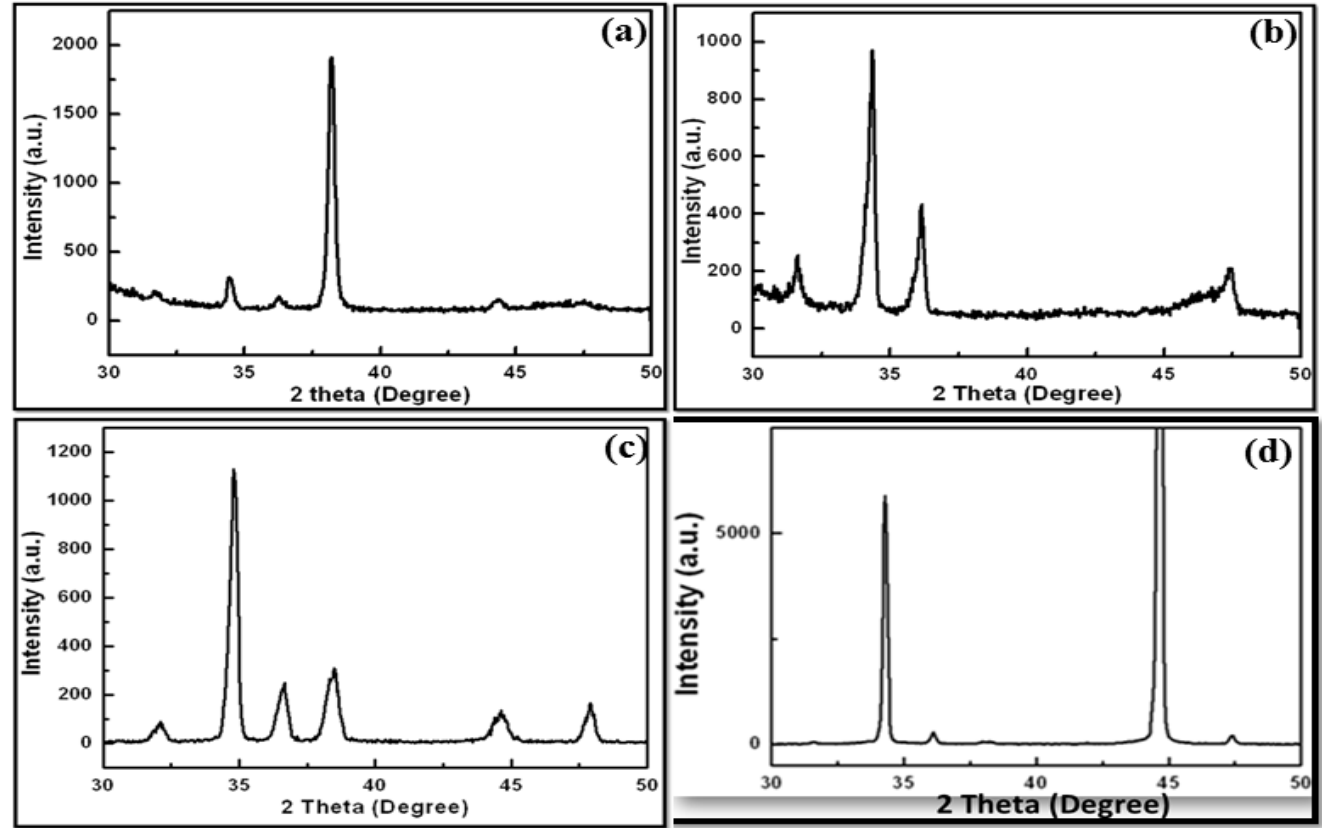

Figure 5.10 XRD spectra of ZnO NRs grown on (a) Common paper (b) Plastic (c) Textile fabric and (d) Aluminum foil substrates.

Figure 5.10 is showing the XRD spectra's of the ZnO NRs grown on common paper, flexible plastic; textile fabric and aluminum foil substrates. All the appeared peaks indexing the hexagonal wurtzite phase of $\mathrm{ZnO}$ NRs and are in agreement with the standard JCPDS card no. 36-1451. The most notable thing in Fig. 5.10 (a-d) is the 
variation in the intensity of the (002) peak with respect to the substrate. In Figure 5.10 (a), the more intense peak belongs to silver and the intensity of (002) peak is relatively less compared to other substrates. While the XRD pattern in Fig. 5.10 (b-d) revealing that the intensity of the (002) peaks is much higher compared to other peaks that strongly suggest the c-axis oriented growth of ZnO NRs [18]. In Fig. 5.10 (d) the highly intense (002) peak is clearly suggesting that aluminum foil is more suitable for the growth of $\mathrm{ZnO} \mathrm{NRs}$ and the highest peak also belongs to aluminum foil.

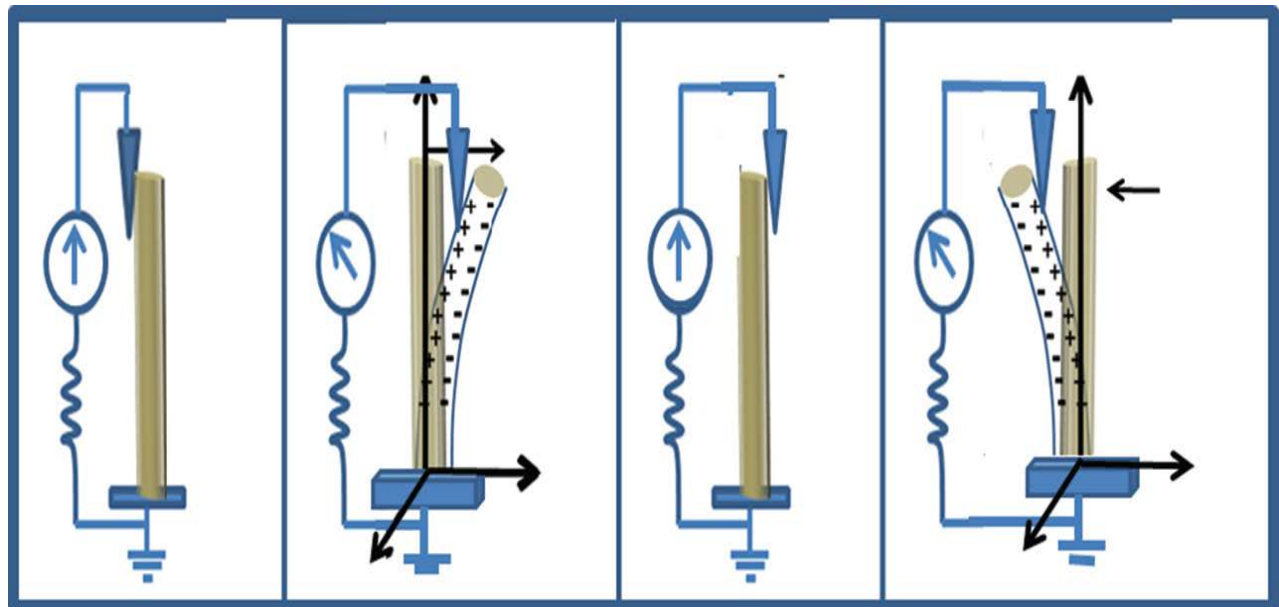

Figure 5.11 Schematic diagrams showing the mechanism of the electrical pulse generation by $\mathrm{ZnO}$ NRs.

In Fig. 5.11 the schematic diagram is revealing the step wise generation process of electrical pulse in ZnO NR. Figure 5.11 (a) is showing the start of the AFM scan process. Figure 5.11 (b) is describing the deflection process, which created positive and negative potential along the stretched and compressed sides of the NR. When the AFM tip touched the compressed side of the NR the presence of the Schottky barrier guides the current to flow in the direction along which the Schottky barrier is at forward bias. Since thousands of NRs are generating electricity at the same time, the Schottky barrier will add all of them and forces them to flow in the same direction [19]. When the NR was released by the AFM tip, it regained its original shape and position as shown in Fig. 5.11 (c). Finally, Fig. 5.11 (d) is describing the re-track of the AFM scan in which the polarization is taking place in identical fashion as was in Fig. 5.11 (b). 


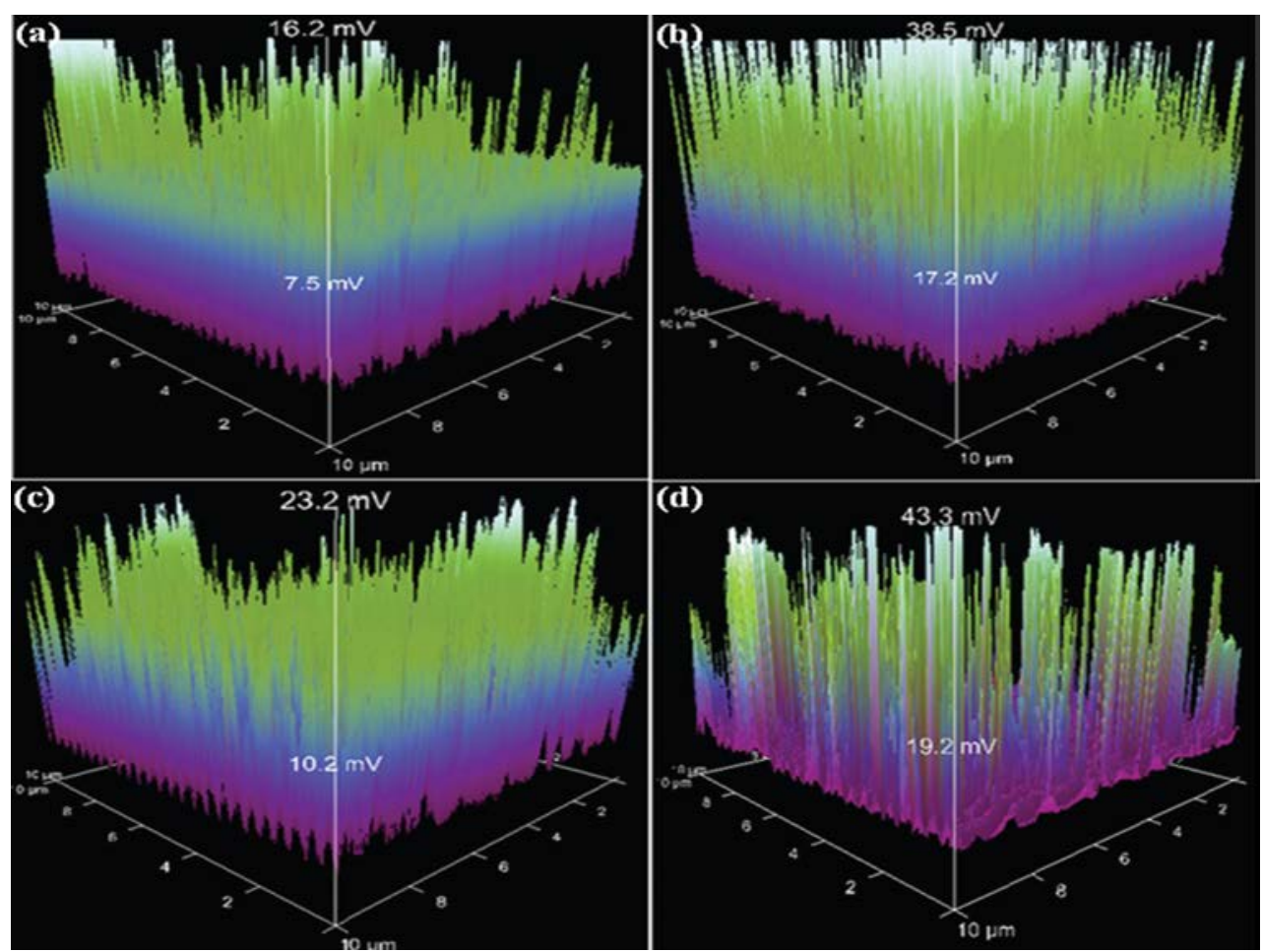

Figure 5.12 Three-dimensional plot of the output voltage from $\mathrm{ZnO}$ NRs grown on (a) common paper (b) plastic (c) textile fabric and (d) aluminum foil

Figure $5.12(\mathrm{a}-\mathrm{d})$ is showing the three-dimensional voltage output images, recorded when ZnO NRs were scanned by an AFM tip over an area of $10 \mu \mathrm{m}^{2}$. We observed many sharp output peaks typically about 5-25 times higher than the noise level. The values obtained for common paper, flexible plastic, textile fabric and aluminum foil substrates are $16.2 \mathrm{mV}, 23.2 \mathrm{mV}, 38.5 \mathrm{mV}$ and $43.3 \mathrm{mV}$, respectively, as shown in Figure $5.12(\mathrm{a}-\mathrm{d})$.

Figure $5.13(\mathrm{a}-\mathrm{d})$ is showing the typical Schottky behavior for common paper, flexible plastic, textile fabric and aluminum foil substrates, respectively. Schottky behavior is mandatory between ZnO NR and AFM tip in order to produce electric power output. In general, the Schottky barrier not only add up all the generated current but also acts like a "gate" that blocks the back flow of electrons and preserves the piezoelectric potential. On the other side the ZnO NR works as a "capacitor” that not only stores the electrons but also moves them back and forth through the external circuit in accordance with the stretch and release of the $\mathrm{ZnO} \mathrm{NR}$. 

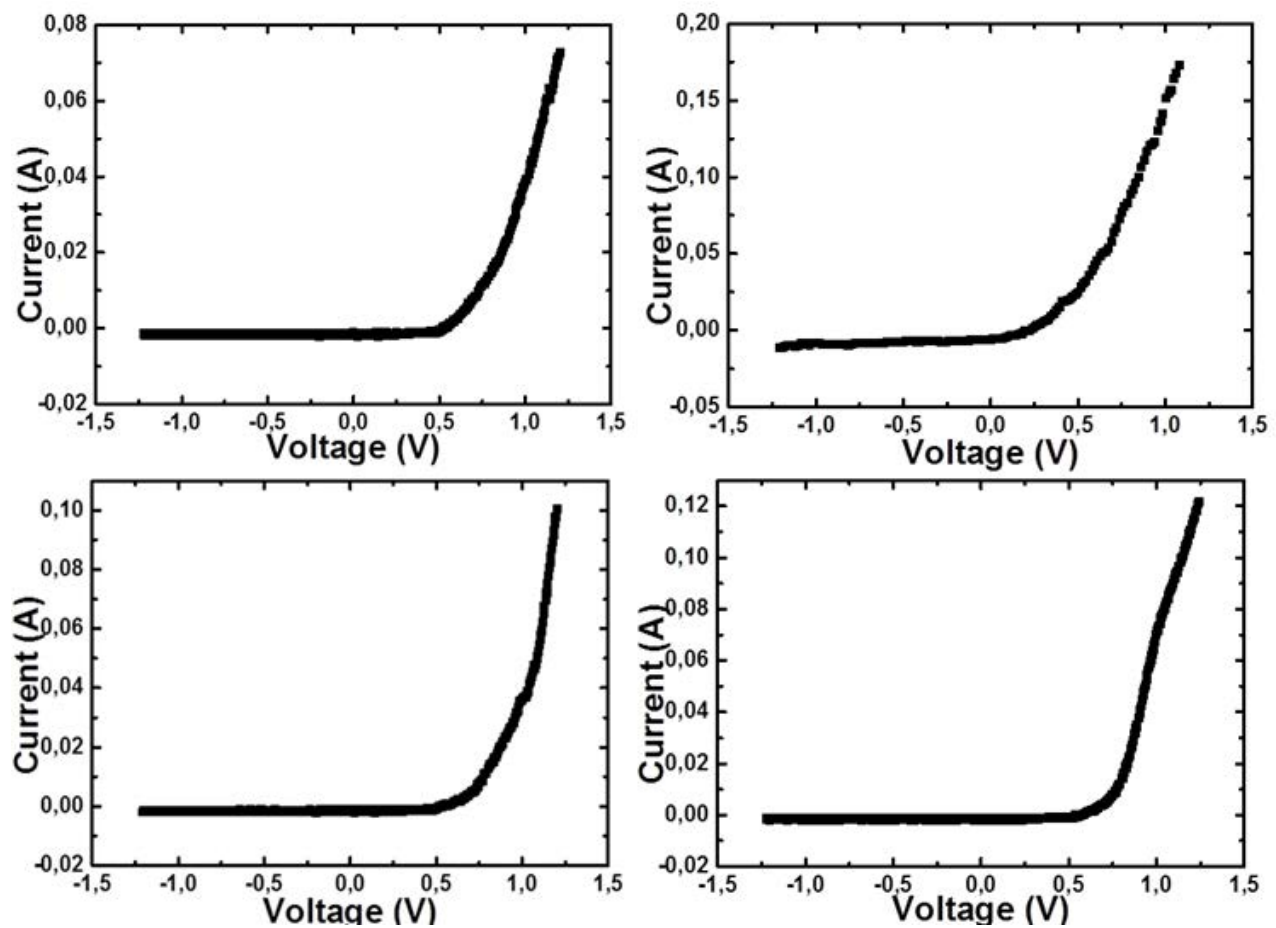

Figure 5.13 I-V characteristics for (a) common paper (b) plastic (c) textile fabric (d) aluminum foil

Table 2 is showing the comparison between the presented work and the already published reports on common paper, textile fabric and flexible plastic to highlight the effect of substrate on piezoelectric properties, without changing the growth and measurement conditions.

\begin{tabular}{lcccc}
\hline & Paper & Plastic & Textile & Al. Foil \\
\hline Presented work & $1-7 \mathrm{mV} \mathrm{[20]}$ & $45 \mathrm{mV}$ for single NW & $9.5 \mathrm{mV} \mathrm{[} \mathrm{14]}$ & - \\
& $2-10 \mathrm{mV} \mathrm{[15]}$ & Average $20-25 \mathrm{mV} \mathrm{[16]}$ & - & - \\
Reported work & $16.2 \mathrm{mV}$ & $38.5 \mathrm{mV}$ & $23.2 \mathrm{mV}$ & $43.3 \mathrm{mV}$
\end{tabular}

Table 2 Showing the comparison between the reported and presented work. 
5.4 Use of ZnO nanorods grown AFM tip in the architecture of piezoelectric nanogenerator.

Due to increasing demand/shortage of energy, it is highly desirable to explore/improve different resources of energy in order to fill the gap between demand and supply of energy. In this context many techniques/methods have been tried/invented in last few years. In this study ZnO NRs grown AFM tip in lieu of normal AFM tip has been used in order to get enhanced piezoelectric output. The ZnO NRs were synthesized on the AFM tip and on the FTO glass substrate, so they can work together as two oppositely gliding walls (composed of $\mathrm{ZnO} \mathrm{NRs}$ ) at the time of scan measurement of the sample.

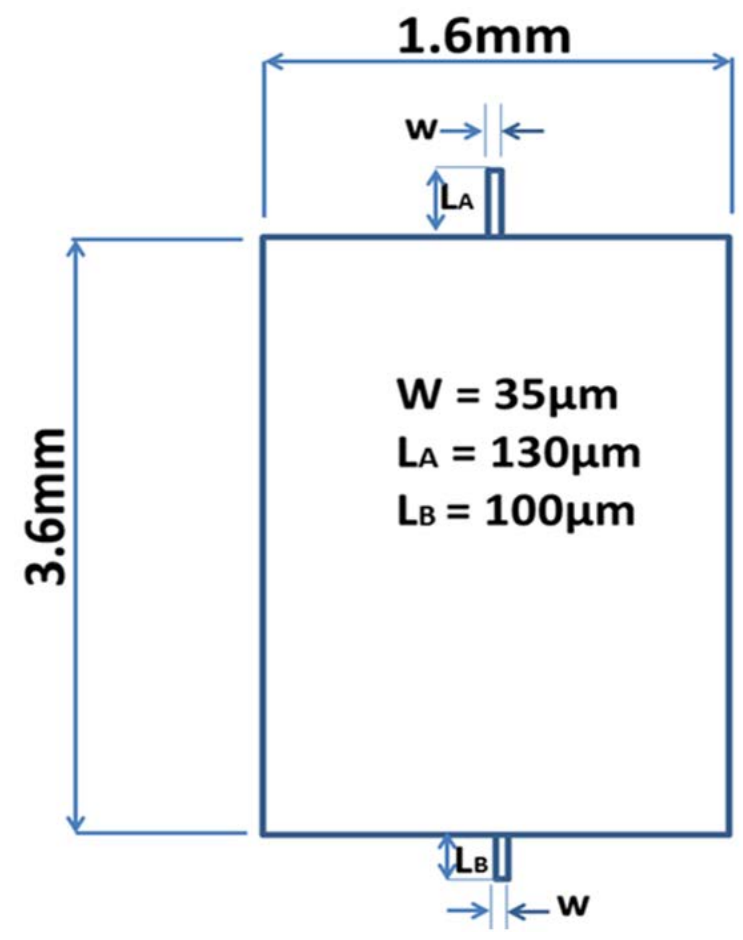

Figure 5.14 Schematic diagram showing the dimensions of the cantilever.

Figure 5.14 is showing the schematic diagram of the cantilevers for clear understanding of dimensions. As seen in the figure 5.14 a pair of cantilevers on opposite sides of the probe is used (with and without ZnO NRs) for the measurements. We named them as Pt/ZnO tip and bare (without ZnO NRs) Pt tip, respectively in order to avoid confusion in the later discussion. 

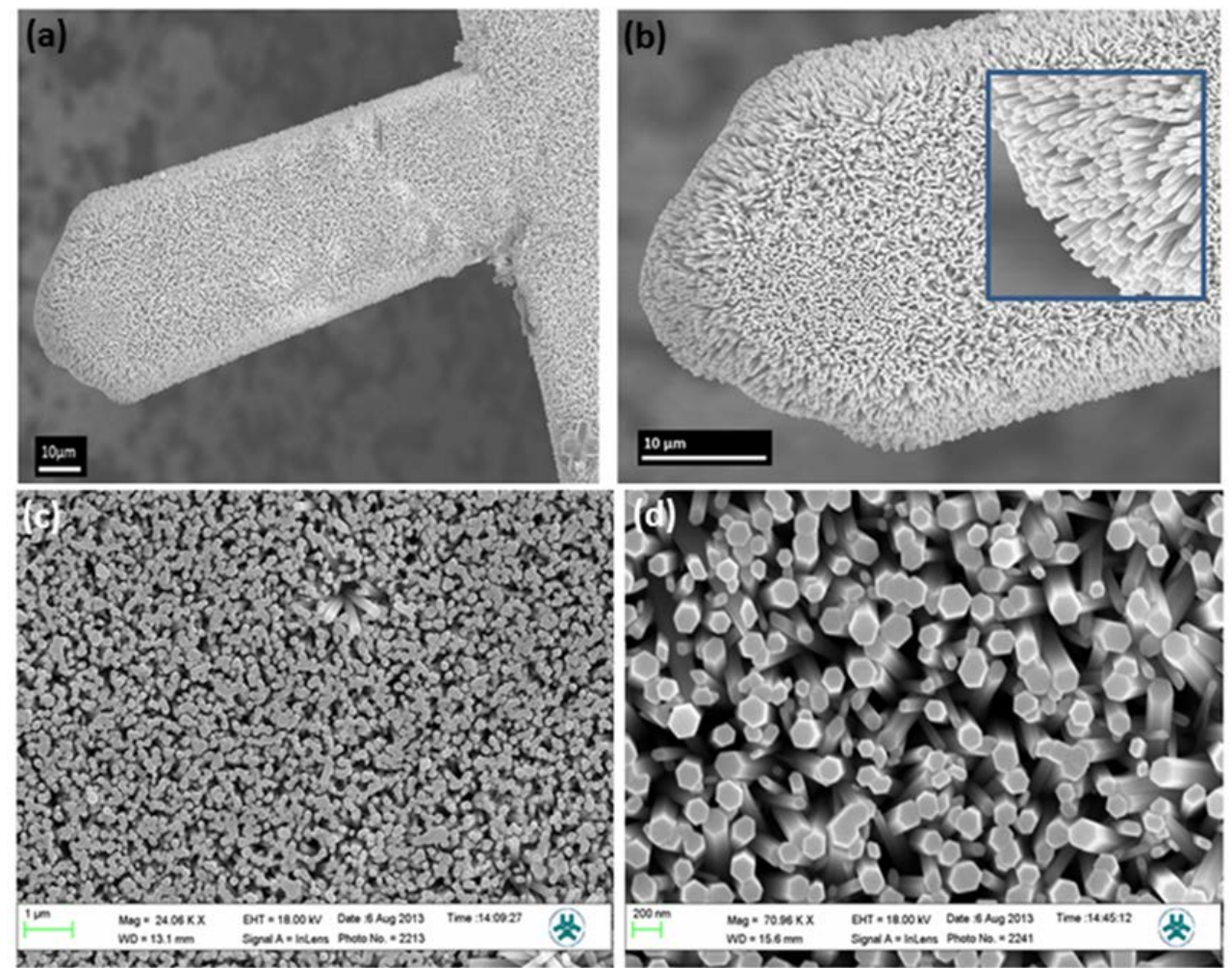

Figure 5.15 The SEM images of ZnO NRs grown on the AFM tip and on the FTO glass

substrate. (a) Low resolution image of the AFM tip (b) High resolution image of the AFM tip (c)Low resolution image of the FTO glass substrate (d) High resolution image of the FTO glass substrate.

Figure 5.15 is revealing the SEM images of ZnO NRs grown on AFM tip and on the substrate. Figure 5.15 (a) is a low magnification and Fig. 5.15 (b) is relatively much higher resolution SEM image of ZnO NRs grown AFM tip. The figures showed that AFM tip is fully covered with highly dense and well aligned ZnO NRs. The inset of Fig. 5.15 (b) is showing that all the NRs have hexagonal faces and the average length and diameter of these NRs is around 1-1.5 $\mathrm{mm}$ and $80 \mathrm{~nm}$ respectively. Figure 5.15 (c) and (d) are low and high magnification SEM images of ZnO NRs grown on FTO glass substrate. It is clear from both figures that NRs are highly dense and uniformly distributed all over the substrate. In addition to this all NRs have hexagonal faces, perpendicular to the substrate with a length of $\sim 1-1.2 \mu \mathrm{m}$ and a diameter of $\sim 150-$ $200 \mathrm{~nm}$. 


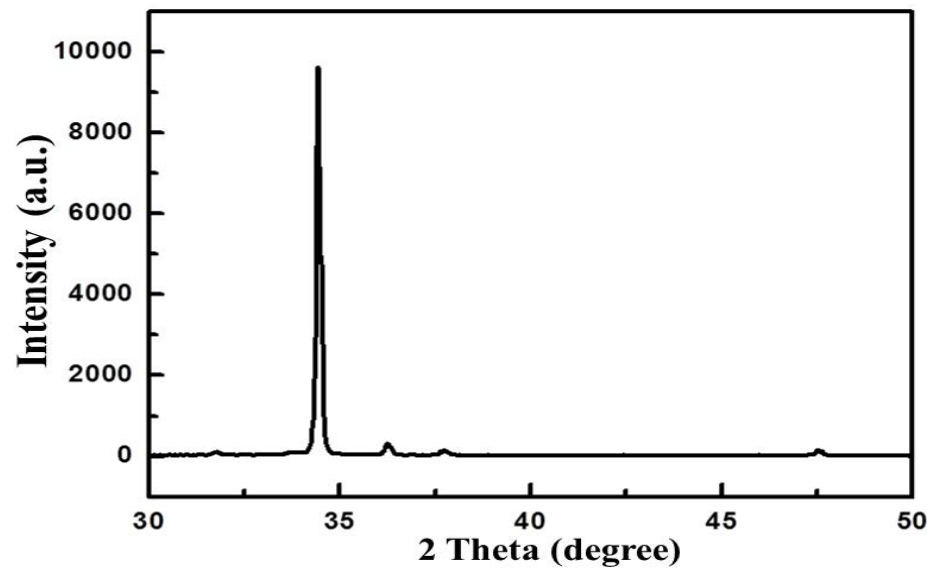

Figure 5.16 XRD spectra of ZnO nanorods grown on FTO glass substrate.

Figure 5.16 is showing the XRD spectra of ZnO NRs on FTO glass substrate. The highest (002) peak at $34.4^{\circ}$ demonstrating the wurtzite hexagonal phase of c-axis oriented $\mathrm{ZnO}$ NRs. The relatively much lower peaks are just the reflections for $\mathrm{ZnO}$. All the peaks appeared in the spectra are pointing out the presence of $\mathrm{ZnO}$ as per JCPDS card no. 36-1451.
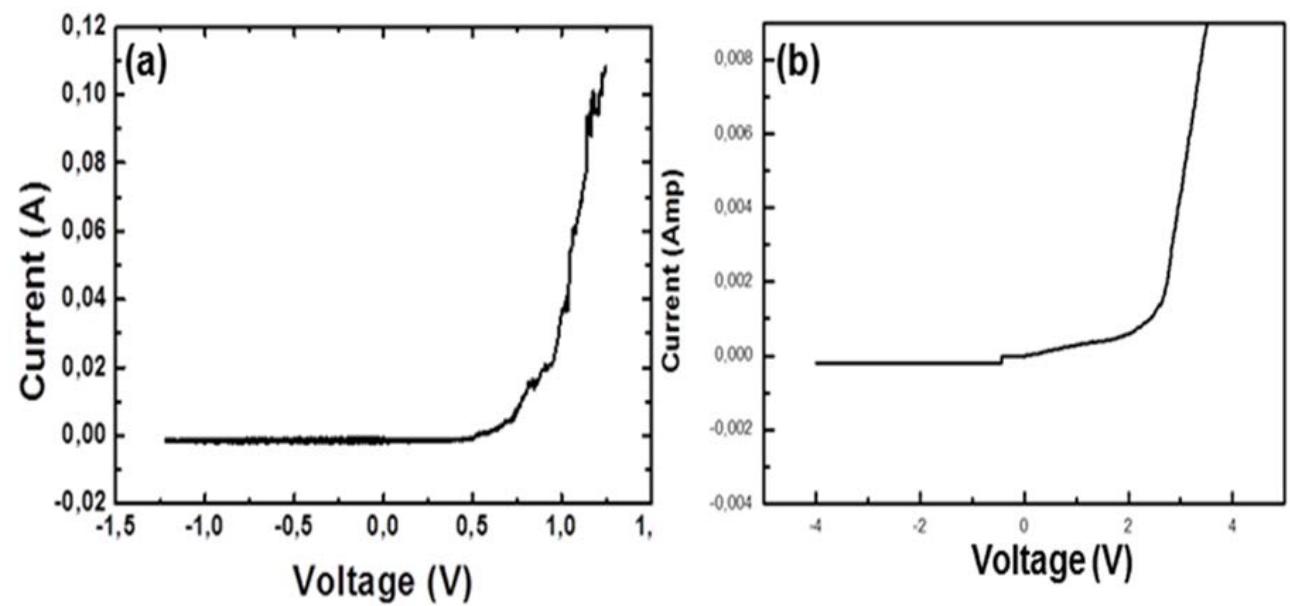

Figure 5.17 Current-voltage (I-V) characteristics between ZnO NRs on FTO glass substrate and (a) Bare (without ZnO NRs) AFM tip (b) AFM tip with ZnO NRs.

Typical current-voltage (I-V) measurements were performed with bare Pt tip and with $\mathrm{Pt} / \mathrm{ZnO}$ tip in order to establish the presence of Schottky contact between the tip and ZnO. The results showed typical Schottky type behavior as shown in Fig. 5.17. 
Figure 5.18 (a) is showing 3D image of the output voltage generated by scanning an area of $10 \mu \mathrm{m}^{2}$ with a bare Pt tip. The average output voltage was recorded as 28.1 $\mathrm{mV}$. It is important to understand that, the potential was only observed at the time of maximum bending of the NRs instead of just the bending of NRs. When the NRs were not in contact with AFM tip, there was no potential. This indicates that the output potential was recorded just at the end of AFM scan as shown in Fig. 5.18 (c). The NRs were deflected consecutively during the scanning process and the topography image in Fig. 5.18 (e) is showing the recorded bending distance. In order to see the effect of NRs grown tip in comparison with bare (without NRs) Pt tip, we repeat the measurements without any change in the parameters of the AFM setup. We only changed the bare Pt tip with Pt/ZnO tip. Figure 5.18 (b) is showing 3D output voltage image of the same area of the sample, as was for Fig. 5.18 (a). The only difference was the use of NRs grown tip instead of bare tip. Now we noticed more pronounced potential pulses. On average these were around 220 to $280 \mathrm{mV}$. One should keep in mind that the generated current is the sum of all those NRs took part in the output power. But the voltage is based on a single NR, because all the NRs are "in parallel"'. By using the $\mathrm{Pt} / \mathrm{ZnO}$ tip $223.4 \mathrm{mV}$ piezoelectric output response was generated. This increase in the output response showed that the $\mathrm{Pt} / \mathrm{ZnO}$ tip is responsible for this enhancement of output response. Because the increased amount of output voltage is due to the NRs that contributed in the generation of electricity. In principle it is feasible to apply in two possible ways. One way is to use all those $\mathrm{ZnO}$ NRs that are uniform in size and length and the second way is to synthesize ZnO NRs on the AFM tip as shown in Fig. 5.14.

In this work, we utilized the later technique that showed an increase in the output voltage, which rose with a simultaneous gain in the output current, directly related to the NRs that contributed in the output. Normally an area of $10 \mu \mathrm{m}^{2}$ has thousands of $\mathrm{ZnO} \mathrm{NRs}$ and capable of generating piezoelectricity in $\mathrm{mV}$. In our case thousands of NRs on Pt/ZnO tip and on FTO glass substrate contributed in the generation of output current randomly. Figure 5.18 (d) and (f) are revealing the tip scan and topography profiles with $\mathrm{Pt} / \mathrm{ZnO}$ tip with the same interpretation as was for bare Pt tip. 

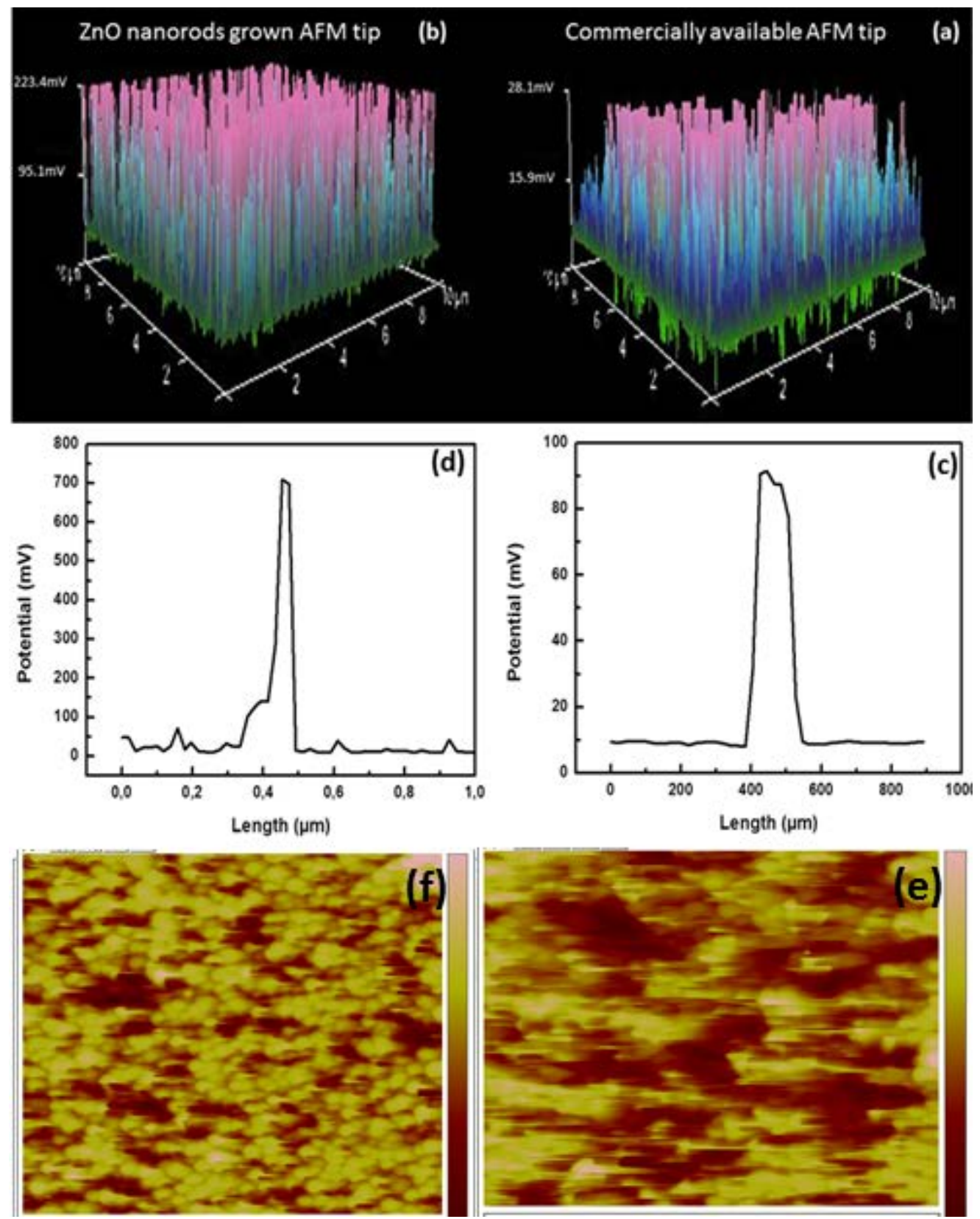

Figure 5.18 (a) Three-dimensional plot of the output voltage from $\mathrm{ZnO}$ NRs using AFM tip with ZnO NRs (b) Three-dimensional plot of the output voltage from $\mathrm{ZnO} N R s$ using AFM tip without ZnO NRs. (c) Tip scan using AFM tip with ZnO NRs. (d) Tip scan using AFM tip without ZnO NRs. (e) Topography image using AFM tip with ZnO NRs (f) Topography image using AFM tip without ZnO NRs. 


\subsection{Effect of anions on the morphology of $\mathrm{Co}_{3} \mathrm{O}_{4}$ nanostructures grown by} hydrothermal method and their $\mathrm{pH}$ sensing application.

It is always interesting to know the effect of different anions of similar source of precursor on the morphology of metal oxides nanostructures. In this work, we observed the effect of anions on the morphology of cobalt oxide nanostructures grown on the p-type silicon substrate by using low temperature aqueous chemical growth method. Beside this, one of the grown cobalt oxide nanostructure was utilized in the development of highly sensitive $\mathrm{pH}$ sensor device as well.

Figure $5.19(\mathrm{a}-\mathrm{d})$ is showing the typical SEM images of $\mathrm{Co}_{3} \mathrm{O}_{4}$ nanostructures with different anions. Fig. 5.19 (a) is revealing the nanoporous morphology obtained from the precursor of cobalt nitrate and urea. The nitrate anion has effectively changed the morphology of $\mathrm{Co}_{3} \mathrm{O}_{4}$ into honey comb like porous nanostructures. For chloride anion

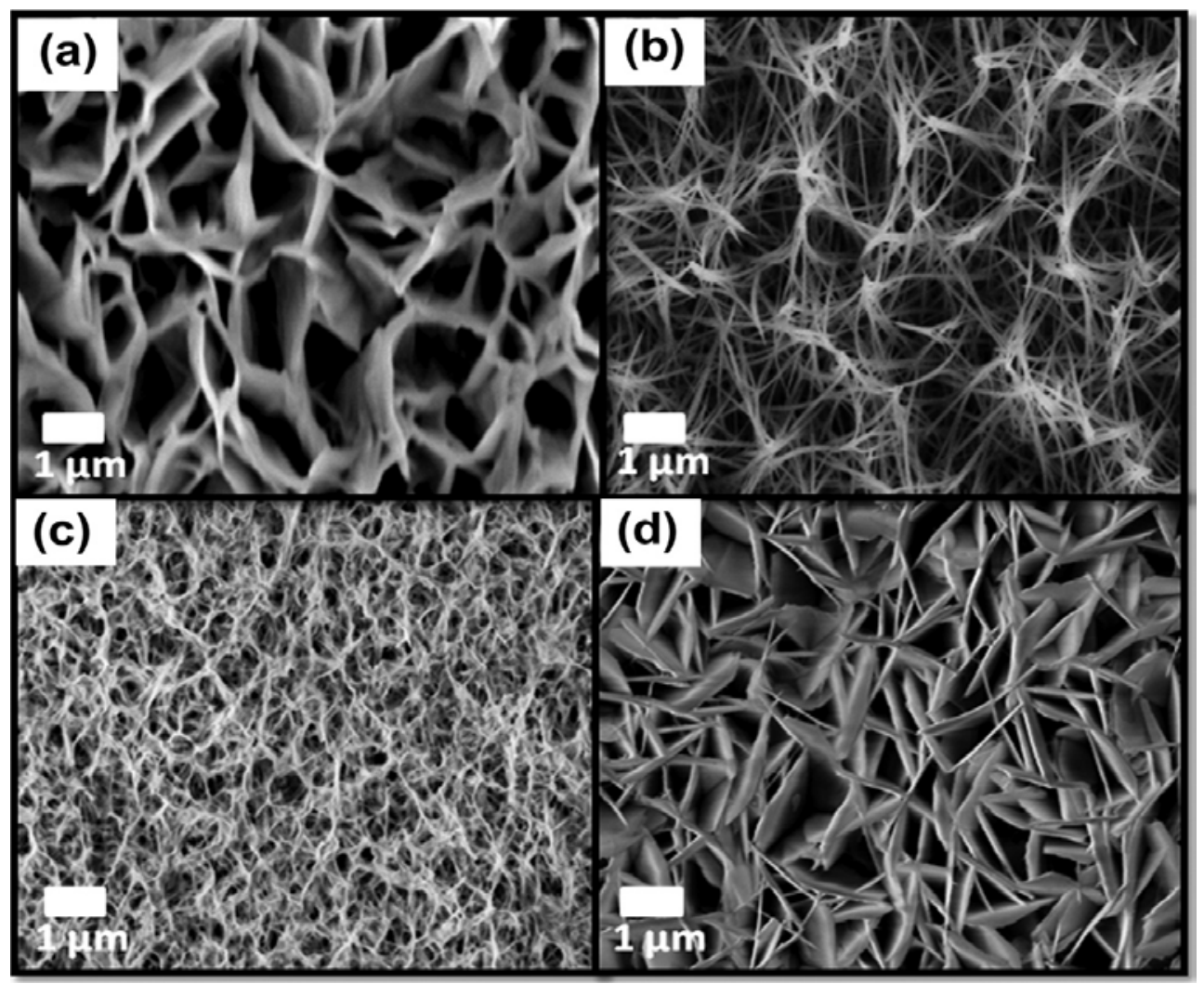

Figure. 5.19 SEM images of different $\mathrm{Co}_{3} \mathrm{O}_{4}$ nanostructures grown in precursors of (a) cobalt nitrate, (b) cobalt chloride, (c) cobalt acetate and (d) cobalt sulfate. 
effect on the morphology of $\mathrm{Co}_{3} \mathrm{O}_{4}$ nanostructures, cobalt chloride and urea were used and we obtained nanostructures of interconnected network of nanowires as shown in Fig. 5.19 (b). In order to obtain acetate anion effect on the morphology of $\mathrm{Co}_{3} \mathrm{O}_{4}$ nanostructures cobalt acetate and urea were used. In response a grass like morphology based on thin wires has been achieved as shown in Fig. 5.19 (c). Finally cobalt sulfate and urea were used and we observed that sulfate anion is suppressing the growth pattern along the 101 plane, thus $\mathrm{Co}_{3} \mathrm{O}_{4}$ nanosheets like morphology is obtained as shown in Fig. 5.19 (d).
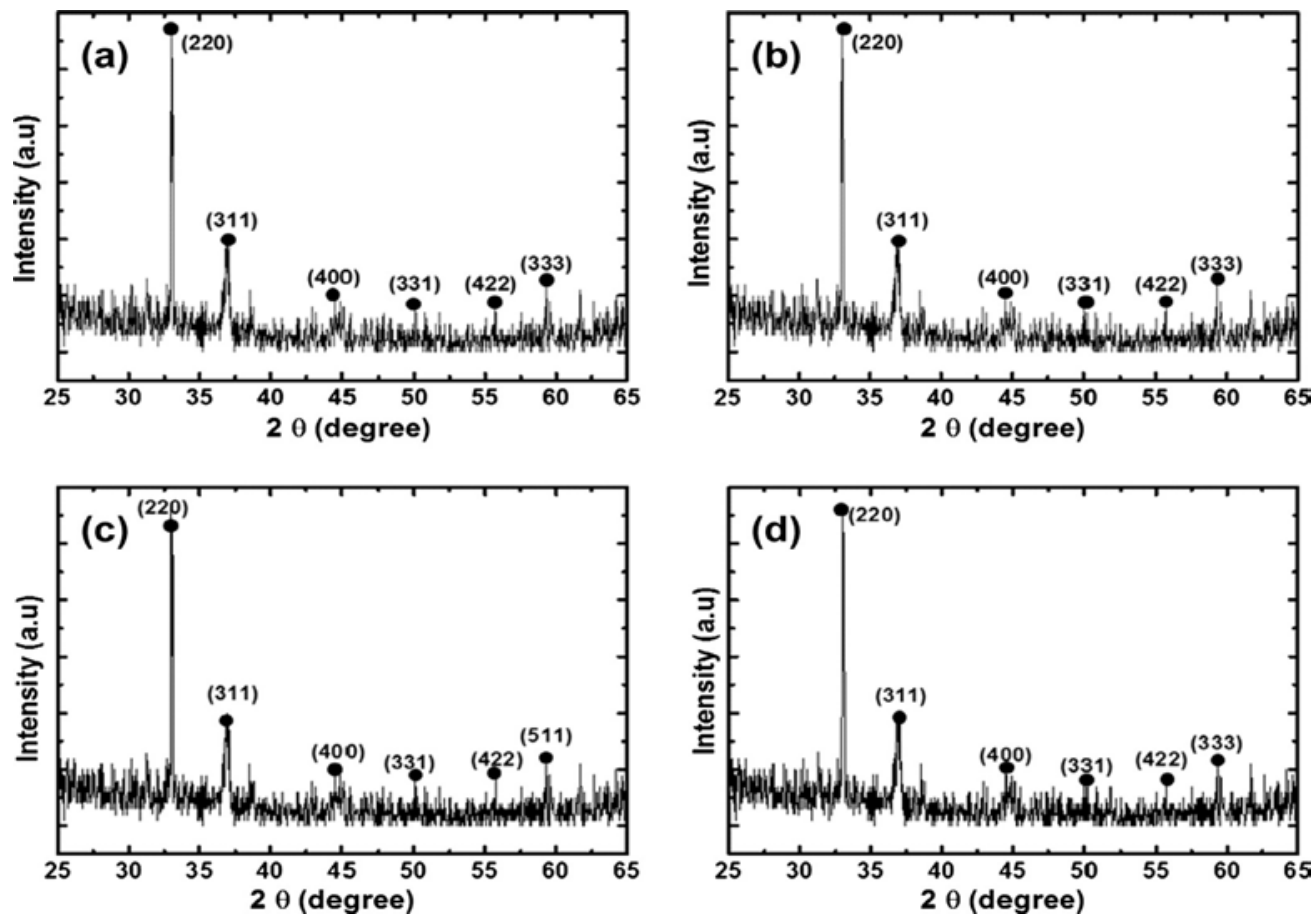

Figure. 5.20 XRD spectra's of cobalt oxide nanostructures grown in different growth mediums. (a) Cobalt nitrate (b) cobalt chloride (c) cobalt acetate (d) cobalt sulfate.

The crystal quality of $\mathrm{Co}_{3} \mathrm{O}_{4}$ nanostructures with different precursors was examined through XRD technique and found that the product is pure-phase of $\mathrm{Co}_{3} \mathrm{O}_{4}$. As shown in Fig. 5.20 the most intense peak (002) in all precursors, which is appearing at around $32.9^{\circ}$ belongs to $\mathrm{Si}$. The well-resolved diffraction peak at $2 \theta=36^{\circ}$ (311) in all precursors is revealing the good crystal quality of the $\mathrm{Co}_{3} \mathrm{O}_{4}$ nanostructures and all the diffraction peaks can be indexed to standard JCPDS card No. 43-1003. 


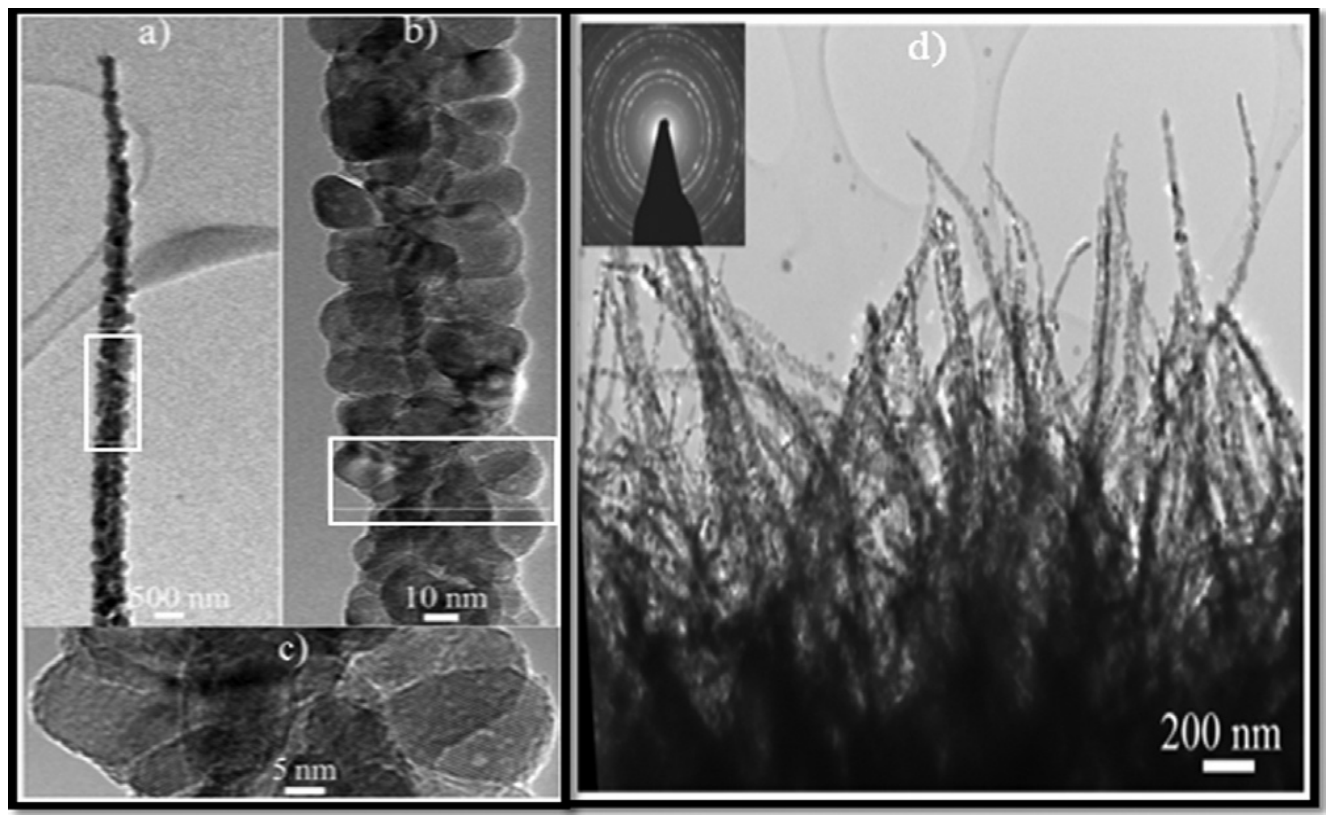

Figure. $5.21(a-c)$ HRTEM image of single nanowire (d) TEM image of $\mathrm{Co}_{3} \mathrm{O}_{4}$ nanowires, inset is the $\mathrm{SAED}$ pattern of $\mathrm{Co}_{3} \mathrm{O}_{4}$ for multi nanowires.

Fig. $5.21(\mathrm{a}-\mathrm{C})$ is showing the TEM image of single $\mathrm{Co}_{3} \mathrm{O}_{4}$ nanowire obtained from the cobalt chloride precursor. It is clear that a $\mathrm{Co}_{3} \mathrm{O}_{4}$ nanowire consists of independent nanoparticles, which are aggregated together and finally giving nanowire morphology. The inset in Fig. 5.21 (d) is the SAED pattern of multi nanowires showing that $\mathrm{Co}_{3} \mathrm{O}_{4}$ nanowires exhibit polycrystalline phase. The obtained results of TEM verified the XRD information.

Figure 5.22 (a) is showing the calibration curve (range of $\mathrm{pH}=3$ to 13) of phosphate buffer solution. Nernstian response has been shown by the $\mathrm{Co}_{3} \mathrm{O}_{4}$ nanostructures with a slope of $-58.45 \mathrm{mV} / \mathrm{pH}$ and correlation coefficient of 0.9963 . The obtained slope is in good agreement with theoretical slope, which could be attributed to the high surface to volume ratio of $\mathrm{Co}_{3} \mathrm{O}_{4}$ nanostructures and high sensitivity could be related to the sensitive surface provided by the $\mathrm{Co}_{3} \mathrm{O}_{4}$ nanostructures. The working performance of a particular $\mathrm{pH}$ sensor assessed through response time, reproducibility, repeatability and stability. The repeatability response shown in Fig 5.22 (b) was checked by conducting a series of experiments for three consecutive days by using similar $\mathrm{pH}$ sensor electrode. The proposed $\mathrm{pH}$ sensor maintained its configuration without any abrupt 

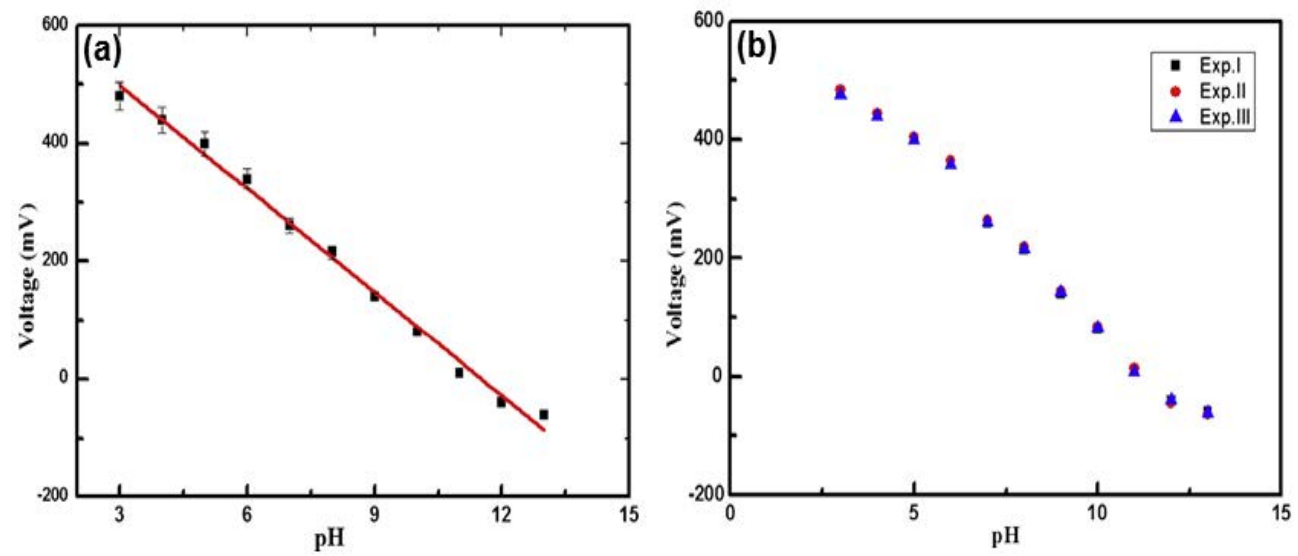

Figure 5.22 (a) The calibration curve of $\mathrm{pH}$ sensor based on $\mathrm{Co}_{3} \mathrm{O}_{4}$ nanostructures grown in precursor solution of cobalt chloride for the $\mathrm{pH}$ range of 3-13. (b) The repeatability of proposed $\mathrm{pH}$ sensor.

change in the sensitivity. The observed repeatability showed that the proposed $\mathrm{pH}$ sensor can be used for monitoring of real $\mathrm{pH}$ samples.

As shown in Fig. 5.23 (a) a response time of $53 \mathrm{sec}$ was also observed, which could be correlated to the highly sensitive surface of $\mathrm{Co}_{3} \mathrm{O}_{4}$ nanostructures. Figure 5.23 (b) is showing the reproducibility response and fabricated $\mathrm{pH}$ sensor showed reproducibility with a relative standard deviation of less than $5 \%$. The proposed $\mathrm{pH}$ sensor based on $\mathrm{Co}_{3} \mathrm{O}_{4}$ nanowires showed excellent stability without any abrupt change during the usage for three consecutive days.
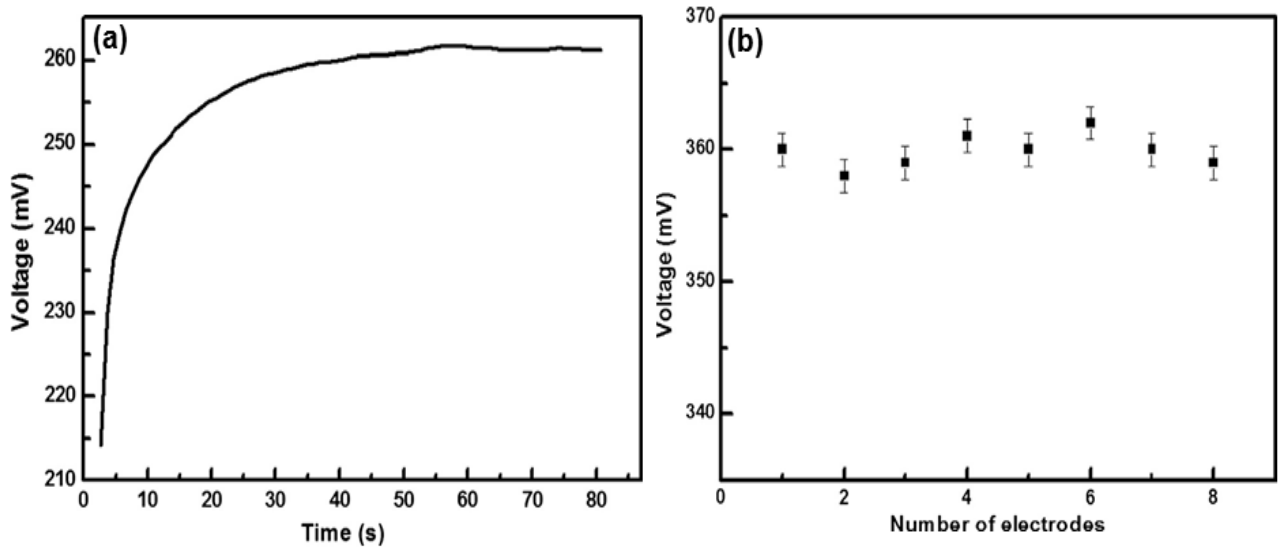

Figure. 5.23 (a) The reproducibility of $p H$ sensor measured in $p H$ 6. (b) The response time of $\mathrm{pH}$ sensor measured in $\mathrm{pH} 7$. 


\subsection{Synthesis of three dimensional nickel cobalt oxide nanoneedles on nickel foam,} their characterization and glucose sensing application.

In different fields of science and technology such as material science, physics and chemistry transition metal oxides nanostructures can play an important role with new attractive shape, dimension, size and morphology [24-26]. Nickel-and cobalt-based binary oxide materials are one of the materials that have lot of potential, because they are not only economical and less toxic but also have high natural abundance with unique morphologies. Beside this they showed excellent electrochemical performance and high degree of redox chemistry as a binary metal oxide [27, 28]. Therefore by exploiting the redox property of binary metal oxides like $\mathrm{NiCo}_{2} \mathrm{O}_{4}$ for the oxidation of glucose molecules, a biosensor is fabricated in the present work.

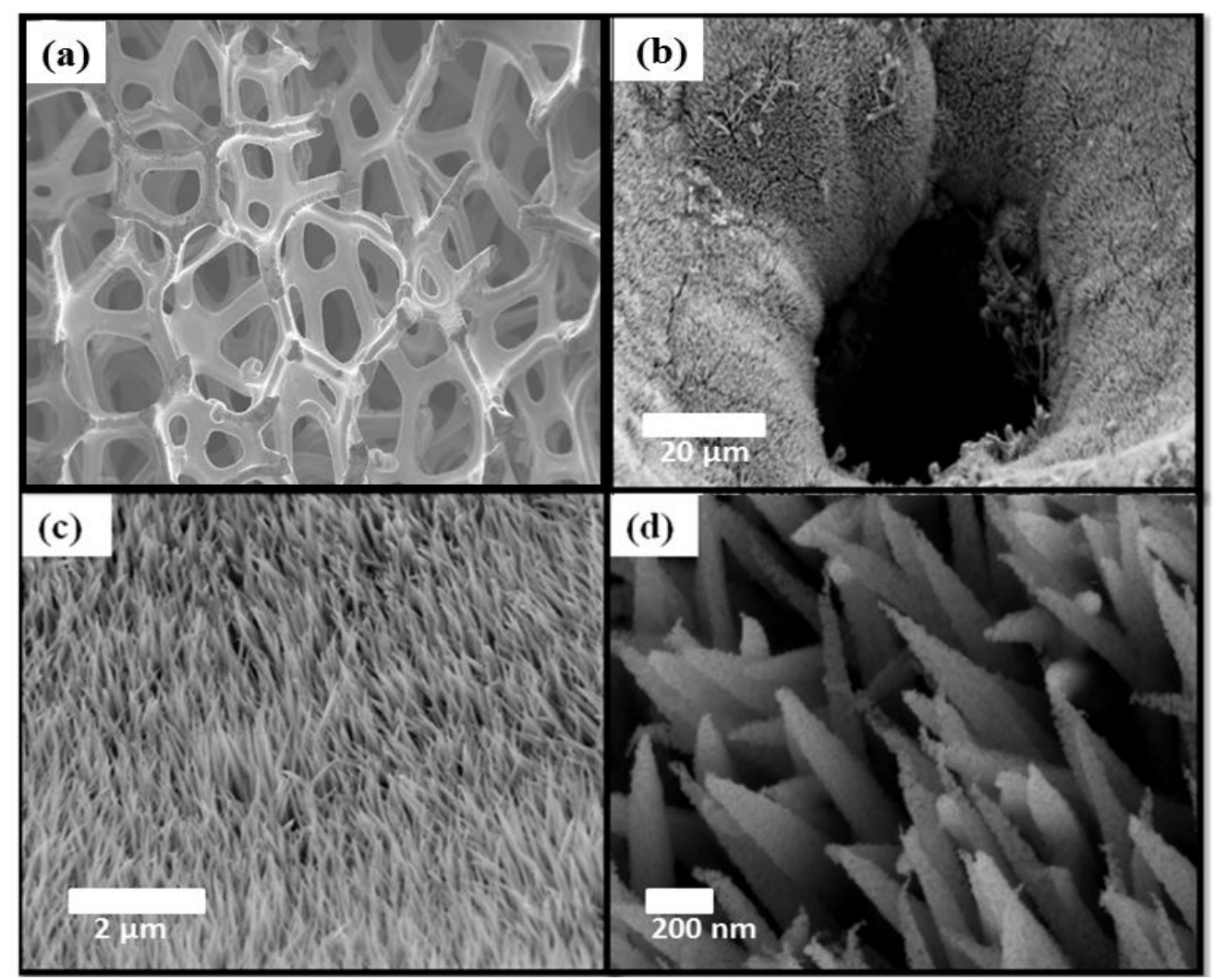

Figure 5.24 (a) SEM image of bare Ni foam substrate (b-d) Typical SEM images at different magnifications of $\mathrm{NiCO}_{2} \mathrm{O}_{4}$ nanostructures grown via low temperature hydrothermal method. 
Nickel foam is a light weight highly porous 3D material with high surface area and is establishing its use as electrode material in batteries and super capacitors [29-31]. Therefore the use of nickel foam as substrate in the present work is attractive both from fundamental and application point of view.

Figure 5.24 (a) is the SEM image of bare Ni foam substrate measured at $100 \mu \mathrm{m}$ and it can be seen that it's a highly porous three dimensional structure. Figure 5.24 (b-d) is showing the SEM images of as grown $\mathrm{NiCO}_{2} \mathrm{O}_{4}$ nanostructures at different magnifications. Figure 5.24 (b) shows that the grown nanostructures are highly dense, uniform and composed of nanowires. Figure 5.24 (c) shows that the top surface of the nanostructures is very thin and looks as needle like morphology. Figure 5.24 (d) is showing a clear view of needle-like morphology and indicates that it is a bunch of nanoparticles, which finally results in the needle-like morphology.

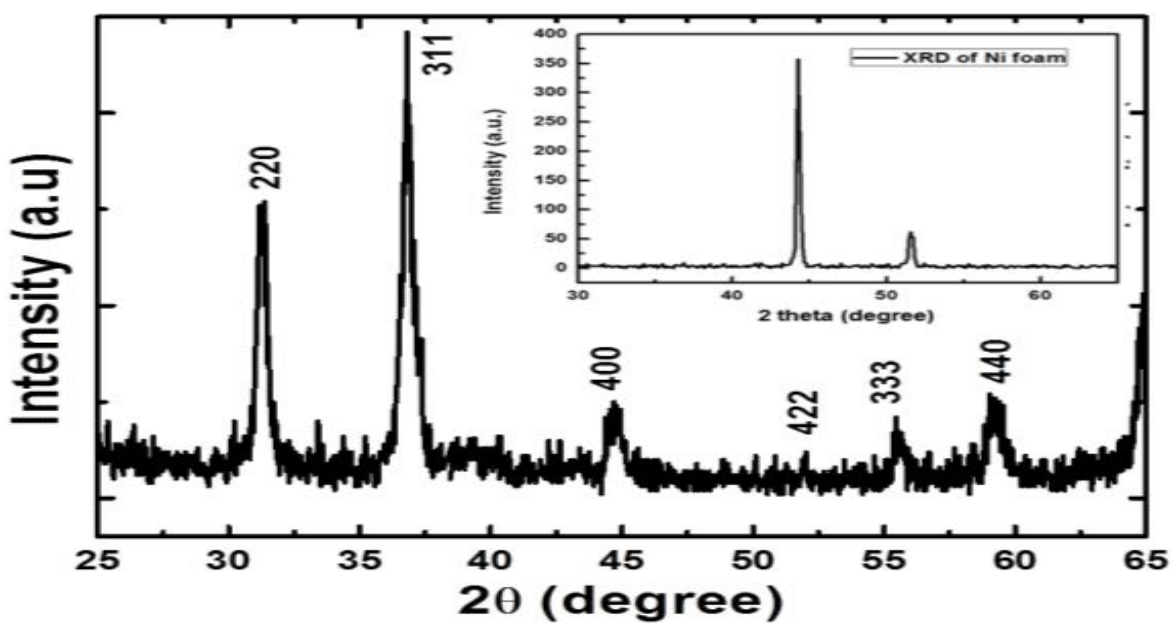

Figure 5.25 The XRD spectrum of $\mathrm{NiCo}_{2} \mathrm{O}_{4}$ nanostructures and inset is showing the XRD spectra of bare Ni foam substrate.

The XRD analysis has been done before and after the growth of $\mathrm{NiCo}_{2} \mathrm{O}_{4}$ nanostructures. The inset of Fig. 5.25 is the XRD of bare Ni foam substrate, which showed two peaks at $\sim 44^{\circ}$ and $\sim 51.5^{\circ}$ related to Ni. Whereas Figure 5.25 is showing the diffraction peaks for the planes 220, 311, 400, 422, 333 and 440 respectively according to JCPDS card no. 73-1702. All the peaks can be attributed to the face centered cubic crystalline arrays of $\mathrm{NiCo}_{2} \mathrm{O}_{4}$ [28]. No other crystalline phase was detected except $\mathrm{NiCo}_{2} \mathrm{O}_{4}$. 

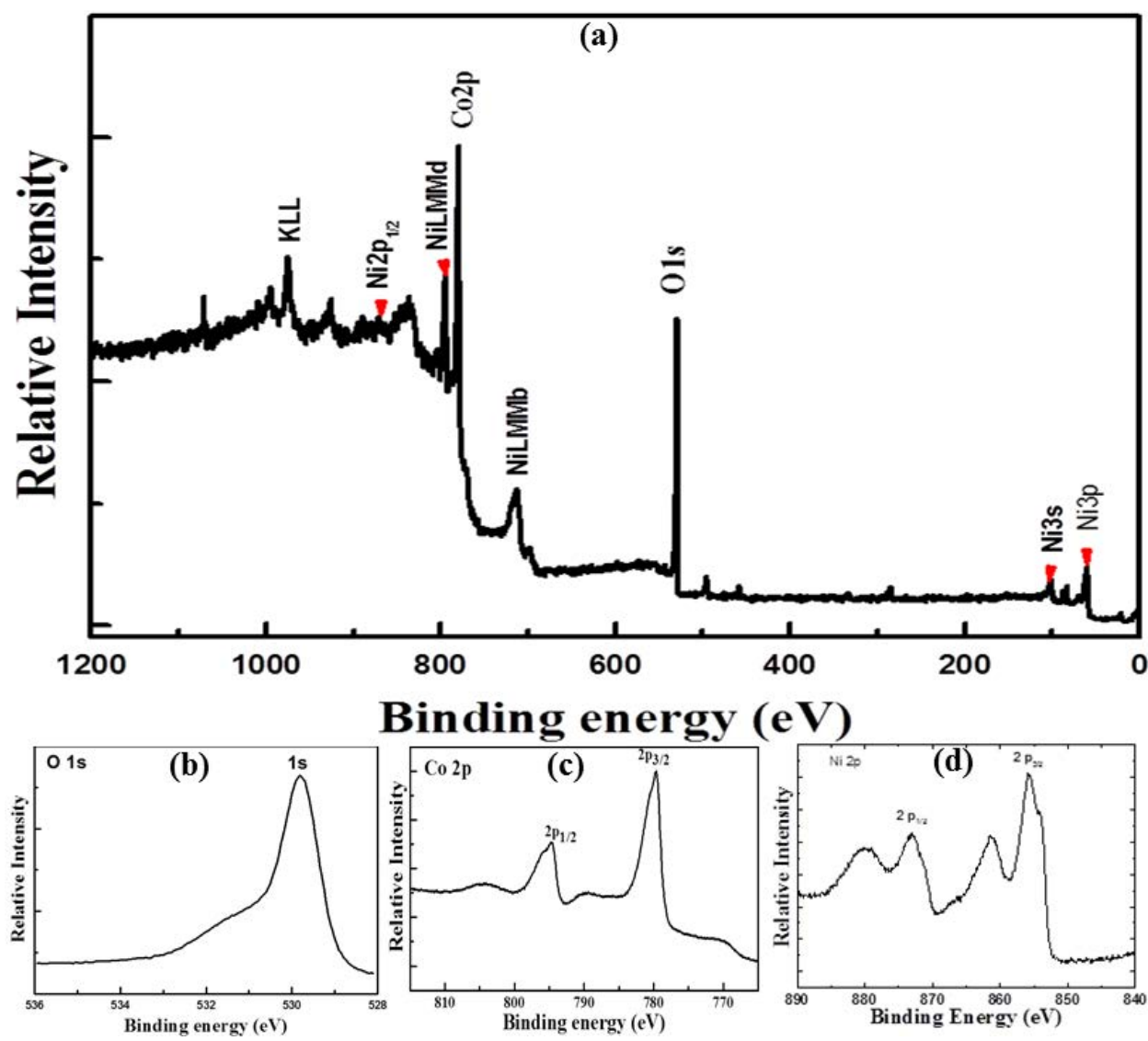

Figure 5.26 XPS spectrum of $\mathrm{NiCo}_{2} \mathrm{O}_{4}$ nanostructures (a) wide scan spectrum (b) $\mathrm{O} 1 \mathrm{~s}$ spectrum (c) Co $2 p$ spectrum (d) Ni $2 p$ spectrum.

Figure 5.26 is showing the X-ray photoelectron spectroscopy (XPS) measurements performed for getting the detailed elemental composition of $\mathrm{NiCo}_{2} \mathrm{O}_{4}$ nanostructures. Figure 5.26 (a) is the wide scan spectrum in which $\mathrm{Ni}$, Co, and $\mathrm{O}$ elements are found. Figure 5.26 (b) is the O 1s XPS spectrum, in which the binding energy at $529.6 \mathrm{eV}$ is for the O-Co/Ni bonding [32] and the well resolved energy peak at $531.4 \mathrm{eV}$ can be assigned to several defect sites having low amount of oxygen coordinated in the sample [33].Figure 5.26 (c) is the Co 2p scan spectra with binding energies of 780.4 $\mathrm{eV}$ for $\mathrm{Co} 2 \mathrm{p}^{3 / 2}$ and $796.2 \mathrm{eV}$ for Co $2 \mathrm{p}^{1 / 2}$, whereas the binding energies of $786.7 \mathrm{eV}$ and $802.5 \mathrm{eV}$ for Co $2 \mathrm{p}^{3 / 2}$ and Co $2 \mathrm{p}^{1 / 2}$, respectively, are as per published work [34]. Figure 5.26 (d) is showing the Ni $2 p^{3 / 2}$ peak at $855.1 \mathrm{eV}$ and the Ni $2 \mathrm{p}^{1 / 2}$ peak at 873.2 $\mathrm{eV}$ attributed to $\mathrm{NiO}$ in the sample [35]. 

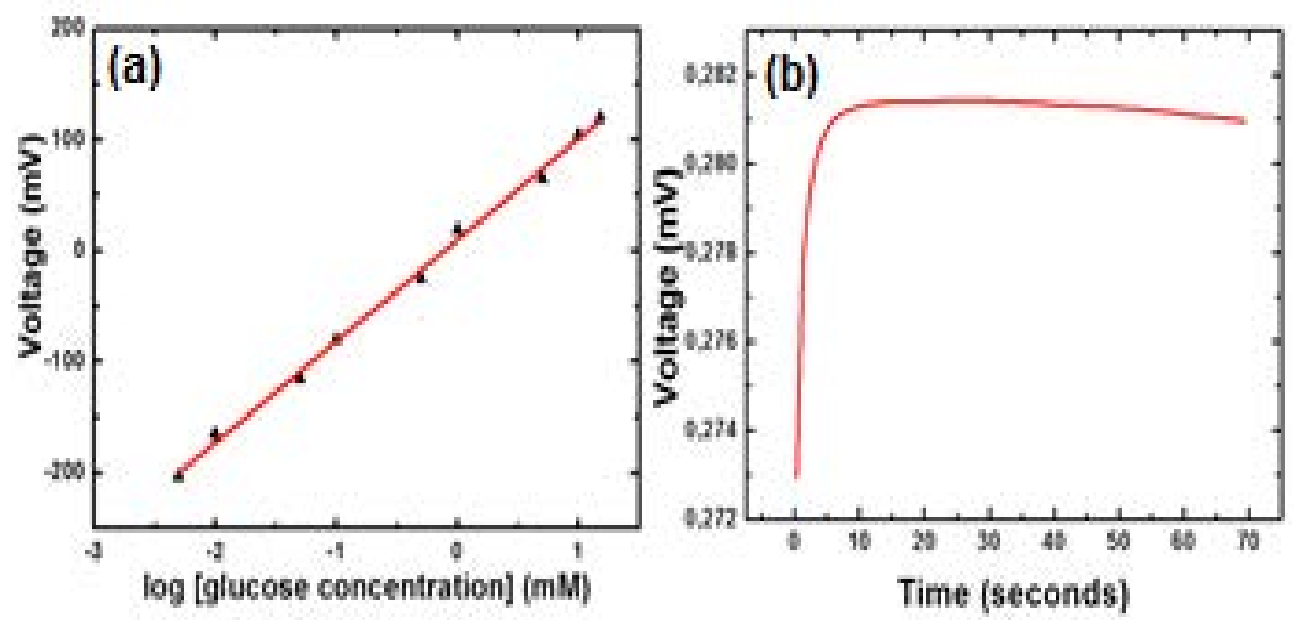

Figure 5.27 (a) The calibration curve of glucose biosensor based on $\mathrm{NiCo}_{2} \mathrm{O}_{4}$ nanostructures for linear concentration range of $0.005 \mathrm{mM}$ to $15 \mathrm{mM}$. (b) The response time of glucose biosensor in $1 \mathrm{mM}$ glucose concentration.

For measuring the output potential response different concentrations of glucose (having range of $0.001 \mathrm{mM}-20 \mathrm{mM}$ ) were prepared in $10 \mathrm{mM}$ phosphate buffer solution ( $\mathrm{pH}=7.4)$. The immobilized GOD-based $\mathrm{NiCo}_{2} \mathrm{O}_{4}$ sensor electrode was inserted in $0.001 \mathrm{mM}$ glucose concentration and sensor showed a response for this concentration. Then the sensor electrode was dipped in $0.005 \mathrm{mM}$ glucose concentration and this time a steady, stable and strong electrical signal was noticed. Afterwards the $\mathrm{NiCo}_{2} \mathrm{O}_{4}$ based electrode was used in higher concentrations of glucose and sensor showed dominant electrical signal up to $15 \mathrm{mM}$ of glucose concentration. Beyond $15 \mathrm{mM}$ concentration of glucose, saturation limit was attained, so as shown in Fig. 5.27 (a) linear range from $0.005 \mathrm{mM}$ to $15 \mathrm{mM}$ glucose concentrations was recorded for the presented glucose sensor. The detection limit was found to be $1.49 \times$ $10^{-3} \mathrm{mM}$ and quantification limit was found to be $1.9 \times 10^{-3} \mathrm{mM}$, which are not shown in the calibration curve. The 3D pattern of grown $\mathrm{NiCO}_{2} \mathrm{O}_{4}$ nanostructures adsorbed high degree of glucose oxidase that resulted in sensitivity of $91.34 \mathrm{mV} /$ decade. As shown in Figure 5.27 (b) the sensor electrode has shown a fast response time ( $<10 \mathrm{~s})$, which could be attributed to the needle-like morphology of $\mathrm{NiCo}_{2} \mathrm{O}_{4}$ with high surface area on a porous 3D nickel foam. The high sensitivity and a fast response time are showing the potential of fabricated sensor in the monitoring of glucose concentrations. 

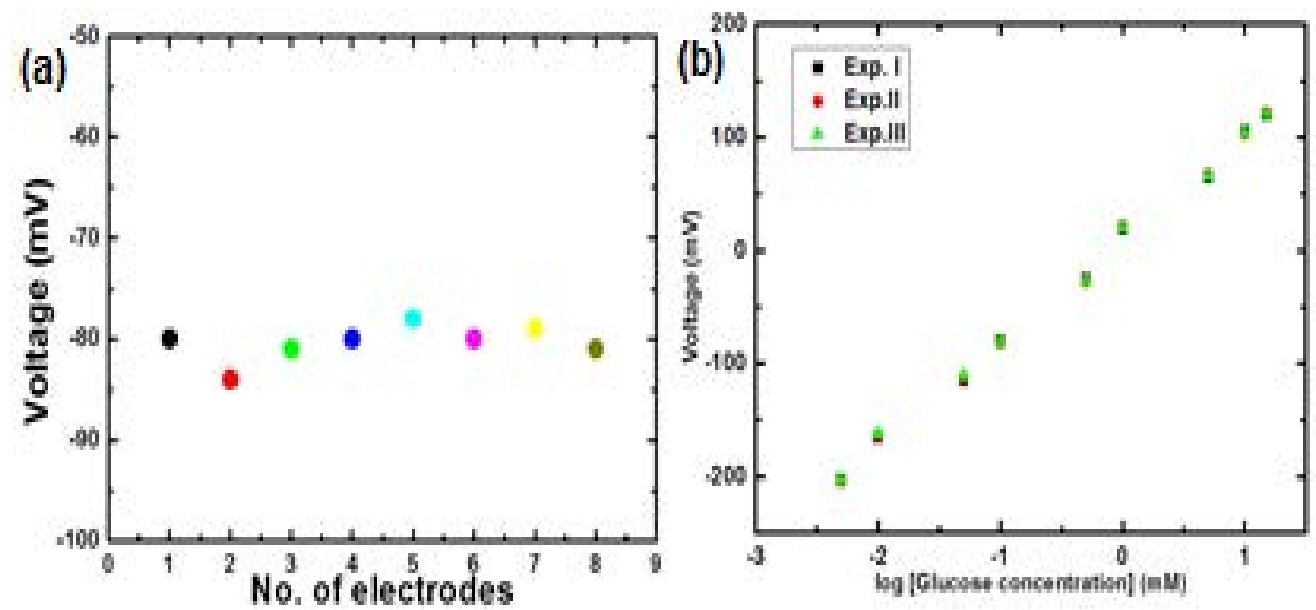

Figure 5.28 (a) The reproducibility of glucose biosensor in $0.1 \mathrm{mM}$ glucose concentration. (b) The repeatability curve of the proposed glucose biosensor for 3 consecutive experiments.

The reproducibility is an important parameter in order to assess the sensor to sensor response for different independent sensor electrodes prepared under similar conditions. As shown in Figure 5.28 (a) that eight independent sensor electrodes were used for checking the reproducibility in $0.1 \mathrm{mM}$ concentration of glucose. We observed that sensor to sensor response deviated less than $3 \%$ from one another by relative standard deviation, which confirms that proposed sensor has good reproducibility response. The stability of the fabricated sensor was also monitored for three consecutive weeks; sensor remained stable and showed same sensitivity and detection range for that period. Sensor was kept at $4^{\circ} \mathrm{C}$ in refrigerator when not in use. The repeatability was evaluated by virtue of three experiments for three consecutive days. The sensor electrode showed excellent repeatable response as shown in Figure 5.28 (b). This proved that same electrode can be used for a period of three days without any abrupt change in the sensitivity, stability and detection range of glucose concentrations. Table 3 is presented for a comparison between the characteristics of the presented potentiometric biosensor and some other previously reported glucose biosensors. 
Table 3. Comparison of the characteristics of the presented work and some other previously reported glucose biosensors.

\begin{tabular}{|c|c|c|c|c|c|c|}
\hline Matrix & Sensitivity & $\begin{array}{l}\text { Response } \\
\text { Time }\end{array}$ & $\begin{array}{l}\text { Shelf } \\
\text { Life }\end{array}$ & Range & $\begin{array}{l}\text { Detection } \\
\text { Limit }\end{array}$ & Ref \\
\hline $\ln N$ & $80 \mathrm{mV} /$ decade & $<2 s$ & 14 days & $1.0 \times 10^{-5}-1.0 \times 10^{-2} \mathrm{M}$ & - & [20] \\
\hline $\begin{array}{l}\text { Multiwall } \\
\text { carbon NTs }\end{array}$ & $12.1 \mu \mathrm{A} / \mathrm{mM}$ & - & 5 weeks & $1-500 \mu \mathrm{M}$ & $1.3 \pm 0.1 \mu \mathrm{M}$ & [21] \\
\hline Polypyrrole & $90 \mathrm{mV} /$ decade & $30 \mathrm{~min}$ & 10 days & $6.0 \times 10^{-5}-5.0 \times 10^{-3} \mathrm{M}$ & - & [22] \\
\hline $\begin{array}{l}\text { Gold nano } \\
\text { particles }\end{array}$ & $2.3 \mathrm{~mA} / \mathrm{M}$ & $<5 s$ & $\begin{array}{c}>2 \\
\text { weeks }\end{array}$ & $\begin{array}{c}1.0 \times 10^{-6}-8.0 \times 10^{-4} \\
\mathrm{~mol} / \mathrm{L}\end{array}$ & $5.0 \times 10^{-7} \mathrm{M}$ & [23] \\
\hline lodide & $\begin{array}{c}65.2 \pm 0.2 \\
\mathrm{mV} / \text { glucose }\end{array}$ & $1-2 \mathrm{~min}$ & $\begin{array}{c}\sim 1 \\
\text { month }\end{array}$ & $1.0 \times 10^{-1}-1.0 \times 10^{-6} \mathrm{M}$ & - & [24] \\
\hline Carbon NTs & $\begin{array}{c}602.04 \\
\mu \mathrm{AmM}^{-1} \mathrm{~cm}^{-1}\end{array}$ & $30 \mathrm{~s}$ & - & $5.0 \times 10^{-7}-1.8 \times 10^{-3} \mathrm{M}$ & $1.0 \times 10^{-7} \mathrm{M}$ & [25] \\
\hline $\begin{array}{l}\text { Silver nano } \\
\text { particles }\end{array}$ & $\begin{array}{l}135.904 \\
\mu \mathrm{AmM}^{-1}\end{array}$ & $>10 \mathrm{~s}$ & 10 days & $0.5-50 \mu \mathrm{M}$ & $0.1 \mu \mathrm{M}$ & [26] \\
\hline $\mathrm{NiCO}_{2} \mathrm{O}_{4}$ & $\begin{array}{c}91.34 \\
\mathrm{mV} / \text { decade }\end{array}$ & $<10 \mathrm{sec}$ & 3 weeks & $0.005-15 \mathrm{mM}$ & $\begin{array}{c}1.49 \times 10^{-3} \\
\mathrm{mM}\end{array}$ & $\begin{array}{l}\text { Recent } \\
\text { work }\end{array}$ \\
\hline
\end{tabular}




\subsection{References:}

[1]. Y. F. Hu, L. Lin, Y. Zhang, Z. L. Wang, Advanced materials. 2011, 20, 1.

[2]. J. Zhong, K. Cheng, B. Hu, H. Gong, S. Zhou, Z. Du, Materials Chemistry and Physics. 2009, 115, 799.

[3]. C. Jaqadish S. J. Pearton, Zinc Oxide Bulk, Thin Films and Nanostructures: Processing, Properties and Applications. Elsevier, 2006.

[4]. W. Wang, Q. Feng, K. Jiang, J. Huang, X. Zhang, W. Song, R. Tan, Applied Surface Science. 2011, 25, 388.

[5]. M. N. Islam, T. B. Ghosh, K. L. Chopra, H. N. Acharya, Thin Solid Films, 1996, 280, 20.

[6]. A. B. Djuriši_c, Y. H. Leung, K. H. Tam, L. Ding, W. K. Ge, Y. H. Chen, S. Gwo, Applied Physics Letters. 2006, 88, 103107.

[7]. Y. Lv, Y. Zhang, C. Li, L. Ren, L. Guo, H. Xu, L. Ding, C. Yang, W. Ge, S. Yan, Journal of Luminescence. 2007, 122, 816.

[8]. Z. L. Wang, J. H. Song, Science, 2006, 312, 242.

[9]. X. D. Wang, J. H. Song, J. Liu, Z. L. Wang. Science, 2007, 316, 102.

[10]. Y. F. Hu, Y. Zhang, Y. L. Chang, R. L. Snyder, Z. L. Wang, ACS Nano. 2010, 4, 4220.

[11]. C. J. Chang, Y. H. Lee, C. A. Dai, C. C. Hsiao, S. H. Chen, N. P. D. Nurmalasari, J. C. Chen, Y. Y. Cheng, W. P. Shih, P. Z. Chang. Microelectronic Engineering, 2011, 88, 2236.

[12]. Y. Y. Zhang, Y. Liu, Z. L. Wang. Advanced Materials. 2011. 23, 3004.

[13]. C. -L. Hsu, K.-C. Chen, The Journal of Physical Chemistry C. 2012, 116, 9351.

[14]. A. Khan, M. A. Abbasi, M. Hussain, Z. H. Ibupoto, J. Wissting, O. Nur, M. Willander. Applied Physics Letters. 2012. 101, 193506.

[15]. Y. Qiu, H. Zhang, L. Hu, D. Yang, L. Wang, B. Wang, J. Ji, G. Liu, X. Liu, J. Lin, F. Li, S. Han. Nanoscale. 2012, 4, 6568.

[16]. P. G. Gao, J. Song, J. Liu, Z. L. Wang, Advanced Materials. 2007, 19, 67.

[17]. M. Riaz, J. H. Song, O. Nur, Z. L. Wang, M. Willander, Advanced Functional Materials. 2011, 21, 628.

[18]. R. S. Yang, Y. Qin, L. M. Dai, Z. L. Wang, Nature Nanotechnology, 2009, 4, 34. 
[19]. Y. F. Hu, Y. Zhang, Y. L. Chang, R. L. Snyder, Z. L. Wang, ACS Nano. 2010, 4, 4220.

[20]. M. Y. Soomro, I. Hussain, N. Bano, O. Nur, M. Willander, Physica Status Solidi (RRL). 2012, 6, 80.

[21]. M. Riaz, A. Fulati, Q. X. Zhao, O. Nur, M. Willander, P. Klason, Nanotechnology. 2008, 19, 415708.

[22]. M. Riaz, A. Fulati, L. L. Yang, O. Nur, M. Willander, P. Klason, Journal of Applied Physics. 2008, 104, 104306.

[23]. M. Riaz, A. Fulati, G. Amin, N. H. Alvi, O. Nur, M. Willander, Journal of Applied Physics. 2009, 106, 034309.

[24]. X. W. Lou, L. A. Archer, Z. Yang, Advanced Materials. 2008, 20, 3987.

[25]. J. Polleux, A. Gurlo, N. Barsan, U. Weimer, M. Antonietti, M. Niederberger, Angewandte Chemie, International Edition. 2005, 45, 261.

[26]. N. Pinna, M. Niederberger, Angewandte Chemie, International Edition . 2008, 47, 5292.

[27]. O. Knop, K. I. G. Ried, Y. Sutarno, Y. Nakamura, Canadian Journal of Chemistry. 1968, 46, 3463.

[28]. Q. Wang, B. Liu, X. Wang, S. Ran, L. Wang, D. Chen, G. Shen, Journal of Materials Chemistry. 2012, 22, 21647.

[29]. H. Wang, Q. Pan, X. Wang, G. Yin, J. Zhao, Journal of Applied Electrochemistry. 2009, 39, 1597.

[30]. J. L. Yang, Y. F. Yuan, H. M. Wu, Y. Li, Y. B. Chen, S. Y. Guo, Electrochimica Acta. 2010 , 55, 7050.

[31]. Q. Pan, J. Liu, Journal of Solid State Electrochemistry. 2009, 13, 1591.

[32]. J. Xiao, S. Yang, Journal of Materials Chemistry. 2012, 22, 12253.

[33]. C. Yuan, J. Li, L. Hou, L. Yang, L. Shen, X. Zhang, Journal of Materials Chemistry. 2012, 22, 16084.

[34]. D. Briggs, J. T. Grant, Surface Analysis by Auger and X-ray Photoelectron Spectroscopy. IM Publications: Chickester, UK, 2003.

[35]. B. Sasi, K. G. Gopchandran, Nanotechnology. 2007, 18, 115613. 


\section{CHAPTER 6}

\section{Conclusion \& future plans}

\subsection{Conclusion:}

The work presented in this thesis has been only centered on following few things.

1- The growth of metal oxide nanostructures by using low temperature aqueous chemical growth method.

2- Their characterization by employing different kinds of techniques such as SEM, TEM, XRD, AFM, XPS, CL etc.

3- Then influence of oxygen plasma treated $\mathrm{ZnO}$ nanorods, effect of different flexible substrate and effect of $\mathrm{ZnO}$ nanorods grown AFM tip on the amount of harvested energy have been discussed in detail.

4- After that the effect of anion on the morphology of $\mathrm{Co}_{3} \mathrm{O}_{4}$ nanostructures is presented along with the development of a $\mathrm{pH}$ sensor.

5- Finally $\mathrm{NiCo}_{2} \mathrm{O}_{4}$ nanostructures on nickel foam as substrate have been synthesized and its glucose sensing application has also been discussed.

Considering different aspects of all the work that has been done in order to get the results which were presented in this thesis, I conclude these in the following manner.

1- Aqueous chemical growth method is the most simple, cheap and effective method to synthesize different metal oxide nanostructures.

2- $\mathrm{ZnO}$ nanostructures are more preferred for energy harvesting applications.

3- Oxygen plasma treatment is an effective way in order to reduce the defects levels in the grown $\mathrm{ZnO}$ nanostructures, which ultimately affects its piezoelectric properties and an enhancement in the amount of piezoelectricity has been observed. Beside this the effect of oxygen plasma on mechanical properties has also been investigated. 
4- Flexible and cheap substrates like paper, plastic, textile fabric can be successfully utilized in the fabrication of piezoelectric nanogenerators.

5- $\mathrm{ZnO}$ nanorods grown AFM tip is also a good alternative in order to get an enhanced amount of piezoelectricity.

6- $\mathrm{Co}_{3} \mathrm{O}_{4}$ is a potential metal oxide with variety of nanostructures. The features associated with $\mathrm{Co}_{3} \mathrm{O}_{4}$ like high surface area, short path length for ion transport and easily tunable surface have made $\mathrm{Co}_{3} \mathrm{O}_{4}$ a promising material for electrochemical devices. Therefore in order to get maximum advantage of these properties a $\mathrm{pH}$ sensor has been developed.

7- The synthesis of three dimensional $\mathrm{NiCo}_{2} \mathrm{O}_{4}$ nanostructures on nickel foam and then their use in fabricating a fast, accurate and reliable glucose sensor showed that the combination of these two is quite beneficial.

\subsection{Future plans:}

As Richard Feynman said in his famous talk ' 'There is plenty of room at the bottom'”, I also feel that lot of things have to be there to work in future directly or indirectly related to the presented work. I am trying to highlight few of them here.

1- There are few issues related to oxygen plasma treatment which needs to be investigated in detail with especial focus on parameters like amount of time, pressure of the chamber, speed of gas flow, RF frequency etc. The variations in these parameters need to be optimized in order to get maximum benefit of induced oxygen plasma.

2- Since different flexible substrate were proved to be successful for the growth and device fabrication of $\mathrm{ZnO}$ nanostructures, therefore it will be interesting to see that how the other piezoelectric materials respond to these flexible substrates. In addition to this other metal oxides can also be possible to use.

3- The success of $\mathrm{ZnO}$ nanorods grown AFM tip in the architecture of piezoelectric nanogenerators will open the gate for the use of two different piezoelectric materials at the same time.

4- The effect of anion on the morphology of $\mathrm{Co}_{3} \mathrm{O}_{4}$ nanostructures has proved that cobalt based oxides also have varieties of nanostructures, which can be 
exploited in different applications, specially related to electrochemical performance.

5- The performance of glucose sensor based on $\mathrm{NiCO}_{2} \mathrm{O}_{4}$ nanostructures along with nickel foam has showed that the porosity of nickel foam is not only quite useful for the growth of three dimensional nanostructures but it also increases the surface area, which plays an important role in the performance of glucose sensor, therefore in future nickel foam should be tried with some other metal oxides to see its response remains same, increases or decreases. Especially in sensing applications nickel foam can produce interesting results.

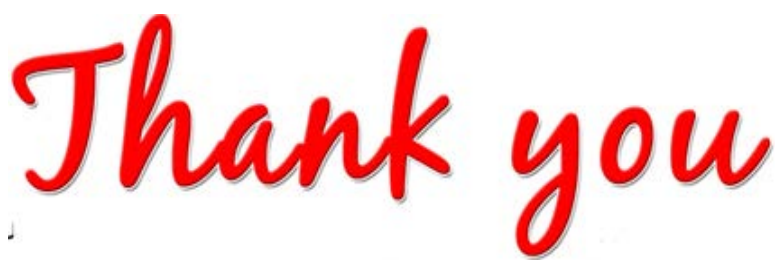





\section{Publications}

The articles associated with this thesis have been removed for copyright reasons. For more details about these see:

http://urn.kb.se/resolve?urn=urn:nbn:se:liu:diva-108894 



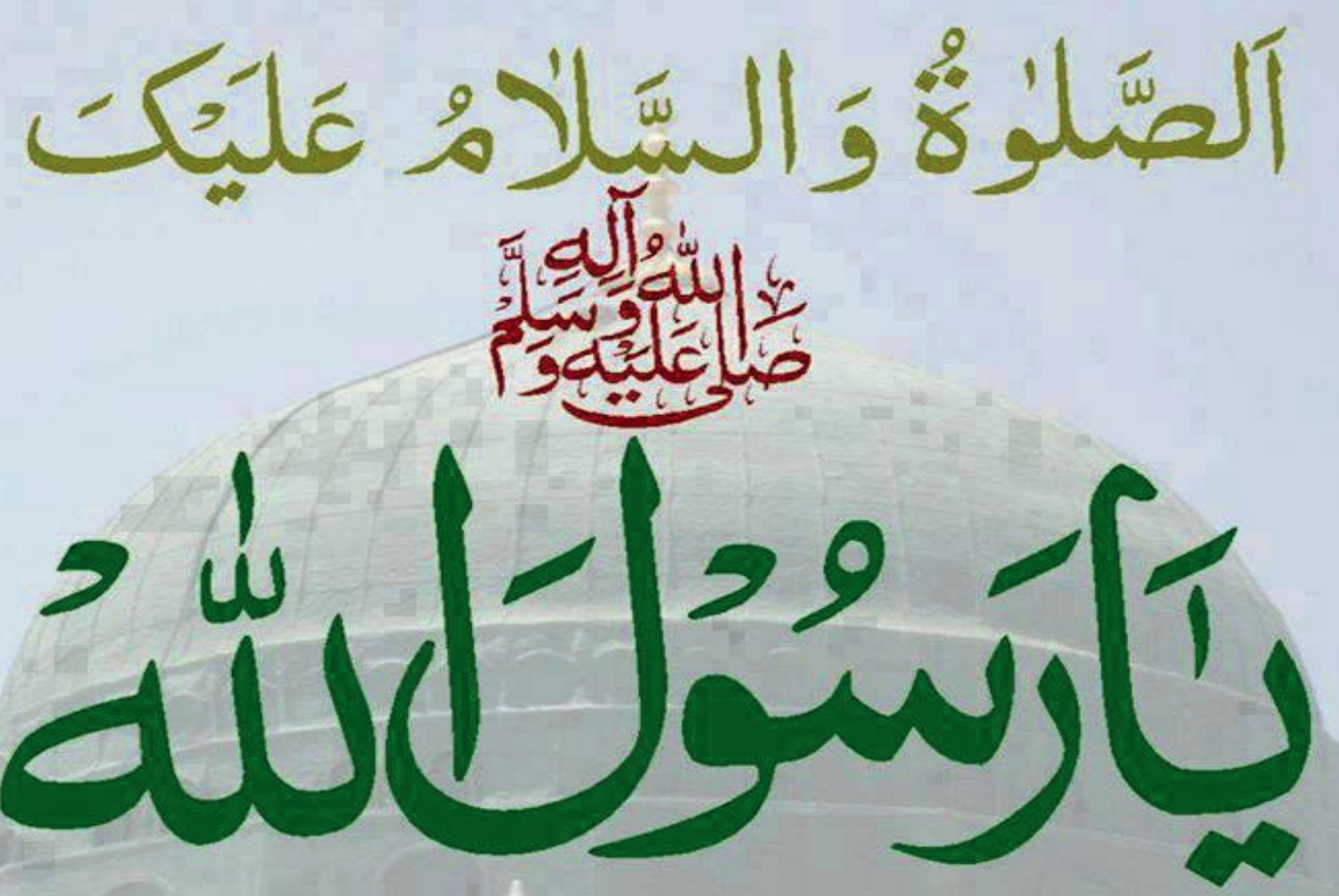

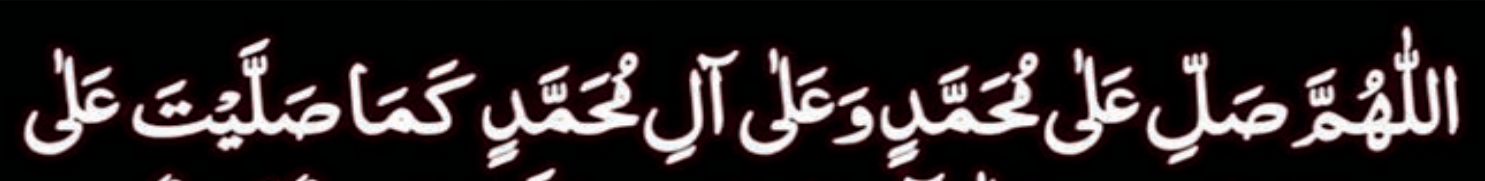

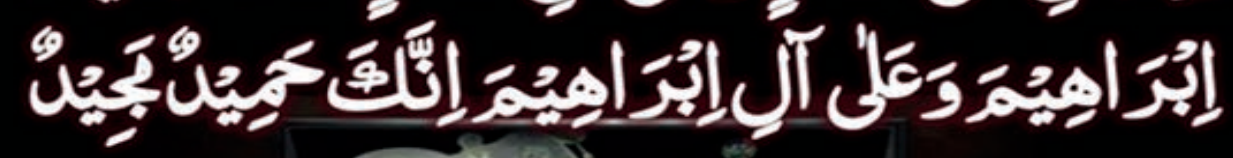

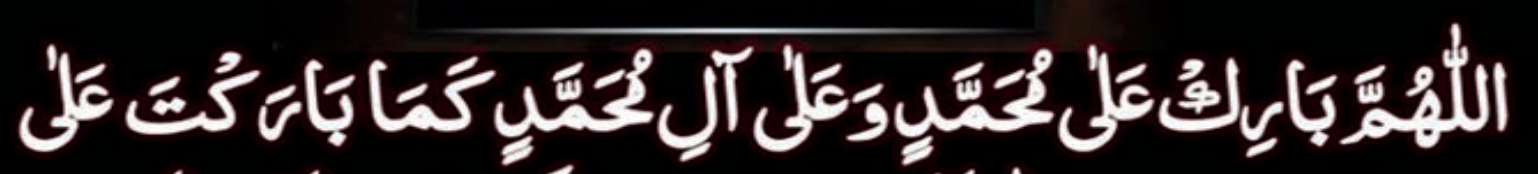

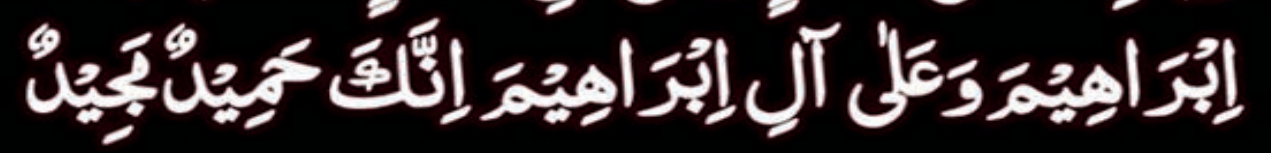

